\title{
DOMINÂNCIA ESTOCÁSTICA VERSUS ESTABILIDADE NA SELECÃO DE GENÓTIPOS
}

FRANCISCO DORI NEY BATISTA DE SOUZA

Engenhelro Agrónomo

Orlentador: Prof. Dr. Fernando Curl Peres

Dissertação apresentada a Escola Superior de Agricultura "Lulz de Quelroz", da Universidade de Săo Paulo, para obtenção do titulo de mestre em Agronomia, Area de Concentração: Economi a Agrária.

\author{
$P I R A C I C A B A$ \\ Estado de Sro Paulo - Brasil \\ Dezembro - 1990
}




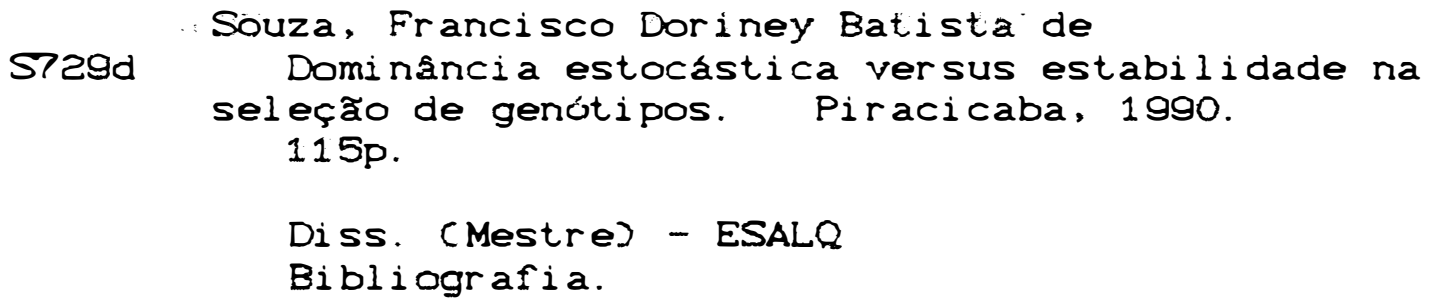

1. Genótipo - Estabilidade 2. Genótipo - Seleção Análise estatistica 3. Modelo matemático 4. Teoria da decisão I. Escola Superior de Agricultura Luiz de Queiroz, Piracicaba.

CDD $\quad 519.542$ 


\title{
DOMINÂNCIA ESTOCÁSTICA VERSUS ESTABILIDADE NA SELECÃO DE GENÓTIPOS
}

\author{
FRANCISCO DORINEY BATISTA DE SOUZA
}

Aprovado em: 11.03 .91

Comissão Julgadora:

Prof. Dr. Fernando Curi Peres ESALQNSP

Prof. Dr. Jose Branco de Miranda Filho ESALQNSP

Profa. Dra. Zilda Paes de Barros Mattos ESALQNSP

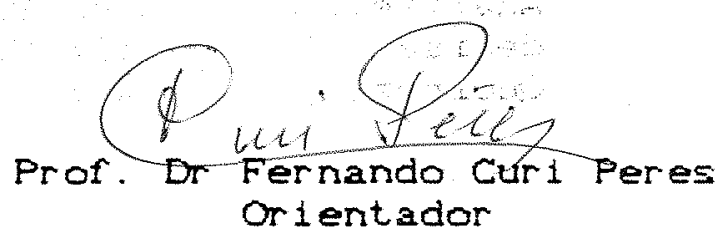


A minha familia. 
AGRADECI MENTOS

Ao Prof. Dr. Fernando Curi Peres não só pela valiosa or ientaça como tambem pelo grande incentivo, sem o qual este trabal ho năo teria sido concluido.

Ao Prof. Dr. Pedro Valentim Marques pela orientação durante a fase iniclal do curso.

Aos demais professores do Departamento de Economia e Sociologia Rural (DESR) da ESALQ pelos ensinamentos.

Ao Prof. Dr. Evaristo Marzabal Neves do Departamento de Economia e Soclologia Rural e ao Prof. Dr. Jose Branco de Miranda Filho do Departamento de Genética pela leitura da primeira versão deste trabalho, pelas criticas e grandes contribuiçóes.

Ao Projeto Avaliação de Novas Tecnologias do Convenio FINEP/FEALQ.

A todos os funcionarios do DESR da ESALQ pelo apolo durante o curso.

A todos enfim que, direta ou indiretamente, contribuiram para a execuça deste trabal ho. 
Página

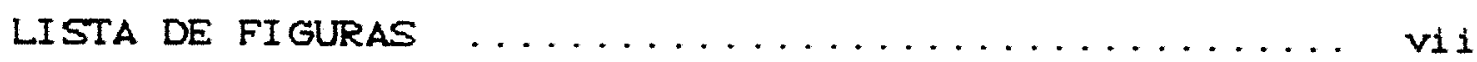

LISTA DE TABELAS $\ldots \ldots \ldots \ldots \ldots \ldots \ldots \ldots \ldots \ldots \ldots \ldots \ldots \ldots$

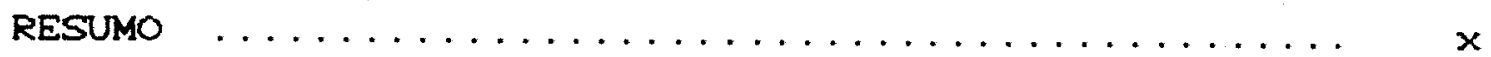

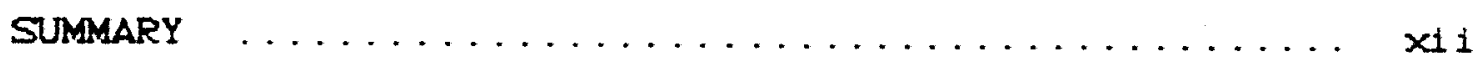

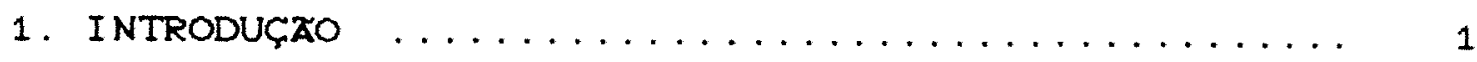

2. REVISATO DE LITERATURA $\ldots \ldots \ldots \ldots \ldots \ldots \ldots \ldots$

2.1. Metodologia empregada na classiflcacáo de gerotipos por estabilidade $\ldots \ldots \ldots \ldots 8$

2.1.1. Adaptabil1dade e Estabilidade ..... 25

己. ¿. Classificaçăo de alternativas sob condiços

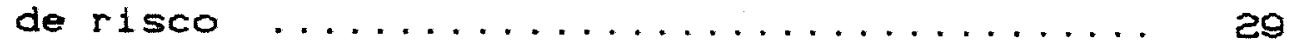

2. 2.1. Análise media-variancia ......... 36

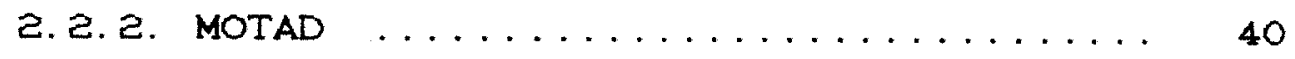

2. Z. 3. Metodo de Hannoch e Levy .......... 41

2. 2. 4. Dominancia estocástica $\ldots . . . . . . .42$

2.2.4.1. Dominăncia estocástica de primeiro grau $\ldots \ldots \ldots \ldots \ldots 45$

ᄅ. 2. 4. 2. Domináncia estocástica de segundo grau $\ldots \ldots \ldots \ldots \ldots \ldots \quad 47$

2.2.4.3. Dominancia estocastica de terceiro grau $\ldots \ldots \ldots \ldots \ldots$

z.2. 4.4. A dominancia estocástica e a analise media-variancia ... 52 
3. MATERI AL E METODOS ................... 56

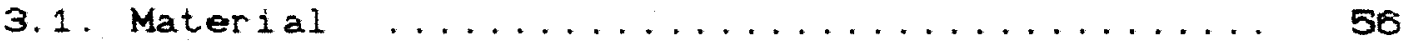

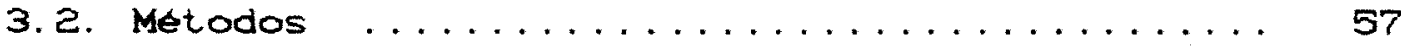

4. RESUltadoS E DISCUSSAO $\ldots \ldots \ldots \ldots \ldots \ldots \ldots$

4.1. Cultura do algodão $\ldots \ldots \ldots \ldots \ldots \ldots$ 6z

4. 2. Cultura do feljăo ............... 85

4. 3. Cultura do milho ................ 68

4.4. Cultura da soja ................. 71

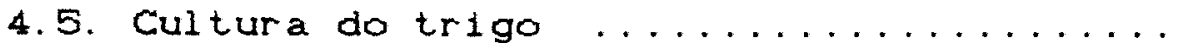

4.6. Avaliação geral

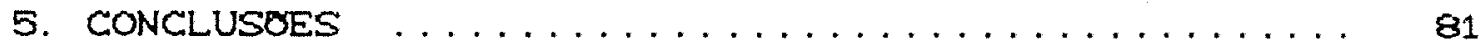

REFERENCI AS BI BLI OGRAFICAS $\ldots \ldots \ldots \ldots \ldots \ldots \ldots \ldots$

APENDICE $\ldots \ldots \ldots \ldots \ldots \ldots \ldots \ldots \ldots \ldots \ldots \ldots \ldots \ldots \ldots \ldots \ldots$ 
Figura 1 - Regressóes e o comportamento das variedades $\ldots \ldots \ldots \ldots \ldots \ldots \ldots \ldots \ldots$

Figura 2 - Media de produção $x$ coeficlente de regressão $\ldots \ldots \ldots \ldots \ldots \ldots \ldots \ldots \ldots$

Figura 3 - Variação da produçao com a variação de um fator $\ldots \ldots \ldots \ldots \ldots \ldots \ldots \ldots \ldots$

Figura 4 - Resposta da produção ao aumento de temperatura $\ldots \ldots \ldots \ldots \ldots \ldots \ldots \ldots . . \ldots$

Figura 5 - Reta ajustada a partir dos nivels de resposta $\ldots \ldots \ldots \ldots \ldots \ldots \ldots \ldots . . . \ldots$

Figura 6 - Diferentes comportamentos em relaçăo a media ......................

Figura 7 - Coeficiente de variaçăo X produtividade

20

Figura 8 - Ajustamento das regresszes por tipo de ambiente $\ldots \ldots \ldots \ldots \ldots \ldots \ldots \ldots$

Figura $\theta$ - Ajustamento da regressão por Silva \& Barreto $\ldots \ldots \ldots \ldots \ldots \ldots \ldots \ldots \ldots$

Figura 10- Curvas de utilidade e o comportamento individual $\ldots \ldots \ldots \ldots \ldots \ldots \ldots \ldots$

Figura 11 - Fronteira eficiente e as curvas de $150-$ utilidade

Figura 12- Domináncia estocastica de primetro grau

Figura 13- Dominaricia estocástica de segurido grau

Figura A.1 - Ajustamento Manual da Função de Distribuição Cumul atıva (FDC) ......... 106 
Tabela 1 - Seleçáo por estabilidade e cunancia estocástica de genotipos de algodáo cultivados em 6 locais da regla or lental do Paraguai nos anos de $1985 / 86 e$

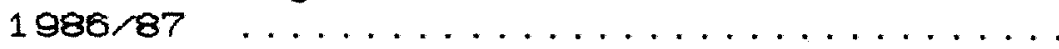

Tabela 2 - Seleção por estabilidade e dominância estocástica de cultivares de feljao cultivados em 11 ambientes combinação de locais e anos? do sul de Minas Ge-

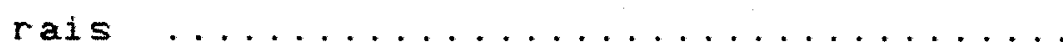

Tabela 3 - Seleção por estabilidade e dominancia estocástica de hibridos de milho cultivados em 10 locals da regiăo Centro-sul do Brasil nos anos $1983 / 84$, $1984 / 85$ e $1985 / 86 \ldots \ldots \ldots \ldots \ldots \ldots$

Tabela 4 - Seleçáo por estabilidade e domináncia estocástica de cultivares de soja cultivados em 11 locals do Rio Grande do Sul nos anos $1972 / 73,1973 / 74$ e

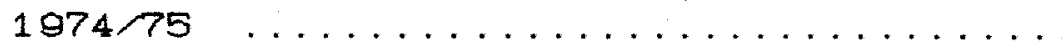

Tabela 5 - Seleçáo por estabilidade e dominancia estocástica de cultivares de trigo cultivados em 7 locais da regia or or ental do Paraguai nos anos de 1886 e 1987

Tabela A.1 - Produtividade média em $\mathrm{kg} / 20 \mathrm{~m}^{2}$ de genótipos de al godão em 6 localidades da regia or iental do Paraguai: 85/86

Tabela A.Z - Produtividade média em $\mathrm{kg} / 20 \mathrm{~m}^{2}$ de genótipos de algodáo em 6 local 1 dades da regia âo Oriental do Paragual: 86/87

Tabela A. 3 - Produção media de grăos de 12 cultivares de feijăo em 11 ambientes do Sul de Minas Gerais (kg/hal ..........

Tabela A. 4 - Produção media em $\mathrm{kg} / \mathrm{ha}$ de $15 \mathrm{hibri-}$ dos de milho em vários locals da regiăo Centro-Sul do Brasil. 1983/84 ...

Tabela A. 5 - Produção media em kg/ha de 15 hibridos de milho em varios locais da regiao Centro-Sul do Brasil. 1984,85

Tabela A.6 - Produção media em $\mathrm{kg}$ ha de $15 \mathrm{hibri-}$ dos de milho em varios locals da região Centro-Sul do Brasil. 1985/86 ... 
Tabela A.7 - Produçóes medias, em kg/ha, dos ensaios realizados com 10 cultivares de soja em 11 locais do RS. $1972 / 73 \ldots \ldots 100$

Tabela A. 8 - Produç̧es medias, em $\mathrm{kg} / \mathrm{ha}$, dos ensalos realizados com 10 cultivares de soja em 11 locals do RS. $1973 / 74 \ldots \ldots 101$

Tabela A. $\theta$ - Produçres medias, em $\mathrm{kg} / \mathrm{ha}$, dos ensaios realizados com 10 cultivares de soja em 11 locals do RS. $1974 / 75 \ldots . .102$

Tabela A.10- Rendimento medio de grãos $(\mathrm{kg} / \mathrm{ha}$ de 10 cultivares de trigo em 7 localidades da região Oriental do Paraguai.

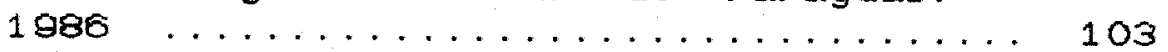

Tabela A.11- Reridimento medio de grăos $(\mathrm{kg} / \mathrm{ha}$ de 10 cultivares de trigo em 7 localidades da regia orlental do Paraguai.

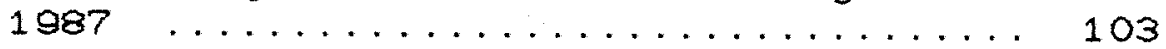

Tabela A.12-Matriz das produtividades para leitura pelo programa de eficiencta estocástica $\ldots \ldots \ldots \ldots \ldots \ldots \ldots \ldots . \ldots \ldots$ 


\title{
DOMINÁNCIA ESTOCÁSTICA VERSUS ESTABILIDADE NA SELECÃO DE GENÓTIPOS
}

\author{
Autor: FRANCISCO DORINEY BATISTA DE SOUZA \\ Orientador: PROF. DR. FERNANDO CURI PERES
}

\section{RESUMO}

Para selecionar genotipos que possam ser indicados aos agricultores, usualmente os pesquisadores, na área de melhoramento vegetal, avaliam a performance dos genotipos atraves de Estabilidade. Estabilidade um concelto ligado a previsibilidade da resposta de genótipos em condiçớes variáveis de ambiente.

Teoria da Decisão e uma ferramenta estatistica usada para indicar a melhor estrategia entre alternativas viáveis. Este estudo pretendeu mostrar que a teoria da decisăo pode ser utilizada por melhoristas no processo de seleça de genótipos visando agricultores aversos ao risco. O processo conhecido como Dominancia Estocástica fol utilizado. Fol mostrado que primeiro, segundo e tercelro graus de Domlnancla Estocastica podem ser usados como um dos passos na seleça de genotipos. Em consequencia, aumentam as chances de aceitação das varledades melhoradas por agricultores aversos ao risco.

Em uma amostra de 57 genotipos estudados, 30 foram selecionados por criterios de estabilidade erou por dominancia estocástica para indicação aos agricultores. 
Entre estes 30, apenas $13 \%$ nao for am membros do grupo dominante estocasticamente. Este fol malor que o grupo estavel e incluiu $75 \%$ dos genótipos classificados por apresentarem caracteristicas de estabilidade. 


\title{
STOCHASTIC DOMINANCE VERSUS STABILITY \\ IN GENOTYPE SELECTION
}

\author{
Author: FRANCISCO DORINEY BATISTA DE SOUZA
}

Adviser: FROF. DR. FERNANDO CURI PERES

\section{SUMMARY}

In order to select genotypes to be offered to farmers, plant breeders usually evaluate their performance through stability. Stabliity is a concept related to predictability of genotypes response on variable environmental conditions.

Decision Theory is a statistical tool used to indicate the best strategy among the alternatives available. This study interided to show that decision theory carn be used by plant breeders in their process of genotype selection for risk averse farmers. The concept known as Stochastic Dominance was used. It was shown that first, second, and third degree stochastic dominance can be used by plant breeders as a step in genotype selection, therefore increasing the 11 kelihood of acceptance of the 1 mproved varieties by $r i s k$ averse farmers.

In a sample of 57 studied genotypes, 30 were selected either by stability or stochastic dominance criteria. Among these 30 , only $13 \%$ were not in the 
$x 111$

stochastically dominant group. This group was bigger than the "stable" group and included $75 \%$ of the genotypes classified as having stability characteristics. 


\section{DOMINANCIA ESTOCASTICA VERSUS ESTABILIDADE}

NA SELECÃO DE GENÓTIPOS

\section{I NTRODUÇÃOO}

O homem ao longo de sua historia vem procurando exercer dominto sobre suas atividades. Multo embora tenha conseguldo grandes progressos, exercer total controle não tem sido possivel, pols significaria possulr conhecimento perfelto de todas as etapas das suas mals diversas atividades, Inclusive dos fatos futuros. Segundo BARNARD (1979), o conhecimento 1 mperfeito caracteriza o que se costuma chamar incerteza.

os agricultores, relativamente aos administradores de outras atividades, săo os que suportam as maiores cargas de incerteza. A falta de controle existente na agricultura $\Leftrightarrow$ proveniente da Imprevisibilidade dos materiais biologicos, das condiçós climaticas, das politicas de preços, das relaçós entre individuos, etc.... elementos de que depende o setor e sobre os quals o agricultor exerce pouca ou nenhuma influencia. 
E claro que o nivel de incerteza dos individuos * algo pessoal e depende de uma serte de condiçóes como ratores biologicos, ambientais e ate mesmo de sua formação psicologica. A experiencia e o conhecimento individual acumulados constituem fatores decisivose estabelecem diferenças entre os agricultores. Quanto malor - conhecimento, menos exposto ele se encontra as 1 mprevisibilidades.

Para reduzir seu nivel de incerteza, o agricultor com mals conhecimento (e dispondo de recursos) pode lançar máo dos resultados da pesquisa efou realizar investimentos em irrigaçăo, drenagem, seguros e diversificaço das culturas, na busca de elevados rendimentos e balxa variabilidade. A escolna das atividades a desenvolver bem como das tecnologias adotadas \&. portanto, de fundamental importancia para a sobrevivencla do empreendimento e do proprio agricultor, pols são elas as grandes causadoras das variaçóes na renda da propriedade.

Embora alguns individuos sejam classificados como tendo preferencia pela incerteza cou riscos, de um modo geral os agricultores são considerados aversos a ela. Este fato termina por leválos a objetivos e comportamentos diferentes daqueles que teriam se rossem apenas maximizadores de lucro. Para os individuos com caracteristicas de aversão ao risco, a sobrevivencia está em primeiro lugar entre as prioridades. Preferem então 
escolher alternativas que lhes proporcionem retornos (ainda que pequenos) certos e suricientes para o cumprimento de seus compromissos, aquel as que, maximizando lucros, trazem um risco mal or embutido.

PASTORE (1975) ao enfocar as decisóes tecnologicas na agricultura de subsistencia, sugere que os agricultores, por exigirem um nivel batxo de retorno, tem preferencia por tecnologias tradiclonals. Temem a inovaçăo pelo fato de saberem que estáo mals expostos aos riscos que os demais. Os agricultores comercials, dispondo de mals recursos para reproduzir as condiçóes em que for am desenvolvidos os experimentos nas instituiçes de pesquisa, podem atingir os elevados rendimentos que a tecnologia e capaz de proporcionar. A incerteza seria então, de acordo com o autor, algo mals associado ao meio e a tecnologia do que a uma caracteristica inerente ao Individuo.

o risco e, portanto, o fator que interfere grandemente na escolha das tecnologias disponiveis e a pesquisa tem uma forte responsabilidade nesse processo. Desta forma, a enfase na escolha deve ser dada náo apenas ao retorno medio, mas ao desempenho das tecnologias em condlçóes adversas, procurando medir suas variabllidades.

Dentre as tecnologias colocadas ao alcance do agricultor, o uso de sementes melhoradas destaca-se como uma das mais importantes na tentativa de proporcionar-l he elevados rendimentos. Objetivando selecionar materiais 
geneticos com boas caracteristicas, sistematicamente são realizados ensalos regionals pelos ógáos de pesquisas. Para elelçăo dos materials melhorados, săo comparados os rendimentos medios apresentados pelos genotipos nas diferentes condlfores ambientals em que são feltos os testes. Durante o processo de seleção, as grandes preocupaçశes tem sido o desempenho dos genótipos quando cultivados em locals cujas condiçóes diferem daquelas em que foram testados e o comportamento em um mesmo local, diante de mudanças amblentais que ocorrem ao longo dos anos. As diferenças apresentadas tornam dificll a decisão de quais genotipos escolher.

Para solucionar esse tipo de problema, diversos métodos tem sido desenvolvidos permitindo avaliar a interação entre os ambientes e os genotipos, classificando estes não aperias pelas medias de produtividades apresentadas nos diversos locals onde foram testados, mas tambem quanto a variabilidade que tals produtividades podem demonstrar ao serem submetidos a diferentes condiçóes ambientals. De um modo geral estas metodologias buscam detectar estabilidade nos materiais geneticos em estudo. Consistem em avaliar as produtividades apresentadas por um grupo de variedades em diferentes ambientes (associaça de locals e epocas), fazendo inferencias sobre seu comportamento a partir dos resultados, com o emprego de instrumentais estatisticos. Em resumo, os métodos empregados para medir estabilidade, 
buscam selecionar os genotipos de forma a recomenda-1os aos agricultores com mai or "segur ança".

o desenvolvimento de tals metodos sem dúvida representa um grande passo na busca de redução das variabilidades que tanta incerteza leva a atividade primária. O termo "segurança", associado aqueles estudos, năo considera os criterios economicos e psicologicos envolvidos no processo de escolha, istoe, os principios básicos da Teoria da Dectsão, os quais, segundo DILLON (1977), "conferem primazla as preferencias pessoals dos tomadores de decisăo e as estimativas de probabilidade". Por envol ver o conhecimento das probabilidades e por serem varladas e desconhecldas as preferenclas dos investidores, a escolha de tecrologias a recomendar transforma-se em um serio problema de decisão. Para contornálo, diversos processos tem sido criados. procurando evitar que a escolna se restrinja a questão puramente intuitiva, recorrendo para tanto, as aproximaçós das possibllidades de ocorrencia dos eventos.

Os metodos de escol ha envolvendo risco visam, portanto, incorporar criterios economicos e de preferenclas, permitindo uma tomada de decisão mais criteriosa. Embora tenham ainda relativamente pouca difusão nos processos de pesquisa no Brasil, eles tem sido aplicados em uma serie de trabalhos com fins praticos de recomendaçăo de tecnologias aos agricultores, inclusive na indicação de vartedades melhoradas geneticamente. 
- problema ora identificado resume-se em averiguar a performance dos metodos utilizados por melhoristas na classificaça de genotipos, daqueles envolvendo Teoria da Declsăo, uma vez que ambos carregam um enfoque de "segurança". A partir de classificaçós realizadas para detectar estabilidade fenotipica e da seleçăo visando 1 ndicar genótipos que levem menores riscos aos agricultores, este trabalho pretende averiguar a existencia de uma relaçăo entre os dols criterios de escolha, buscando constatar de que forma as variedades mals estavels são tambem lse e que sãos as que concedem menores nivels de incerteza.

A importancia de encontrar-se tais relaçós reside no fato de que, uma vez constatadas, seria possivel indicar genótipos estávels fenotipicamente incorporando, paralelamente, a ldela do risco envolvido na adoçáo. Tal fato garantiria malor segurança, na medida em que as variabilidades detectadas estariam não apenas associadas as qualidades intrinsecas do genotipo, mas tambem considerando a questão relativa ao comportamento do agricultor diante da incerteza.

O presente trabalho tem como objetivos:

1. Descrever os procedimentos adotados na utilizaçăo dos metodos desenvolvidos para detectar estabilidade de materials geneticos, durante o processo de seleça de genót I pos ; 
2. Estudar os processos de ordenaça de alternativas sob condiçoses de incerteza, especialmente os metodos de Dominancia Estocastica;

3. Comparar, a partir de diversos trabalhos que visam a escolha de genotipos estaveis, o grupo classificado por métodos de estabilidade com aquele obtido pelo emprego da Dominancia Estocástica, averiguando as possivels relaçós existentes entre ambos; e, dependendo dos resultados, 4. Formular regras básicas, para que os responsaveis pela criaça e difusáo de varledades melhoradas, possam, de modo pratico, realizar classificaça pela Teoria da Decisão (Dominancia Estocástica), detectando a superioridade do material genetico tanto no aspecto da interaçăo com o ambiente quanto ná segurança que levaria ao agricultor ao ihe ser recomendada. 


\section{REVISÃO DE LITERATURA}

2.1 Metodologia empregada na classificação de genótipos por estabilidade

os melhoristas vem, ao longo dos anos. procurando encontrar genotipos que apresentem bom desempenho em varladas condiçóes amblenta1s. Varledades adaptadas apenas a condiçoes ecologicas restritas podem ser bastante útels no caso de horticultura, por exemplo, em que as condiçбes ambientais săo controladas. Em culturas de carater extensivo, entretanto, aparecem serias $11 \mathrm{mitaç}$ Jes devido as variaçóes encontradas nos fatores que comporem o ambiente onde venham a ser cultivadas.

Estratificar os ambientes poderia ser uma soluçăo; por em, mesmo em condiçôes de ampla uniformidade, devem ser consideradas as modificaçós que ocorrem nas condicfes climaticas a cada ano. Da1 a importancia de desenvolver materiais que apresentem considerável grau de adaptação e que reajam satisfatoriamente as mudanças amblentais naturais ou mesmo causadas pelo homem (adubaçăo, irrigaçăo, etc....). 
YAIES \& COCHRAN (1938), questionaram a validade de extrapolar resultados de experimentos desenvol vidos em uma determinada regiăo e epoca, pols seriam adequados apenas aquelas condiçбes onde for am desenvolvidos. Entre as análises estatisticas realizadas para estudar o problema, ajustaram regressóbes para cada genótipo, tentando investigar o grau de associaçăo entre as diferenças apresentadas e a fertilidade geral cindicada pela media de produção de todas as variedades). Os dados utilizados foram resultado de um ensaio desenvolvido nos anos de 1931 e 1932 em seis locals, utilizando cinco varledades de cevada. Esta linha de trabalho foi, posteriormente, ampliada e seguida por muitos pesqui sadores.

FINLAY \& WLKINSON (1963) estudando a interaçăo genótipo $x$ ambiente, buscavam encontrar formas de detectar variedades adaptadas a mudanças ambientais, tendo em vista as grandes modificaç̧es nas condiçzes edaficas e as varlaçóes sazonals que se veriflcavam nas localidades que compótem o cinturăo de cereals do sul da Australia. Foram utilizadas no ensaio 800 variedades de cevada, tomando como amostra 277 daquele total, cultivadas em tres locals: Minlaton e Clinton nos anos de 1958,1959 e 1960 e no Instituto Waite no aro de 1960. Para comparar a performance do grupo de varledades, nos tres centros, nos diferentes periodos, foram ajustadas regressofes ilneares, uma para cada varledade, utilizando as produçóes 
Individuals "contra" o que chamaram de "Indice de Avaliaçăo Ambiental". Este indice consiste na media de produção de todas as varledades calculadas para cada combinaçăo de local e ano.

assim:

$$
I_{j}=\frac{\sum_{i=1}^{Y} Y_{i j}}{V} \text {, onde }
$$

$I_{j}$ : Indice de Aval 1 açăo Ambiental na combinaçăo de local e aroj.

$Y_{i j}$ : Produção da varledade $i$ na combinaçăo de ano e local j.

$\checkmark$ : Numero total de genotipos.

Esta media fol utilizada dada a impossibilidade de se trabalhar com todas as variaveis ambientais, assim como as suas interaçóes, capazes de causar influencia na produção.

A media de produçáo de todas as varledades em Clinton no ano de 1959 (C59) foi a mais baixa de todas, o que representa um ambiente de baixas produçơs, isto e, as caracteristicas edaficas daquele local, interagindo com as condiçós climáticas ocorridas naquele ano, determinaram o mal ambiente, afetando a produção. Isto não significa dizer que o local e responsável pelo mal desempenho das culturas, pois no mesmo local no ano de 1958 ocorreram as malores produçóes, fornecendo a mais alta medida ambiental cC58 - associaça de suas condiçós de fertilidade às ocorrencias climaticas de 1958). Um ambiente natural. complexo, póde dessa forma ser descrito, utilizando a media de produção de um grupo de variedades. 
Ajustadas as regressoes, for am tomados como parametros de analise, a media de produtividade de cada variedade ao longo de todos os ambientes e coeficiente de cada regressáo $\left(b_{i}\right)$, medindo este a respectiva estabil1dade fenotiplca em todos os ambientes.

Para interpretar o comportamento das variedades. foram tomadas como exemplo quatro regressóes ilneares das mals representativas, mostradas na Figura 1.

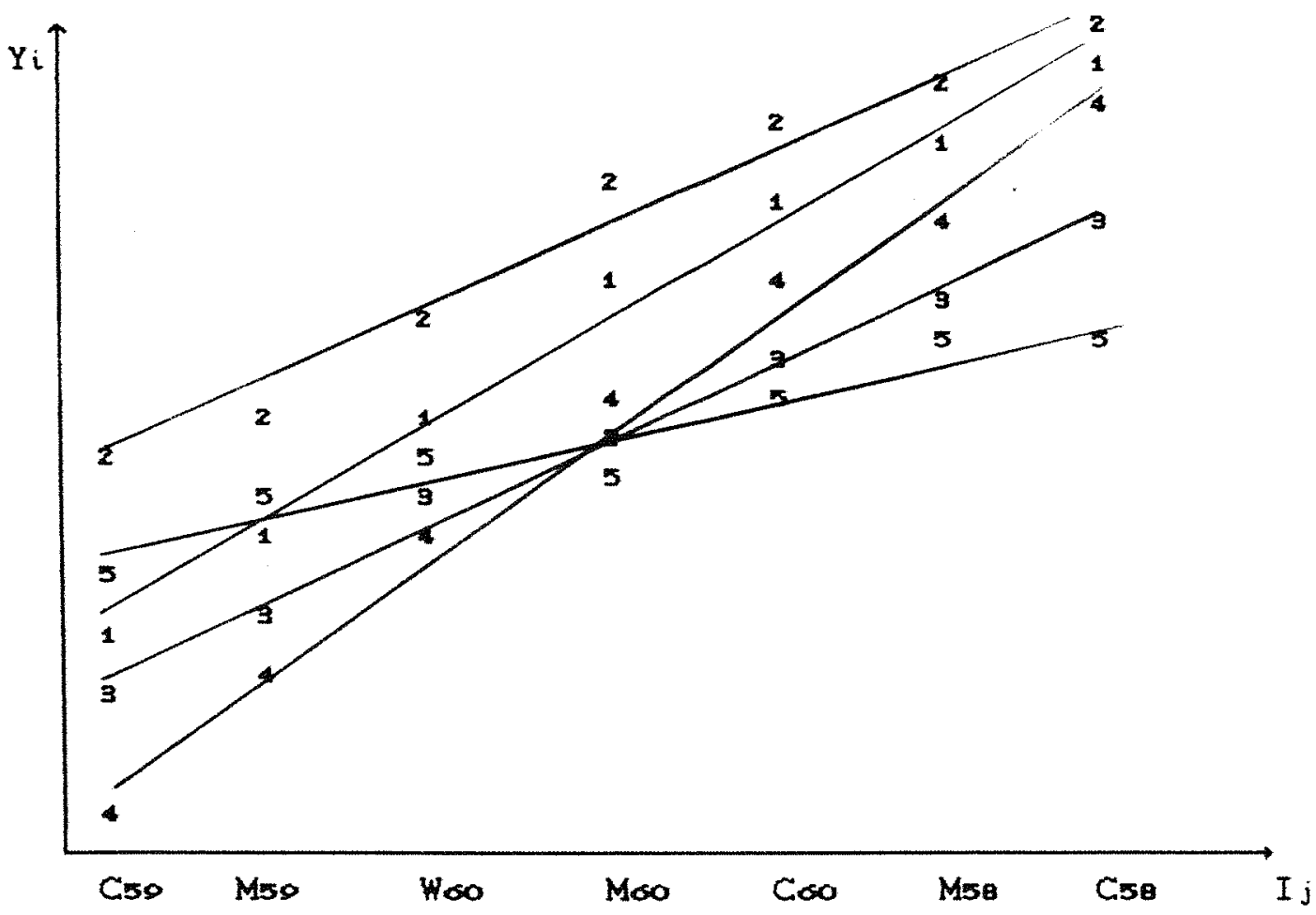

F1gura 1 -Regressóes e o Comportamento das Variedades

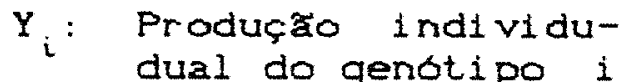

1: Media da Popul ação
$I_{j}$ Avaliação Ambiental

3: Variedades com di4: ferentes comporta5: mentos 
Tomando uma variedade hipotetica cujas produçóes individuals fossem 1 guals as medias de produção de cada variedade em cada local e ano, ou seja, iguais aos valores dos indices ambientais, a reta ajustada mostraria uma inclinaçăo de $450 \mathrm{C} b=1$, representada por 1 na Fig.1). Varledades como as indicadas por $2 e 9$, ou seja, com coeficientes de regressão aproximadamente 1 guals a 1,00 , seriam de estabilidade média para aquelas condiçóes de ambientes consideradas. Neste caso, quando a variedade apresenta produçóses acl ma da media da população $(2)$ ela \& dita de adaptabilidade geral; quando abaixo ( a) diz-se que fracamente adaptada a todos os ambientes.

Variedades com coeficiente de regressăo significativamente maior que $1<* 3$ mostram elevada sensibilidade a mudanças ambientais. Diz-se que tem estabilidade fenotipica abaixo da media, pois pequenas mudanças no ambiente provocam mudanças mals que proporclonais na sua produça. Produzem abaixo da media em ambientes "pobres" e acima da media em ambientes de "elevadas produçroses".

Variedades com coeficiente de regressão significativamente menor que 1 ( 5 ) mostram baixa sensibilidade a mudanças ambientais. Produzem actma da media em ambientes "de baixas produçZ̃es" e abalxo, em ambientes favoraveis. Diz-se que possuem estabilidade fenotipica acima da media e são especificamente adaptadas a ambientes caracterizados pela balxa produção. 
Distribuindo os dois parametros cmedia de produção e coeficiente de regressăol em um grafico bidimensional (Figura 2), possivel visualisar melhor o comportamento das varledades.

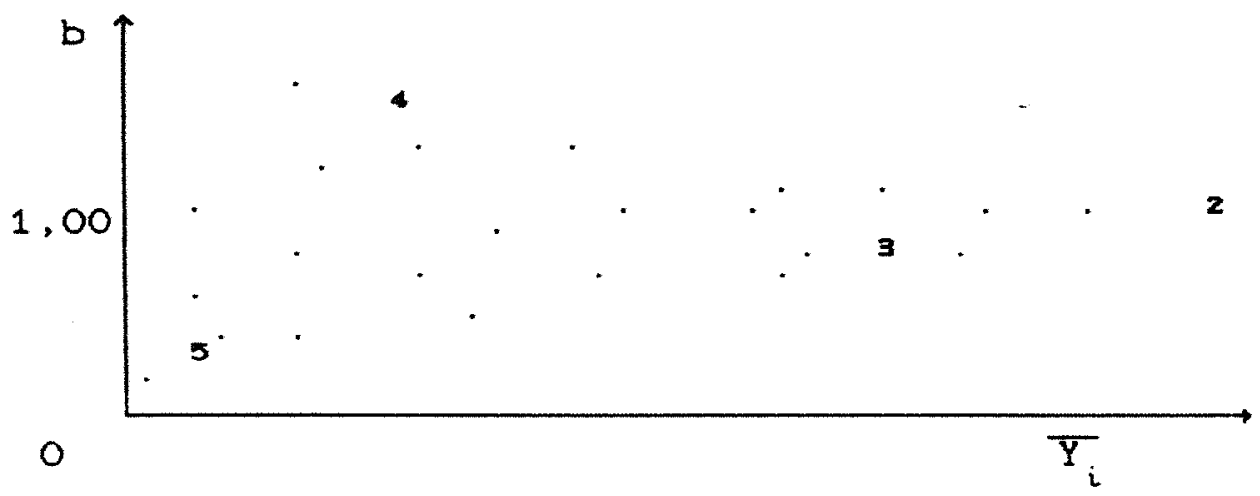

Figura 2 - Media de Produção $\times$ Coeficlente de Regressão

As variedades mais estaveis apresentaram baixa media potencial, tornando-se pouco indicados para a explor ação em condiçбes boas de ambiente, enquanto os de elevada produtividade potenclal mostraram-se muito instavels fenotipicamente celevado coeficiente de regressãol reduzindo mals que proporcionalmente a produtividade com a diminuiça do indice ambiental. 0 ideal seria um genotipo com máxima produçao potencial no ambiente mals favoravel e maxima estabilidade fenotipica, ou seja, balxo coeficlente de regressão.

EBERHART \& RUSSELL (1966) sugeriram alem do estudo de parametros como a média $e$ o coeficiente de regressão que se levasse em consideraçăo a estimativa dos desvios das regressóes ajustadas de acordo com o seguinte modelo: $Y_{i j}=\mu_{i}+\beta_{i} \cdot I_{j}+\delta_{i j}+e_{i j}\left(i=1, \ldots, v_{i} j=1, \ldots n\right)$ onde: 
$\mu_{i}$ : Media de produção da varledade $i$ em todos as ambientes.

$\beta_{i}$ : Coeficiente de Regressão

$I_{j}$ : Indice de Avaliaçăo Amblental, sendo

$$
I_{j}=\frac{\sum_{i=1}^{V} Y_{i j}}{V}-\frac{\sum_{i}^{V} \sum_{1} \sum_{j}^{n} Y_{i j}}{V: n}
$$

$\delta_{i j}:$ Desvios da Regressão

$e_{i j}$ : Erro medio da varledade i no amblente $j$

o desempentio de cada variedade poderia ser previsto usando as estimativas dos parametros:

$$
\hat{\mathrm{Y}}_{i j}=\mathrm{X}_{i}+\mathrm{b} \cdot \mathrm{I}_{j}
$$

onde: $\quad \hat{Y}_{i j}$ : Estimativa de produtividade da variedade $i$ no ambiente $j$

$X_{i}$ : Estimativa da media de produtividade da variedade 1.

b: Estimativa do coeficiente de regressão ajustada para a variedade 1.

$\hat{\mathcal{E}}_{i j}=Y_{i j}-\hat{Y}_{i j}$, onde:

$\hat{\delta}_{i j}$ : Estimativa do desvio da regressão.

o parametro de estabilidade seria a soma de quadrados dos desvios da regressão representado por $\alpha_{d i}^{2}$, podendo ser estimado calculando $S_{d i}^{2}$. Este modelo separa a interação genotipo $x$ ambiente de cada variedade em duas partes: 13 variaça devida a resposta da variedade a variaça do Indice ambiental (soma do quadrado devido a regressão), e 2) desvios não explicados pela regressão no indice 
ambiental. Segundo o modelo, a variedade desejavel deveria apresentar elevada media, coeflciente de regressáo 1 gual a 1,00 desvio da regressăo tăo pequeno quanto passivel $\left(s_{\mathrm{di}}^{2} \simeq O\right)$

BREESE ( 1969 ) estudando as interaçres genotipo $x$ ambiente de variedades de gramineas ajustou regressofes de acordo com o modelo de Finlay \& Wilkinson. 0 calculo das variaçós para os coeficlentes de regressăo levou-o a concluir que a constancia do coeficiente de regressão (pequeno desvios) Indicaria que a performance de uma varledade em um local poderia ser utilizada para prever seu desempenho em outros, ou ate mesmo em diferentes epocas e tipos de manejo. Isto es se há estabilidade em uma restrita falxa de ambiente, tal padrăo poderia ser usado como refertucia para determinar comportamento em outros amblentes. Dessa forma, como proposto por Eberhart e Russell, sugeriu que a expressão fenotipica de uma popul ação depende de tres propriedades: a expressão media, uma resposta linear ao ambiente desvios residuais da regressão.

KNIGHT (1970), analisando o que havia sido estudado ate então, principalmente o trabalho de Finlay e Wilkinson, alertou para a questáo do indice de amblente. Sugeriu que o ideal seria medir o comportamento dos genotipos ao variar isoladamente o fator $11 \mathrm{mitante}$ ao seu desempenho. Diversos autores estudaram o fenomeno para fatores como temperatura, niveis de nitrogenio, fósforo, 
calclo, etc. e observaram distribulçăo das produçóes $\left(Y_{i}\right)$, inlciando-se com as balxas (condiçoes sub-btimas), atingindo um maximo nas condiçoes otimas e por fim reduzindo-se em condlgóes acima das otimas (Figura 3 ).

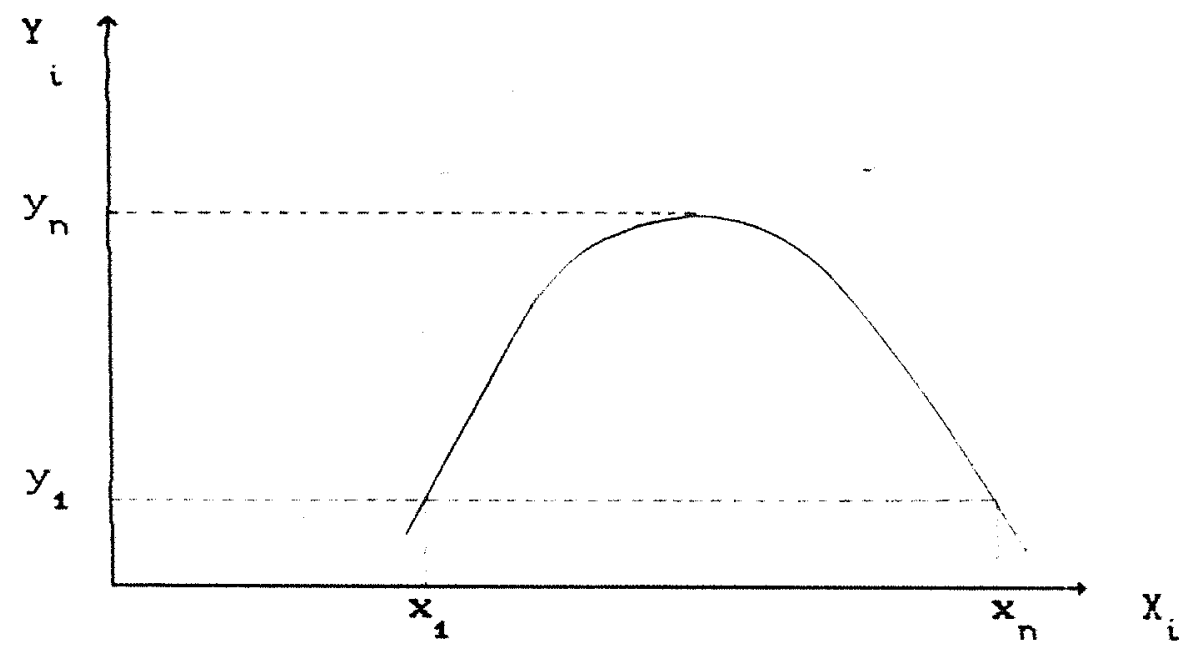

Figura 3 - Variaçăo da Produção com a variaçăo de um fator

Assim, ao usar-se indices ambientais no ajuste de regressóes lineares, deve-se ter em mente que os mais baixos representam produtividades obtidas tanto em condiçóes adversas quanto nas acima do otimo, enquarito o indice mals alto mostra apenas as condiços otimas estudadas CFiguras 4 e 5 .

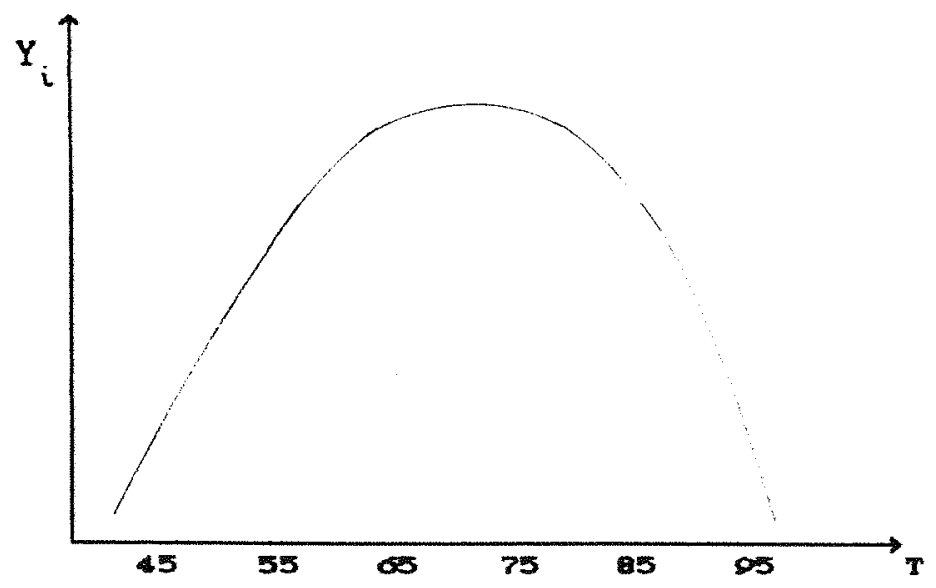

Figura 4 - Resposta de Produçăo $\left(Y_{i}\right)$ ao aumento de temperatura $(T)$. 


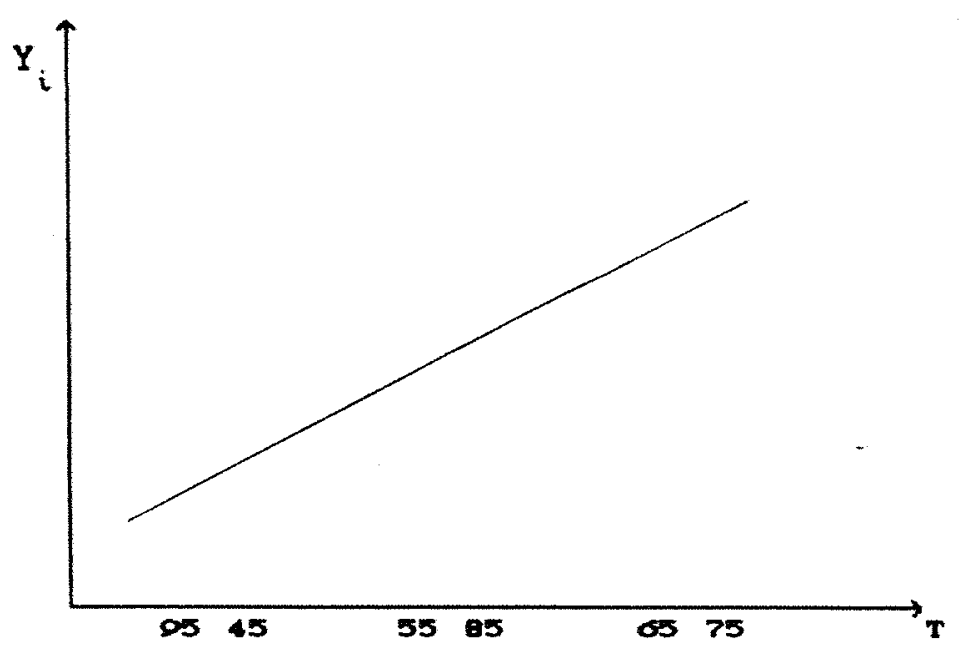

Figura 5 - Reta ajustada a partir dos niveis de resposta

As regresores ajustadas mostrariam, portanto. balxas produçơes obtidas em condiçófes abalxo e acima do otimo, sendo o otimo responsável pelo máximo de produção. Portanto a extrapol ação da regressão linear não poderá ser felta se os indices for am obtidos cobrindo condiçóes acima do otimo, pols mostraria produtividades mals altas que aquelas obtidas nas condiçбes ideais. Como as condiçres consideradas super-otimas năo ocorrem a nivel de campo, as regressóes 11 neares tornam-se validas. Knight considerou ainda que deve-se estar atento para o fato de que o desvio da regressão ccomo referido por Eberhart e Russell e tambem por Breesel pode não ser uma proprledade do genotipo mas algo relativo ao fato da media ambiental ter sido influenciada por genotipos de comportamento semelhantes. Para explicar a Idela, o trabalho de Mitchell 
\& Lucanus! foi citado por KNIGHT (1970) mostrando que de 6 cultivares de gramineas estudadas, 5 apresentavam comportamento semelhante, enquanto o sexto (Paspalum) diferia na resposta a variaçóes de temperatura. Logicamente as cinco que se assemel havam tiveram grande influencla sobre a media que representou cada indice ambiental e consequentemente, a regressão da sexta CPaspalum mostrou elevada vartancia já que suas produçóes diferiram da media. Se, ao contrario, houvesse 5 cultivares semelhantes a Paspalum, a regressão ajustada para esta $\&$ que apresentaria baixos desvios $e$ as que porventur a fossem diferentes, os teriam altos.

Sem traçar regressores, apenas comparando as curvas de resposta de cada variedade com a curva que representaria a media de produça de todas as variedades, pode-se "avaliar" a magnitude das produtividades e os coeficlentes de regressão, como tambem ter uma 1 dela dos desvios (Figura 6). O genótipo gerador da curva de resposta 1 teria produção media, inclinação aproximadamente 1 gual a 1,00, mas grande desvio. As demais teriam pequeno desvio, pols assemelham-se a curva media. sendo que o de número 2 teria balxa produtividade $e \mathbf{b}<1$ o genótipo 3 balxa produtividade esperada e b $>1$

\footnotetext{
1 MI TCHELL, K. J. \& LUCANUS, R. 1962. Growth of pasture species under controlled environments. N. Z. J. Agric. Res. 5: $135-44$.
} 


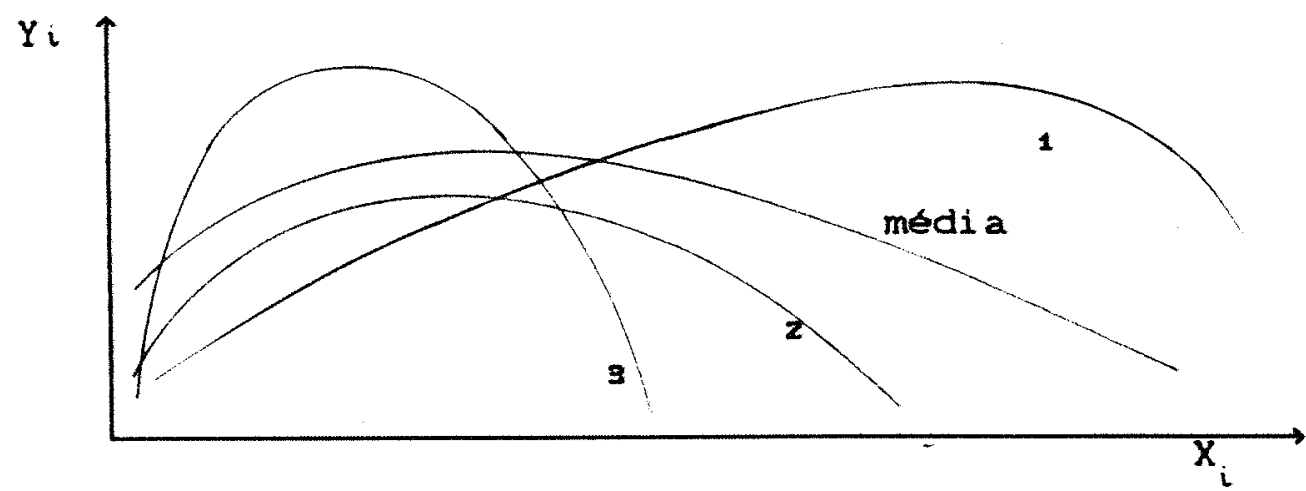

Figura 6 - Comportamentos Diferentes em Relaçăo a Media

Tomando-se as regressరes lineares como representantes de uma curva hipotetica resultante da variaçáo dos fatores, o coeflciente de regressão estaria representando a diferença de comportamento de cada uma das varledades em relação a media de comportamento das demals. $\mathrm{Na}$ prática, a dificuldade estaria no fato de năo ser possivel medir o efelto isolado do fator limitante, uma vez que ele interage com os demais. Em vista da interpretacăo dos valores de $b$ das curvas de resposta, para Knight, a terminologia empregada por Finlay \& Wilkinson parece ser preferivel como indicador de uma baixa flutuação na produçăo com a mudança no ambiente.

FRANCIS \& KANNENBERG (1978) fizeram um estudo comparativo entre metodos de classificaça de genótipos por estabilidade e propuseram um metodo alternativo. Observaram que os genótipos estavels apresentaram, em geral, produção abalxo da media, o que não seria surpresa. segundo eles, pols nåo oferecendo o genótipo grande resposta a mudanças ambientais, a varlaçăo na produção 
pequena. Os responsivos com o crescimento da fertilidade, por sua vez, possulam elevada variaç̃o e portanto el evada media. Em seu ensalo, os 15 hibridos apresentaram correlaçao positiva entre media e variancia de 0,65. Dado que a variedade responsiva tende a ter variancia elevada, dever-se-ia ter uma medida de consistencia considerando tambem a produção e não apenas a variancia. Esta medida seria o Coeficiente de Variação (CV). O objetivo seria agrupar genotipos pelo CV. A produça média $\left(\bar{Y}_{i}\right)$ foi plotada na Figura 7 "contra" O CV, determinando os seguintes grupos:

Grupo I : alta produção media e balxo CV

Grupo II : alta produção media e alto CV

Grupo III: baixa produção media e baixo CV

Grupo IV : balxa produção media e alto CV

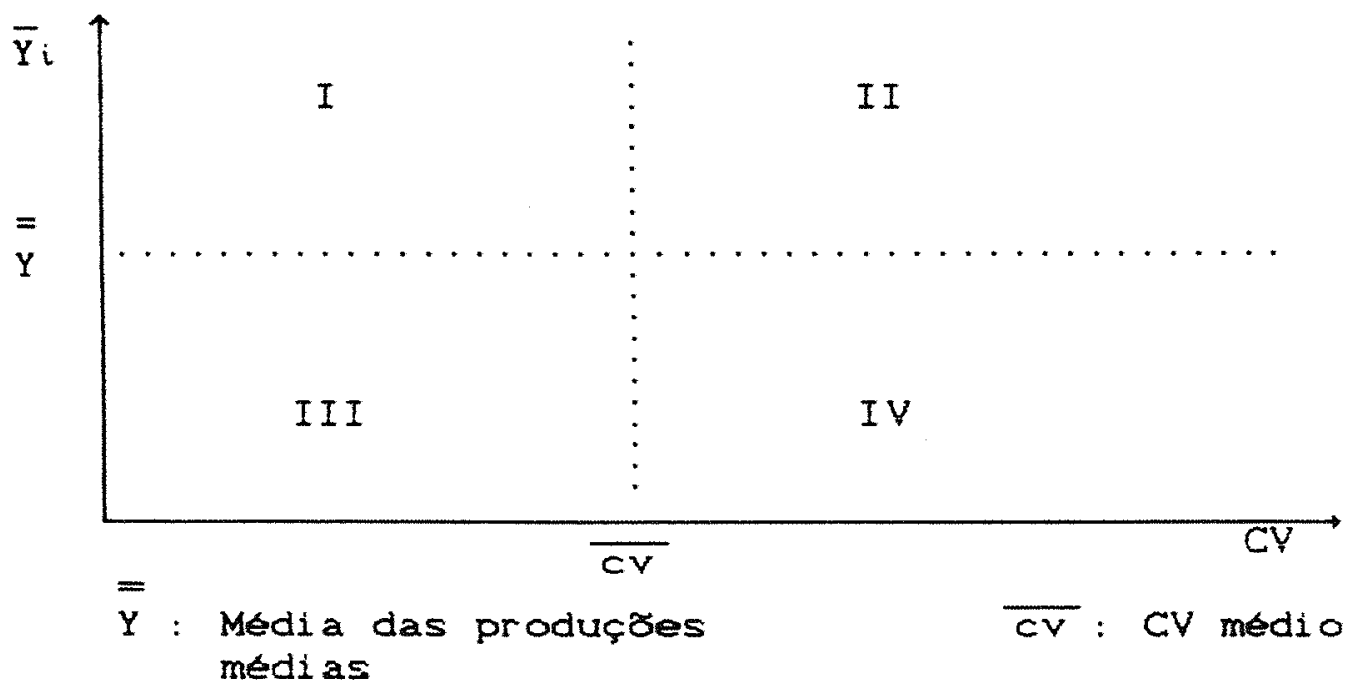

Figura 7 - Coeficiente de Variaçăo X Produtividade 
Francis \& Kannenberg tomaram cada um dos grupos calculando para cada um deles a produça, coeficiente de regressão, desvios da regressão e variancia da estabilidade [tecnica proposta por SHUKLA (1972)], todos tomados pela media dos componentes do grupo. Comparando os grupos, concluiram que o grupo I mostrou-se o mais desejavel, considerando qualquer dos parametros de estabilidade pols apresentou media de produção elevada. coeficiente de regressão aproximadamente igual a 1,00 e $S_{d}^{2}$ năo signiflcativo. Seria o grupo mals estavel. O grupo III poderia ser tomado como estavel, pois em media $b=0,79$ (relativamente baixo), Indicando estabilidade acima da media; porem, a media geral de produçăo do grupo e baixa, $S_{d}^{2}$ e significativo e a variancia da estabilidade tambem significativa. Por outro lado, tomando hibridos pertencentes ao grupo I (estavel) individualmente, alguns mostraram-se instaveis por outros metodos.

VERMA \& CHAHAL (1978) propzem que numa grande amostra podem ser encontrados genótipos dos seguintes tipos: a) sensibilidade baixa em condigres ambientais abalxo da média, mas elevada em condlçбes ravorávels (genótipo teoricamente ideal) e b) sensibilidade alta em condiçóes abaixo da media, mas balxa sob condlçóes favoráveis. Genotipos de ambos os tipos existem, mas que năo podem ser detectados pelas tecnicas ate entäo apresentadas. Quanto aos desvios da regressão, um genótipo próximo do ideal pode ter sua regressão abandonada se não 
forem examinadas a magnitude e a regiăo dos desvios, pols desvios na regressão correspondentes ao intervalo dos amblentes "pobres", pode ser um fato vantajoso. A proposta de Verma \& Chahal e que a falta de ajustamento de algumas regressores Iineares, Indicada pela elevada variancia apresentada, poderia ser reduzida separando os indices ambientals em dols grupos e ajustando duas regressóes, uma baseada nos indices que comprem os ambientes desfavoraveis $(\rightarrow$ outra utilizando os Indices que identificam os amblentes favoravels $(+)$ (Figura 8). As duas regressós permitiriam verificar quals dos genotipos em estudo apresentam comportamento mals aproximado daquele teoricamente ideal, sem necessitar buscar outros tipos de ajustamento mals complicados, como o curvilineo, ao tentar reduzir a variancia existente na única regressão inear anteriormente ajustada.

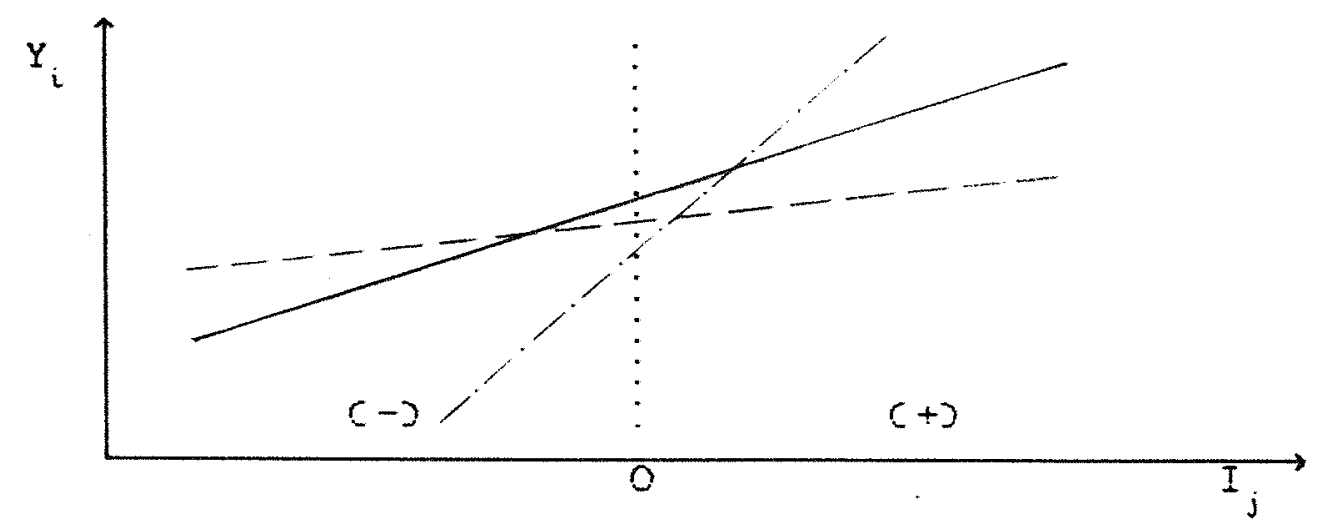

Figura 8 - Ajustamento das Regressóes por Tipo de Ambiente - $: b$ baseado em todos os ambientes $\left(I_{j}\right)$ _ _ _ - : b baseado em amblentes desfavoravels $C \rightarrow$ -.......: b baseado em ambientes favoraveis $C+$ b 
Em seu trabalho, Verma \& Chahal compararam genotipos calculando coeficientes de regressão para o ajustamento de uma única reta com base em todos os 1 ndices e para duas retas ajustadas com base nos dols grupos de ambientes, separadamente. Genotipos que apresentavam semelhança de comportamento ao ajustar-se regressóes únicas mostraram-se diferentes ao serem comparados ut1lizando as duas regressóes, separadas de acordo com os ambientes. Eles mostravam semelhança em condiçres favoravels $(+)$ porem um deles apresentava-se superior em estabilidade nos ambientes ditos pobres $(\rightarrow)$. A deficiencia do metodo esta no fato de que dependendo do número de ambientes, ao serem separados, sobram poucos pontos em cada um deles para os ajustamentos isolados.

SILVA \& BARRETO (1985) propuseram o ajustamento de uma única regressão composta pelos dols segmentos propostos por Verma \& Chahal, tomando a media de todas as variedades em todos os ambientes (media geral), como valor de conexão entre os segmentos CFigura 9 . 0 ajustamento rol proposto de acordo com o seguinte modelo:

$$
\hat{Y}_{i}=b_{0}+b_{1} \cdot x_{n}+b_{2} \cdot T\left(X_{n}\right) \text {, onde }
$$

$Y_{i}$ : Produtividades observadas para a vairedade 1 ;

$X_{n}$ : Indice ambiental correspondente ao $I_{j}$ descrito nos modelos anteriores;

$b_{0}$ : Estimativa da media de produção $\left(\mu_{i}\right)$ da variedade $1 ;$

$b_{1}$ e $b_{2}$ : Estimativa dos coeficientes de regressao.

$T\left(x_{n}\right)=0$ se $x_{n}<0$ e $T\left(x_{n}\right)=x_{n}$ se $x>0$ 


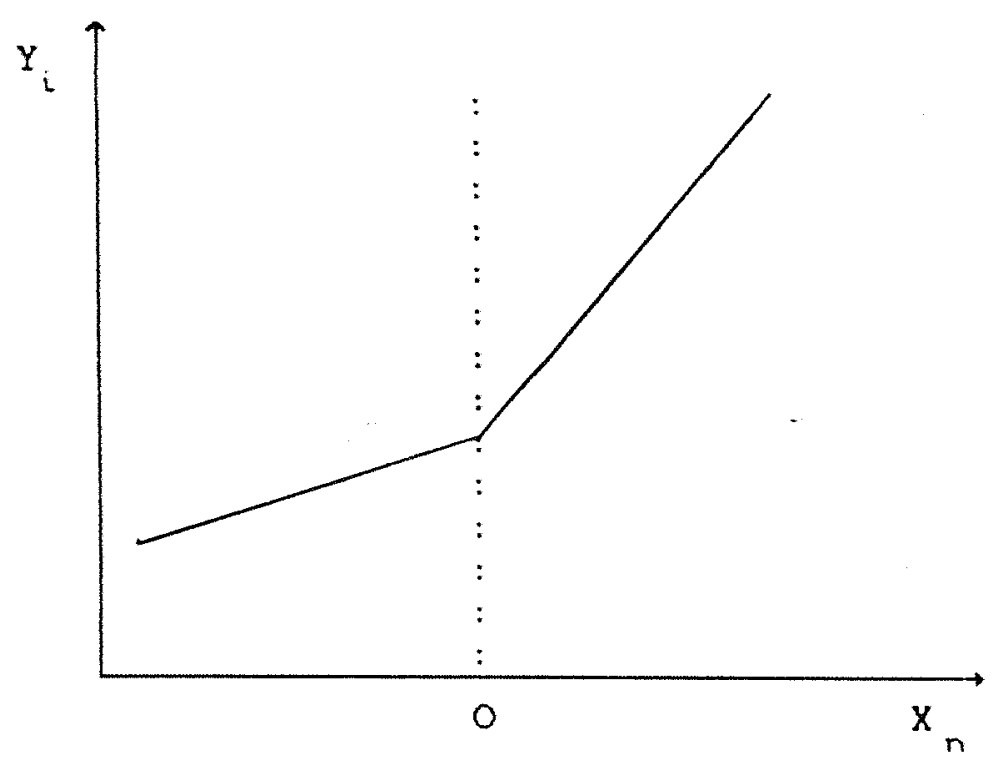

Figura 9 - Ajustamento da Regressão por SILVA \& BARRETO.

os métodos ja desenvolvidos para ajustar regressóes, inclusive o desenvolvido por Silva \& Barreto for am comparados por PEIXOTO et alii. (1985), em um estudo com cultivares de cana, tendo concluido que o metodo da regressão única, utilizando variavel "dummy", mostrou-se mais representativo do comportamento no campo, que os demais metodos empregados.

CRUZ et aliz (1988), apos constatação de que o método proposto por Silva \& Barreto gerava correlação entre as estimativas dos parametros de estabilidade, propuser am uma modificação ao método, mantendo os mesmos conceltos, mas acrescentando um apr 1 mor amento estatistico. O aprimoramento consiste em uma redefiniça da variável $T\left(X_{n}\right)$, a qual passa a ser calculada de modo diferente: $T\left(x_{n}\right)=0$ se $\left.x_{n} \leq 0 \quad t \quad T x_{n}\right)=x_{n}-x_{p}$ se $x_{n}>0$ onde, $\bar{X}_{p}=$ media dos indices $x_{n}$ positivos. 
A varledade de metodos para medir estabilidade mostra-se grande e năo para por aqui. Alem dos metodos que não foram enfocados, a cada novo trabalho na área de estabilidade, novos aprimoramentos certamente serão buscados, procurando el $1 \mathrm{mt}$ nar os vieses que se 1 dentificam e assim aproximar-se o mals possivel da metodologia 1 deal. Nos trabalhos que vem sendo desenvolvidos na ESALQ envolvendo estabilidade de genotipos, embora outros metodos sefam utilizados, observa-se uma tendencia ao emprego do metodo suger 1 do por EBERHART \& RUSSELL (1966) e também o de SILVA \& BARRETO (1985).

\subsubsection{Adaptabil1dade e Estabil1dade}

Na literatura dedicada ao comportamento de genotipos são frequentes as referencias aos termos estabilidade e adaptablilidade provocando uma certa confusão entre seus significados. Desta forma torna-se importante fazer uma retrospectiva das suas utilizaçós pelos estudiosos da área, para maior esclarecimento.

FINLAY WILKINSON (1983) empregaram a expressão estabilidade fenotipica como sendo a caracteristica medida pelo coeficiente da regressáo ajustada. De acordo com o tipo de estabilidade Identificada, o genotipo e então classiflcado por adaptabilidade. Assim, um genótipo com coeficiente de regressão aproximadamente 1 gual unidade, considerado 
como de estabilidade fenotiplca média. Quando este apresenta produçåo media elevada diz-se que possui adaptabilidade geral e quando a media de produçăo e balxa $\Leftrightarrow$ dito pobremente adaptado aos ambientes. Se o coeficiente de regressão for malor que 1,00 diz-se que apresentam estabilidade fenotipica baixa, sendo especialmente adaptado a ambientes de elevadas produções. Quando o coeficiente de regressão apresenta valor menor que 1,000 genotipo é dito de estabilidade fenotipica elevada, sendo especialente adaptado a ambientes de balxas produções.

EBERHART \& RUSSELL (1966) introduziram a soma do quadrado dos desvios da regressáo como um parametro novo. que ao lado do coeficiente de regressao constituiriam medidas de estabilidade fenotipica. 0 genotipo ideal seria aquele que apresentasse alem de elevada média, coeficiente de regressão igual a unidade e soma dos quadrados dos desvios igual a zero. A adaptabilidade ficaria definida pelo coeficiente de regressão. Quando maior que 1 cum significaria que o genotipo e adaptadado a amblentes de elevadas producões. quando menor que $1 \mathrm{Cum}$ adaptado a ambientes "pobres". A estabilidade seria medida, em cada caso, pelos desvios da regressão.

BREESE (1969) tomou o coeficiente de regressão - o rendimento medio como medidas de adaptabilidade geral e especifica. O desvio da regressão serta o indicador da estabilidade do genotipo. 
VENCOVSKY \& TORRES (1986) estudaram a questão das interaçoes de genotipos com localidades e anos separadamente, tentando verificar que relaçăo haveria entre estabilidade sob o ponto de vista temporal e sob o ponto de vista geografico, uma vez que os programas de melhoramento dão maior enfase a adaptabilidade em dada regiăo para o agricultor $\&$ mals importante que a variedade seja estavel ao longo dos anos em sua propriedade. O objetivo do trabalho fol verificar se a selecăo de variedades de acordo com a adaptaçáo ecologica teria o mesmo significado que selecionar quanto ao aspecto temporal.

Aqueles autores tomaram os coericientes de regressão medilos das localidades reunindo anos e dos anos reunindo localidades, e calcularam os coeficientes de correlaça entre eles. Concluiram haver independencia entre as duas propriedades e que a seleçăo, portanto, deve ser independente para tempo e local. A ausencla de correlaçăo náo exclul a possiblildade de se obter cultivares estáveis nos dois sentidos. Os autores adotaram o termo estabilidade para avaliar o comportamento da produção ao longo dos anos em um mesmo local e adaptabilidade (estabilidade geografica ou espacial) para avaliar modificaçóes na produção em diversos locais.

Em geral os autores tem utilizado as terminologias de Finlay e Wilkinson e de Eberhart e Russel ou variaçóes das mesmas. Nos trabalhos de escolha de 
genót1pos, o termo adaptabilidade tem sido usado de acordo com Finlay e Wilkinson, empregando o coeficiente de regressão associado a media de produçăo, enquanto os desvios das regressóes são utilizados de acordo com Eberhart e Russel 1, para medir estabilidade.

Neste trabalho, os genótipos em estudo serão classificados por estabilidade de acordo com os termos adotados pelos respectivos metodos empregados nos trabal hos consultados. 


\section{Z. Z Classificacāo de Alternativas sob Condlcōes de Risco}

Incerteza e risco säo termos comumente empregados como sinónimos. KNIGHT (1972) estabelece uma diferença entre risco e incerteza, dizendo que "risco" encontra-se associado a idela de perdas e "incerteza" a de ganhos. A noção de "risco-incerteza" estaria tambem assoclada a medição. O "risco" seria algo mensurável enquanto a "incerteza" seria 1 mensuravel. O risco estaria associado a probabilidades objetivas enquanto incerteza a probabilidades subjetivas. Trata-se de risco quando "a distribulção do resultado num grupo de casos conhecida enquanto na incerteza 1 sso năo ocorre, em geral, devido ao fato de que impossivel formar um grupo de casos, porque a situaçăo que se enfrenta $b$, em alto grau, singular" CKNIGHT, 1972 p. 249). Quanto mais conhecimentos acumulamos dos fatos, mals as incertezas transformam-se em risco ${ }^{1}$.

STONE (1970) considera que um individuo esta tomando risco ao comprar um conjunto de ativos cujo valor futuro uma variavel aleatoria. Aqui tambem. o concelto de risco encontra-se associado a uma distribuição de probablilidades.

1

Neste trabalho os termos risco e incerteza ser ão empregados como sinonimos pols diferem apenas quanto ao conheclmento das probabilidades associadas. 
Para caracterizar o comportamento dos Individuos nos processos de escolha, diante da Incerteza, os primeiros estudos sobre a Teoria da Utilidade Esperada foram realizados por Gabriel Cramer em 1728 e Daniel Bernoull1 em 1738. Eles procuravam explicar o Paradoxo de Petersburg. Investigavam o motivo pelo qual as pessoas pagariam uma pequena quantia por um jogo de infinitas expectativas matematicas. (ARROW,1974; SCHOEMAKER, 1982 ). Para explicar o Paradoxo. Bernoulli sugeriu que as pessoas tendem mais a maximizar a utilidade esperada em vez do valor monetario esperado. A funça de utilidade deveria apresentar caracteristicas de crescimento da utilidade menos que proporclonal ao crescimento dos retornos. Propos que a funçăo sería logaritmica e assim a utilidade esperada do jogo não seria infinita. Bernoulli não chegou a questão de como medir a utilidade nem demonstrou a racionalidade de seu principio.

Foi porem com John von Neumann e Oskar Morgenstern que a maximizaçăo da utilidade esperada fol formalmente explicada como um criterio de decisão racional. A utilidade de von Neumann e Morgenstern aplica-se a qualquer tipo de resultado inclusive a questão de dinheiro que seria um caso particular. Os autores demonstraram que 5 (cincol axiomas basicos implicam na existencia de utilidades numericas em que matores utilidades estão associadas a elevadas preferenclas. De acordo com SCHOEMAKER (1982), os axiomas são os seguintes: 
1) As preferencias por loterias sao completas e transitivas. Isto e, diante de uma escolna entre duas loterias $L_{1} \in L_{2}$, $L_{1} e$ preferida a $L_{2}\left(L_{1}>L_{2}\right)$, ou $L_{2} \Leftrightarrow$ preferida a $\left.\mathrm{L}_{1} \mathrm{CL}_{2}>\mathrm{L}_{1}\right)$ ou ambas săo igualmente atrativas. A transitividade implica em que se $L_{1} \geq L_{2} e$ L2 $\geq$ L9 entao L1 $\geq$ L9;

2) Se $x_{1} \geq x_{2} \geq x_{3}$, então há alguma probabilidade $p$ entre zero e um tal que a loteria $\frac{p}{1-p} x_{1}$ - atrativa tanto quanto receber x2 com certeza. Significa que existe um nivel de atração intermedisulo entre duas loterlas. Este axioma garante monotonicidade;

3) Se duas alternativas $x_{1} \in x_{2}$ são 1 gualmente atrativas (arriscadas ou nao), entao duas loterias $\int_{1-p}^{P} x_{1}$ e $\frac{p}{1-p} x_{2}$ são igualmente atrativas para qualquer valor de $p \in x_{g}$. As preferencias entre certeza e risco são invariáveis quando tudo o mais permanece igual;

4) Considerando as loterias $\frac{P}{1-P} \times_{1}$ $\frac{q}{1-q}-x_{1}$ que diferem apenas na probabilidade, se $x_{1} e$ preferida a $x_{2}$ então a primeira loteria será preferida a segunda se e aperias se $p>q$;

$5)$ Uma loteria complexa cisto e, seus retornos såo loteriasj e tåo atrativa quanto uma loteria simples que resultaria quando multiplicadas as probabilidades de acordo com a teoria das probabilidades. For

exemplo:

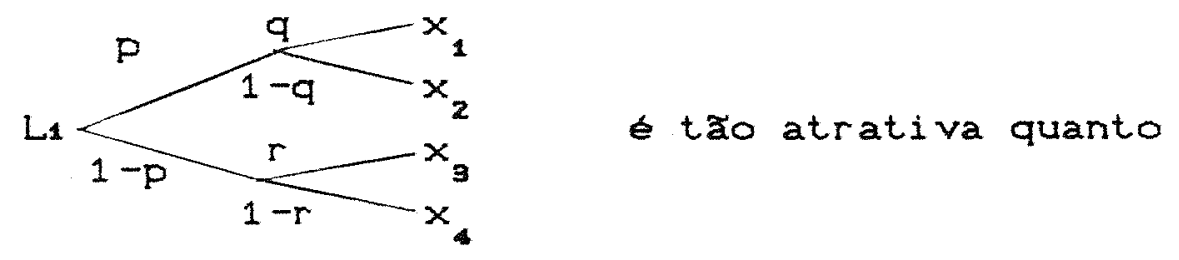




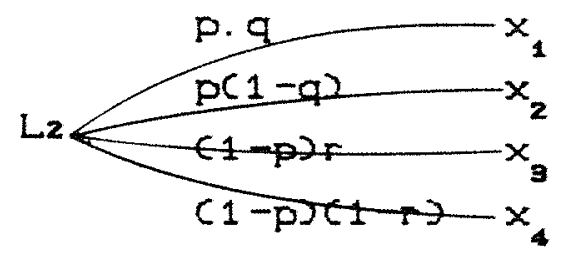

Os axiomas são suficientes para garantir que há um Indice de utilidade tal que a ordenaçáo de loterias por sua utilidade colncide com as preferencias das pessoas (SCHOEMAKER, 1882). A partir destes axtomas possivel obter pontos de utilidade, atraves dos quais a função de utilidade pode ser interpolada.

Pela observaçăo dos diferentes tipos de funçăo de utilidade dos individuos surge a noçăo de aversão a risco. De acordo com STONE (1970) a medida do risco, seria a diferença entre a utilidade de ganhos futuros esperados e a esperança da utilidade dos ganhos futuros:

$$
\phi=U(\bar{y})-E[U(\tilde{y})]
$$

Um investidor seria averso a risco, se $\phi>0$ (curva 1), indiferente se $\phi=0$ e propenso a risco se $\phi<0$ Ccurva 23 , conforme Figura 10. Em outras palavras, o Investidor sera averso a risco se a utilidade da media da distribulçăo for maior que a utilidade esperada. 


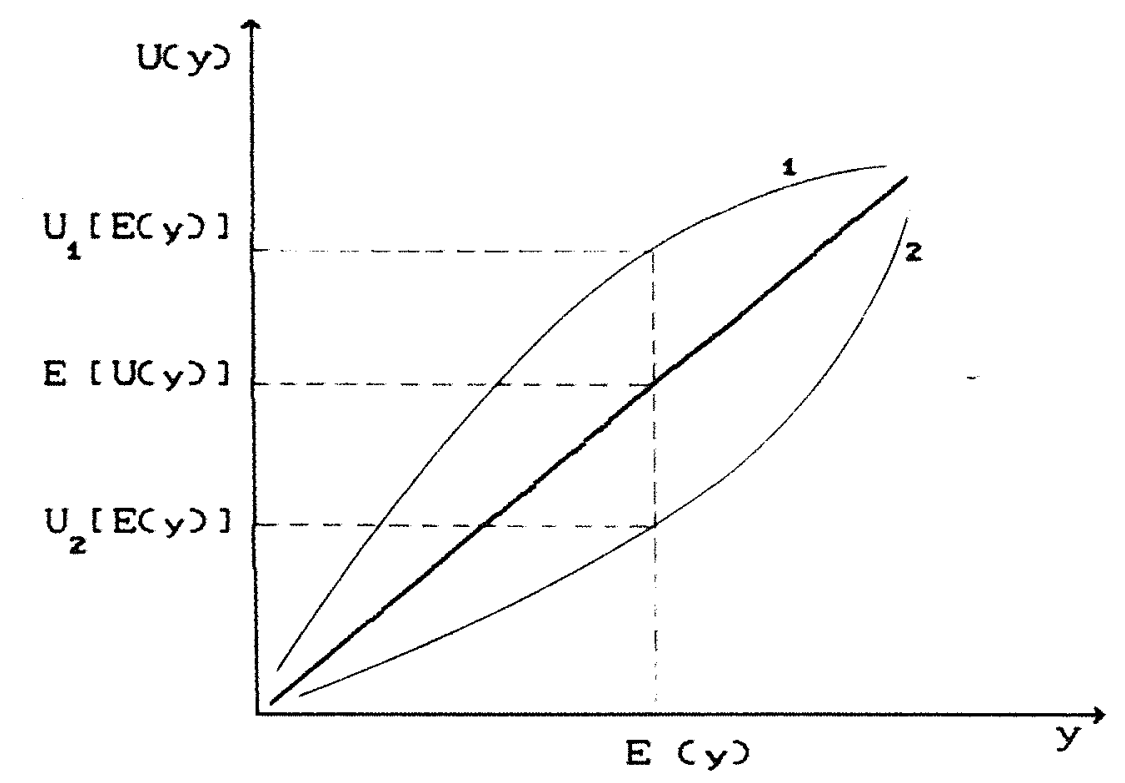

Figura 10 - Curvas de utilidade e o comportamento Indi vidual

O investidor averso a risco preferiria a media da distribuição como certo a correr o risco oferecido pela distribuição de probabilidade. o risco não $e$, como a variancia, apenas funçăo da distribulgăo de probabilidade dos ganhos, mas depende da forma da funçăo de utilidade. Para os aversos a risco ela seria concava, para os indiferentes Iinear, e convexa para os propensos a risco.

Como medidas de aversão ao risco ARROW(1974) propos uma relaçăo negativa entre a derivada segunda $\left[U^{\prime}(y)\right]$ e a derivada primeira $\left[U^{\prime}(y)\right]$ da funçăo de ut1lidade $[U(y)]$. As medidas de aversáo absoluta e relativa ao risco, podem ser calculadas, respectivamente, por :

$$
R_{A}(y)=-U^{\prime \prime}(y), U^{\prime}(y)
$$


Estas medidas foram tomadas por serem invariantes com qualquer transformação ilnear. Para individuos aversos a risco elas assumiriam valores positivos, pois U' $(y)>0$ e $\dot{U} \dot{(y)}<0$. Para os propensos a risco tanto RA como RR seriam menores que zero pols $U^{\prime \prime}>0$. A aversão relativa a risco parece ser mais compativel com a realidade, já que Individuos mais ricos deveriam estar dispostos a correr mais riscos.

Dentro dos conceitos estudados, os individuos considerados aversos a risco apresentam utilidade marginal da renda positiva, porem decrescente. Eles so aceltam aumentos no nivel de risco se forem acompanhados de ganhos mais que proporcionals. Baselam sua decisão năo na maximização de lucros mas na maximização da Utilidade Esperada, envolvendo portanto criterios individuals de ordem economica cultural e psicologica.

$\mathrm{Na}$ tentativa de resolver problemas emvolvendo decisão esbarra-se frequentemente nas dificuldades de conseguir medidas exatas das preferencias, ou seja das probabilidades subjetivas e das funç̧es de utilidade. Conhecidos estes elementos o processo se tornaria relativamerte fácil, porem dadas as dificuldades năo se pode fazer estimativas sobre as melhores al ternativas.

DILLON (1976), classsifica as abordagens ao problema de escolha de tecrologias, em categorias, mostrando que, em geral, o agricultor ao fazer sua escolha 
opta pela tradição. O agricultor não admite, em principio, que novas tecnologias venham a the oferecer menores perdas. Em suas escolhas baseia-se no conhecimento que possui e na sua visáo de probabilidade da ocorrencia dos fatos. A intuiçăo, continua Dillon, $\Leftrightarrow$ outro fator considerado no momento da escolha, seja pelos agricultores seja pelos tecnicos. Na maioria dos casos e o úrico instrumento de que se dispóse para optar por uma tecnologia. Segundo o autor, a habilidade em usar a intuiçáo \& que caracteriza um elemento cpesquisador, extensionista, agricultorj como sendo bem sucedido. A intuiçăo tem grande valor para decisóses pessoais. Quando porem os reflexos da escolna extrapolam esse limite, passando a atingir uma coletividade, parece injusto que a experiencia de um elemento venha a prevalecer sobre a dos demais.

$$
\text { Diversos processos de classificaçăo de }
$$
alternativas tem sido propostos, procurando conduzir a tomada de decisão por um caminho que fuja da questáo puramente intultiva. A seguir serăo enfocados algurs desses processos na seguinte sequência: Análise $E-V$, MOTAD, Método de Hannoch e Levy e a Dominância Estocastica, procurando mostrar suas principais caracteristicas e aplicaçôses. 


\section{2. 1 Analise Media - Variância (E - $V$ analysis)}

Segundo STONE (1970) a historla da moderna seleçá normativa começou com a publicaça por Harry Markovitz do artigo "Portfolio selection" no "Journal of Finance" em 195e. Entre vârlas assertivas com respelto ao comportamento dos individuos, Markovitz afirmou que eles tem cou formami distribuiçóes de probabilidade a respelto dos retornos das alternativas a escolher e que as preferencias dos individuos são função da media e da variancia daquelas distribulçóes. Para um certo retorno esperado, teria preferencia a alternativa com menor variancia. Para uma certa variancia. teria preferencia a alternativa com o mais elevado retorno. Este conjunto de pontos (variancia $\approx$ retorno) preferidos, delineia o que se conhece como fronteira eficiente.

A utilizaçao do metodo de Markovitz. entretanto, fol criticada por varios autores, entre eles BORCH (1989) e FELDSTEIN (1969), quanto a validade do seu emprego. Esta irivestida confunta levou TOBIN (1989), um dos pioneiros da análise E-V C"Expected Value"-"Variance") a admitir quo a aplicação do metodo se restringiria aos casos em que a funça de utilidade do tomador de decisáo e quadratica ou quando se considera os retornos incertos como tendo funçå de densidade de probabilidade com distribuiçáo rormal. 
Analisando a discussão em torno do assunto. TSIANG (1972) argumentou que a funça quadratica, como qualquer polinomial, alem das limitaçóses quanto à aplicabłlidade, implicaria em aversäo absoluta a risco crescente com o aumento da riqueza, ou seja, individuos meis ricos prefeririam incorrer em menos riscos em termos absolutos. Quanto a pressuposicá de distribuicăo normal para os retornos de investimento, por sua vez, classificou de nâo realista.

Tsiang demonstra que há justificativa para o uso da analise E-V mesmo que a funçăo não seja polinomial pois qualquer que seja a furgá de utilidade, ela pode ser aproximada para uma polinomial ao ser expandida de acordo com a "Série de Taylor", desde que certas condiç̧es sejam satisfeitas. Assim, a utilidade esperada passa a depender somente do valor dos dois primeiros momentos centrais da distribuifäo. Se a serie for fortemente convergente, isto $\epsilon$ apresentar um numero multo grande de termos, aqueles que se localizam alem do segundo podem ser eliminados, $e$ a utilidade esperada pode ser aproxlmadamente determinada pelos dois primeiros momentos: media e variancia. A dificuldade da analise para qualquer tipo de funça reside em necessitar-se conhecer as condlçes em que devemos esperar convergencia da funç̃o de utilidade e ao problema de programaçäo quadratica que surge, dificultando sua resol ução. 
A escolha das alternativas com menor variancia consiste em minimizar a variancia dada por

$$
\begin{gathered}
V=\sum_{j=1}^{n} \sum_{k=1}^{n} y_{j} \cdot y_{k} \cdot \sigma_{j k} \\
\text { tal que } \\
\quad \sum_{j=1}^{n} f_{j} \cdot y_{j}=\lambda \\
\left.\quad \sum_{j=1}^{n} a_{i j} \cdot y_{j} \leq b_{i} \quad c i=1,2, \ldots, m\right) \\
y_{j} \geq 0
\end{gathered}
$$

ou seja, encontrar a menor variancia para um determinado retorno $\lambda$, deritro das $m$ restriços dos fatores $\left(b_{i}\right)$ e restriçós iristitucionals 1 mpostas ao modelo, onde $y_{j}$ são as $n$ diferentes atividades envolvidas nos retornos esperados e $\sigma_{j k}$ são os elementos da matriz de variancia e covariancia para cada uma das $\mathbf{n}$ atividades.

Na analise media-variancia teria preferencia a alternativa coentro da fronteira eficiente) que reunisse retornos e variabilidades que proporcionassem a mator satisfaçăo possivel, isto e, aquela que atingisse a mais elevada curva de iso-utilidade, numa funça de utilidade $U(y)=f[E(y), V(x)]$ (Figura 11$)$

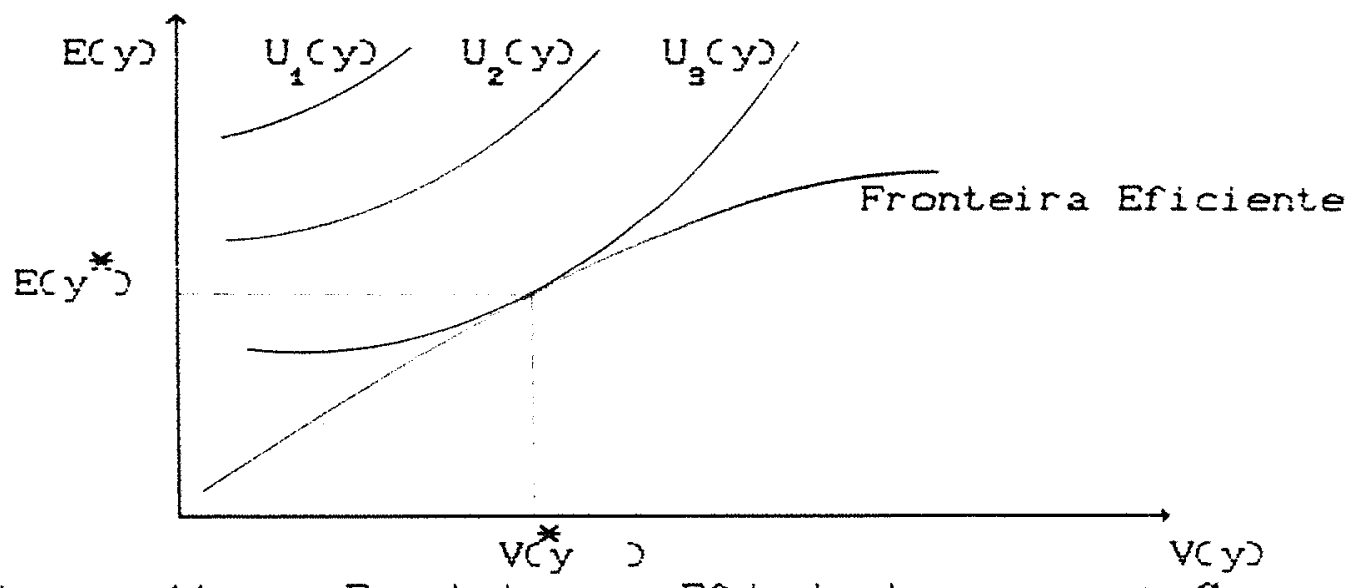

Figura 11 : Fronteira Eficiente $e$ as Curvas de Iso-Utilidade. 
Com função de utilidade quadrática

$U(y)=a+b \cdot y+c y^{2}$,

a ut1lidade esperada apresenta-se com a seguinte forma:

$$
E[U(y)]=a+b \cdot E(y)+c \cdot E\left(y^{2}\right)
$$

a variancia de $y$ e dada por:

$$
V(y)=E[y-E(y)]^{2}
$$

expandindo $(3)$ e simplificando fica,

$$
V(y)=E\left(y^{2}\right)-[E(y)]^{2}
$$

que substituindo em (2) resulta

$$
E[U(y)]=a+b \cdot E(y)+c \cdot\left(V(y)+[E(y)]^{2}\right\}
$$

A ut1lidade esperada pode ser desta forma observada em função da media e da variancia.

A funça (1) satisfaz os criterios de utilidade marginal positiva, aversão a risco, e ainda que a utilidade marginal e decrescente. Porem, considerando que um individuo averso a risco apresenta funçăo de utilidade com

$$
\begin{aligned}
& \left.U^{\prime}(y)=b+2 c \cdot y\right\rangle 0, e \\
& U^{\prime}(y)=2 c\langle 0,
\end{aligned}
$$

a medida de aversão absoluta a risco de Arrow ficaria:

$$
R_{A}(y)=-\frac{2 c}{b+2 c \cdot y} \text {, cuja transformação }
$$

resulta em

$$
R_{A}(y)=\frac{1}{d-y} \text {, onde } \quad d=-b / 2 c e 0
$$

ponto de máximo da curva. o dominio de y fica restrito ao intervalo $[0, d)$. Quando y cresce, aproximando-se de d a aversão absoluta ao risco tambem cresce. Se $y=d$, RA(y) 
assume valores infinitamente grandes, ou seja no ponto de utilidade máxima a aversão ao risco tende para o infinito, resultado discordante em rel açáo ao comportamento esperado dos individuos e portanto considerado discrepante. Por esta razao se tem evitado adotar o uso da Funçăo Quadratica como representante da função de utilidade dos individuos.

\section{อ. ᄅ. 2 MOTAD}

O MOTAD Cminimization of total absolute
deviations, proposto por HAZELL (1971), surge como
alternativa a "E-V Analysis", uma vez que utiliza os
desvios absolutos totais, em vez da variancia.
Apresenta-se como vantajoso pelo fato de trarisformar o
problema de programação quadratica em programaçáo linear.

Os dois metodos pressupóem que a função de utilidade do tomador de decisaro apresenta as seguintes caracteristicas:

$1) \delta_{E} / \delta v>O$ Cmaior $r i s c o$ apenas se houver maior retornos.

2) $\delta \frac{2}{R} / \delta v^{2}>$ o (crescimento do retorno deve ser mals que proporctonal ao crescimento do riscos, já que ambos admitem aversão ao risco. A escolna da alternativa otima depende, como na análise media-variancia das hipoteses sobre a funçäo de utilidade, merecendo o mesmo tipo de discussão da seção anterior. 


\section{2. 3 Metodo de Hannoch e Levy}

O metodo sugerido por Hannoch e Levy baseia-se nos axiomas de Berroulli e no Teorema da Utilidade Esperada, com as seguintes hipóteses adicionais.

1) A função de utilidade do tomador de decisáo equadratica:

2) A função de distribuiçăo de probabilidade dos retornos e simetrica. Permite realizar escolhas entre alternativas mesmo aquelas descartadas pela análise $E-V$.

De acordo com o método, quando pretendemos escolher entre alternativas $1 \mathrm{e}=\mathrm{em}$ que $\mu_{1}>\mu z$, mas a variancia da primeira tambem e maior que a da segunda, a alternativa 1 será escolhida se seu rendimento médio for mats que proporcional a variancia da seguinte forma:

$$
\begin{aligned}
& 2\left(\mu_{1}-\mu_{2}\right) \sigma_{1}+\left(\mu_{1}-\mu_{2}\right)^{2}-\left(\sigma_{1}^{2}-\sigma_{2}^{2}\right)>0 \text {, onde (7) } \\
& \mu_{1}=E\left(X_{1}\right) \\
& H_{2}=E C X_{2} \\
& \sigma_{1}=E \sqrt{\operatorname{VarCX_{1}^{3}}} \\
& \sigma_{2}=E \sqrt{\operatorname{VarcX_{2}}} \\
& \text { Como este metodo e uma extensão da Arálise } E-V \\
& \text { permanece a discussão em torno do uso da funçăo de }
\end{aligned}
$$




\section{2. 4 Dominância Estocastica}

Nos metodos anteriormente referidos apenas consideram os dois primeiros momentos da distribuição ou suas aproximaçớes; porem, ao levar-se em consideração apenas a média e a variancia na maximização da utilidade esperada, os demais momentos da distribuição estão sendo abandonados. O tercelro momento em relaçăo a media mede a assimetria das distribuiçóses de probabilidade de ocorrencia dos eventos. isto e. sua inclinaça para a direlta ou para a esquerda. A assimetria deve ser levada em consideraçăo pols duas distribulçóes podem apresentar mesma média e variancia mas diferir na assimetria. Segundo STONE (1970) a distribuiça assimetrica a direita e a mals desejavel para um elemento averso a risco. Dessa forma ao não considerar a assimetria pode-se estar incorrendo num grave erro.

Os conceltos de Dominancia Estocástica foram criados para evitar as deficiencias teoricas dos criterios de ordenação como por exemplo o da media-variancla. Os metodos de escolha deveriam considerar não apenas media e variancia pois a utilidade esperada pode ser funçăo de momentos da distribulçăo de ordem mals elevada.

As tecricas de Dominancia Estocastica foram deservolvidas por QUIRK e SAPOSNIK (1962), estendidas posteriormente por HADAR e RUSSEL (1969). Visam classificar alternativas incertas, mesmo desconhecendo-se 
detalhes sobre a funçá de utilidade do tomador de decisao - sem a pressuposiçáo de que o retorno das açßes apresenta funça de densidade de probabilidade com distribuifáo normal. As regras de Dominancia Estocástica levam em consideração toda a distribuiçăo cumulativa de probabilidade dos retornos ao inves de simplesmente a media e a variancia. Por estes metodos as condiçós 1 mpostas a função de utilidade săo menos restritivas que a pressuposição de determinada função de utilidade. Por suas vantagens, estas tecnicas tem sido empregadas em diversos trabalhos envolvendo processo de decisão, como em GARCIA $(1979$ e 1984$)$, CORVALAN (1987), PACHECO (1985), SALOMAO (1990).

Quando dispomos de duas "atividades" $\alpha \in z$ em que Ua $\triangleleft U b$, isto $\Leftrightarrow, b$ concede maior satisfacão que $a$, tera preferencia o conjunto de alternativas em que a maior utilidade se encontra associada a maior probabilidade. isto e,

$$
(1-\beta) \cdot \mathrm{U} \alpha+\beta \cdot \mathrm{Ub}>\mathrm{C}-\infty-\infty \cdot \mathrm{U} \alpha+\alpha \cdot \mathrm{Ub}
$$

onde,

$\alpha$ e $\beta$ săo probabilidades associadas e $\alpha<\beta$.

No caso de n "atividades" com as respectivas probabilidades a $\left.c_{i}=1,2, \ldots, n\right)$ sempre será possivel construir um outro conjunto, com probabilidades Bi $(i=1,2, \ldots, n)$, tal que este verma a conceder malores satisfaçooses. Assim: 


$$
\begin{aligned}
& \underbrace{\beta_{1} \cdot U_{1}+\beta_{2} \cdot U_{2}+\ldots+\beta_{k} \cdot U_{k}+\ldots+\beta_{n} \cdot U_{n}}_{B}> \\
& \underbrace{\alpha_{1} \cdot U_{1}+\alpha_{2} \cdot U_{2}+\ldots+a_{k} \cdot U_{k}+\ldots+a_{n} \cdot U_{n}}_{A} \\
& \text { onde } U_{i}>U_{j} \text { para } i>j \quad \Leftrightarrow \quad \beta i<a i \quad i=1,2, \ldots, k-1 \\
& \beta i>\text { ai } \quad i=k \\
& \beta i=\alpha i{ }^{-} \quad i=k+1, \ldots, n
\end{aligned}
$$

mesmo sendo $\beta i=\alpha_{i}$ para as maiores utilidades, devido ao ponto $k$, onde $\beta i>\alpha_{i}, B$ passa a ser preferida a A Consequentemente:

$$
\sum_{i=1}^{n} \beta_{i} . U_{i}>\sum_{i=1}^{n} a_{i} . U_{i} \quad \text { e } \sum_{i=1}^{r} \beta i<\sum_{i=1}^{r} a_{i} \quad r=1,2, \ldots, n-1
$$

Conclui-se então que a alternativa preferida $B$, nunca tem sua distribuigão cumulativa excedendo a alternativa A. A probabilidade de ocorrencia de resultados mals favoraveis e mals elevada. Esta condiça e conhecida COMO DOMI NANCI A ESTOCASTICA.

Há uma estreita relação entre DOMINANCIA ESTOCASTICA e preferencia entre alternativas incertas. Dadas duas alternativas quaisquer $A \in B$, se $B$ e estocásticamente superior a A, então $B$ e preferido a $A$ indiferente as especificaçóses da funçăo de utilidade. Inversamente, diante de duas alternativas $A$ e preferido a A para qualquer funçăo de utilidade, então $B$ estocasticamente superior a A. Estas proposiç̃es foram demonstradas por QUIRK e SAPOSNIK (1962), para um número Inito de retornos. De acordo com as restriçoses impostas à função de utilidade, pode-se aumentar o poder de classificação de alternativas pela DOMINANCIA ESTOCASTICA. 


\section{2. 4.1 Dominância Estocástica de Primeiro Grau (DEP)}

Seja $x \circ$ conjunto das varisveis $x i, f$ e funçótes de probabilidade dessas variaveis e $F(\times)$ s $G(\times 2)$ as respectivas funços de distribuiça cumulativas. A função de probabilidade $\&$ dita pelo menos tăo grande quanto $f$ no sentido da DEP se

$$
G\left(x_{i}\right) \leq F\left(x_{i}\right) \quad \text { para todo } x_{i} \in X
$$

A distribuiçăo cumulativa $G(x i)$ apresenta-se intelra ou parcialmerte sob $F(x i)$. O criterio de DEP envolve preferencias entre alternativas incertas sob condiçós em que a funçáo de utilidade năo e restrita em qualquer aspecto essencial. Apenas e extgido que a primeira derivada da função no intervalo considerado seja positiva, ou seja, ela deve ser crescente.

$$
\text { Pode-se demonstrar }{ }^{1} \text { que se } \& \text { superior a } f \text { no }
$$
sentido da DEP, entao $s \leqslant$ pelo menos tåo preferida quanto $f$. ou seja, se $G\left(x_{i}\right) \leq F\left(x_{i}\right)$ para todo $x i$, entao a utilidade esperada de $\&$ maior ou igual a de $f$, isto $e$, $\bar{U}_{g}-\bar{U} f \geq 0$, sendo $\mathrm{U}=\phi(x)$

$$
\overline{\mathrm{U}}_{f}=\sum_{i=1}^{n} f\left(x_{i}\right) \cdot \phi(x i) \quad \in \quad \overline{\mathrm{U}}_{\mathscr{\delta}}=\sum_{i=1}^{n} \nLeftarrow\left(x_{i}\right) \cdot \phi\left(x_{i}\right)
$$

entăo. 


$$
\begin{aligned}
\bar{U}_{\mathcal{B}}-\bar{U}_{f}=\sum_{i=1}^{n} \&\left(x_{i}\right) \cdot \phi\left(x_{i}\right)-\sum_{i=1}^{n} f\left(x_{i}\right) & =\phi\left(x_{i}\right)= \\
& =\sum_{i=1}^{n}\left[g\left(x_{i}\right)-f\left(x_{i}\right)\right] . \phi\left(x_{i}\right)
\end{aligned}
$$

pelo teorema do valor medio [CHIANG (1982) p. 238]

$$
\phi(x i)=\phi(x n)-\sum_{r=i}^{n-1} \phi^{\prime}(\xi r) . \Delta x r \quad i=1,2, \ldots, n-1
$$

$z_{r} \leqslant$ um ponto qualquer entre $x_{r}$ e $x_{r+1}, e \Delta x_{r}=x_{r+1}-x_{r}$, assim, substituindo (9) em (8), fica:

$$
\bar{U}_{g}-\bar{U}_{f}=\sum_{i=1}^{n}\left[8\left(x_{i}\right)-f\left(x_{i}\right)\right] \cdot\left[\phi\left(x_{n}\right)-\sum_{r=i}^{n-1} \phi^{\prime}(\xi r) \cdot \Delta x_{r}\right]=(10)
$$

$=\sum_{i=1}^{n}\left[8\left(x_{i}\right)-f\left(x_{i}\right)\right] \cdot \phi(x n)-\sum_{i=1}^{n}\left[8\left(x_{i}\right)-f\left(x_{i}\right)\right] \cdot \sum_{r=i}^{n-1} \phi^{\prime}(\xi r) \cdot \Delta x r=$

$=0-\sum_{r=1}^{n-1} \phi^{\prime}\left(\xi_{r}\right) \cdot\left[\sigma_{1}\left(x_{r}\right)-F_{1}\left(x_{r}\right)\right] \Delta x_{r}$

como $\phi^{\prime}>0, \Delta x_{r}>0$ e $G_{1}\left(x_{r}\right)-F_{1}\left(x_{r}\right) \leq 0$

pois por hipotese $G_{1}\left(x_{i}\right)-F_{1}\left(x_{i}\right) \leq 0$ para pelo menos um único i. Então,

$$
\overline{\mathrm{U}}_{f}-\overline{\mathrm{U}}_{f} \geq 0 \text {. }
$$

1sto $E$ a utilidade esperada de $\delta$ maior ou 1 gual a utilidade esperada de $f$. Graficamente a Dominancia Estocástica de Primeiro Grau pode ser representada como na Figura 12 na qual a alternativa 8 domina $f$. 


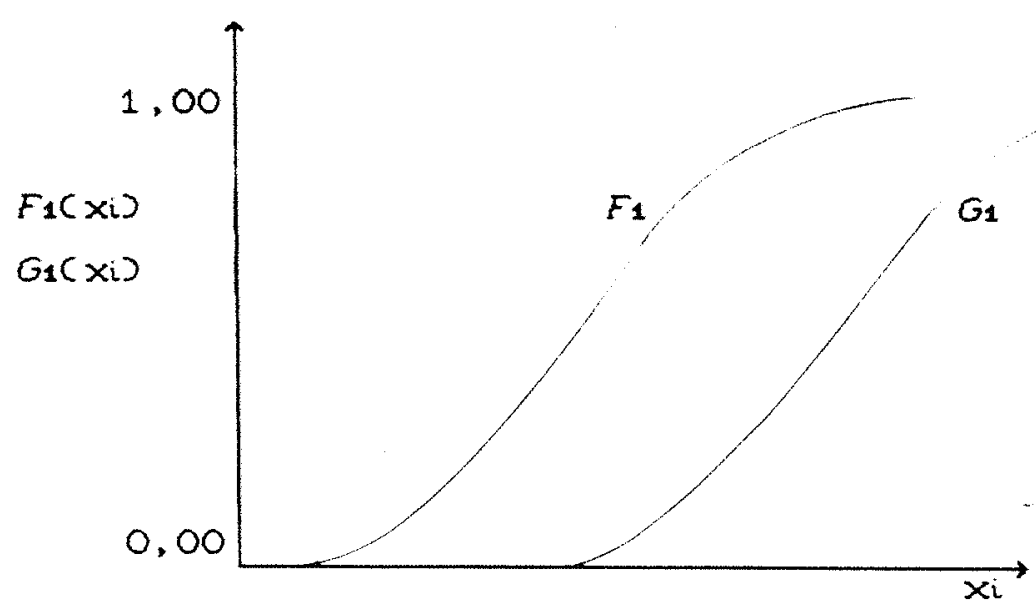

Figura 12 : Domináncia Estocástica de Primeiro Grau

A Dominancia Estocástica de Primeiro Grau (DEP) refere-se ao comportamento de individuos indiferentes, aversos ou propensos a risco, pols aperas exige que a funça de ut111dade seja monotonlcamente crescente. ocorre porem, de distribuiçoses cumulativas se interceptarem pelo menos uma vez, impossibilitando identificar a alternativa mals eficiente de acordo com os criterios da DEF. Assim o poder de discriminaça entre alternativas $e$ bastante reduzido.

\section{2. 4. 2 Dominância Estocástiva de Segundo Grau (DES)}

Para identificar alternativas superiores, não ordenadas pela DEF, uma restriço ao comportamento dos individuos pode ser imposta. Alem da erescente monotonicidade, admite-se que a funcazo de utilidade dos 1ndividuos apresenta retornos marginais decrescentes, sendo concava em relacăo ds variavels de $x$, ou seja 
$\left[\delta^{2} \phi(x) / \delta(x)^{2}\right]<0$. Funçסes de utilidade com estas caracteristicas, identiflcam individuos com aversão a risco. Pode-se demonstrar que se 8 pelo menos tao grande quanto $f$ no sentido da DES a utilidade marginal e decrescente, então pelo menos tão preferida quanto $f$, isto e, se

$r \sum_{1}^{n} G_{1}\left(x_{r}\right) . \Delta x_{r} \leq \sum_{r=1}^{n} F_{1}\left(x_{r}\right) . \Delta\left(x_{r}\right)$. para todo $r(n$, entao

$$
\bar{U}_{\mathcal{B}}-\bar{U}_{f} \geq 0
$$

Partindo de (11):

$\bar{U}_{8}-\bar{U}_{f}=-\sum_{r=1}^{n-1} \phi^{\prime}(\xi r) \cdot\left[G_{1}\left(x_{r}\right)-F_{1}\left(x_{r}\right)\right] \Delta x_{r} \geq 0$

pelo teorema do ponto medio...

$\phi^{\prime}(\xi r)=\phi^{\prime}(\xi n-1)-\sum_{s=r}^{n-2} \phi^{\prime \prime}(n s) . \Delta \xi s \quad r=1,2, \ldots, n-2$

no $\&$ um valor qualquer entre $\xi s e \xi+1$

$\Delta z=k a+1-z a$

entao, substituindo (12) em (11), resulta:

$\bar{U}_{\mathscr{g}}-\bar{U}_{f}=-\sum_{r=1}^{n-1} \phi(\xi r) \cdot\left[G_{1}\left(x_{r}\right)-F_{1}\left(x_{r}\right)\right] \cdot \Delta x_{r}=$

$=-\sum_{r=1}^{n-1}\left[\phi^{\prime}(\xi n-1)-\sum_{n-1}^{n-2} \phi^{\prime} \cdot\left(r_{s}\right) \cdot \Delta \xi s\right] \cdot\left[G_{1}\left(x_{r}\right)-F_{1}\left(x_{r}\right)\right] \cdot \Delta x_{r}=$

$=-\phi^{\prime}(\xi n-1) \sum_{r=1}\left[G_{n-2}\left(x_{r}\right)-F_{1}\left(x_{r}\right)\right] \Delta x_{r}+$

$$
+\sum_{s=r} \phi \text { " }\left(n_{s}\right) \cdot \Delta \xi s \sum_{r=1}^{n-1}\left[G_{1}\left(x_{r}\right)-F_{1}\left(x_{r}\right)\right] \cdot \Delta x_{r}=
$$

como

$\sum_{r=1}^{\infty} G_{1}\left(x_{r}\right) \cdot \Delta x_{r}=G_{2}\left(x_{8}\right)=\sum_{r=1}^{s} F_{1}\left(x_{r}\right) \cdot \Delta x_{r}=F_{2}\left(x_{\theta}\right)$, entăo...

$\bar{U}_{8}-\bar{U}_{f}=-\phi^{*}(\xi \hat{n}-1) \cdot\left(G_{2}\left(x_{8}\right)-F_{2}\left(x_{8}\right)\right]+$ 
por pressuposiçăo

$G_{2}\left(x_{0}\right) \leq F_{2}\left(x_{0}\right)$, isto e,

$G_{2}\left(x_{0}\right)-F_{2}\left(x_{0}\right) \leq 0$,

como $\phi^{\prime}(x)>0$ e $\phi^{\prime \prime}(x)<0$ entao

$$
\bar{U}_{\mathcal{B}}-\bar{U} f \geq 0
$$

Graficamente, podemas representar a DES de acordo com a Figura 13.

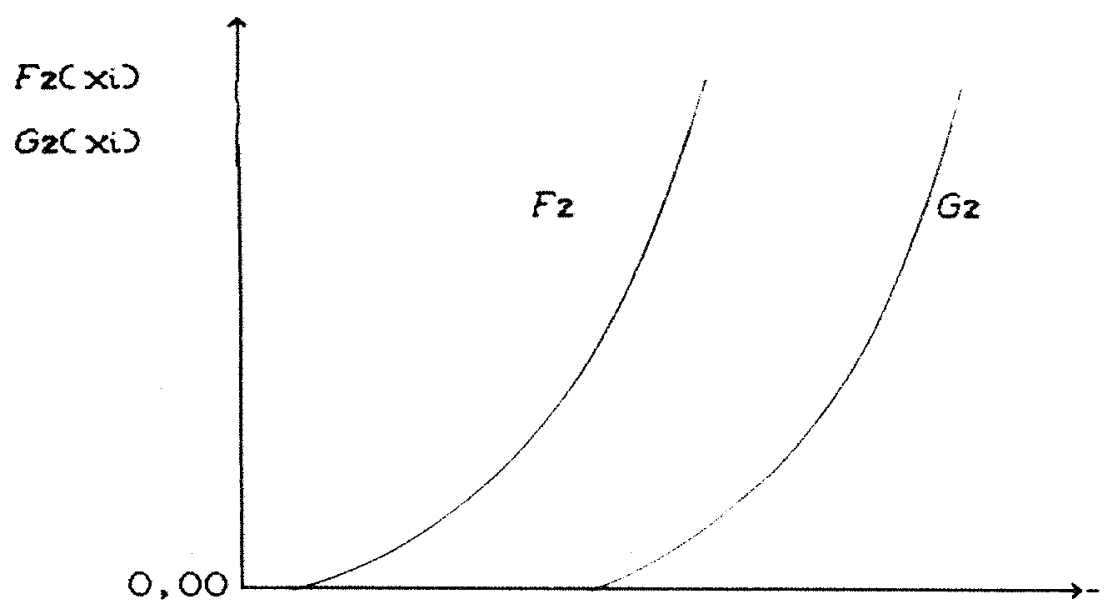

Figura 13 : Dominaricia Estocástica de Segundo Grau

O grupo de distribulçбes que pode ser ordenado por melo da DES é, em geral, maior que aquele or denado por melo da DEP. Separa alternativas que apresentam mesmo desempenho ao nivel da DEF. As alternativas selectonadas por DES são as que estão associadas a funçóses de utilidade com retornos decrescentes e portanto indicadas a individuos aversos ao risco. 


\subsection{3 Dominância Estocástica de Terceiro Grau (DET)}

Nos casos em que năo e possivel determinar quals das alternativas são eflcientes empregando os criterios da DES, uma nova restrição e imposta a função de utilidade. A pressuposiçăo com respelto a preferencia do tomador de decisão e que sua aversão a risco diminul a medida que sua riqueza aumenta, isto e:

$$
\delta^{9} \phi(x)<\delta(x)^{9}>0
$$

a partir de um certo nivel de beris, sua satisfaça inclui a exposição ao risco. Sua aversão ao risco diminui.

Fode-se demonstrar que se $\&$ e pelo menos tão grande quanto $f$ no sentido da DET, entæo $\&$ e pelo menos tăo preferida quanto $f$, isto el:

se $\sum_{s=1}^{\infty} G_{2}\left(x_{s}\right) \cdot \Delta x_{s} \leq \sum_{s=1}^{s} F_{2}\left(x_{s}\right) \cdot \Delta x_{s}$ para todo $s(n$, entao

$$
\mathrm{U}_{\mathcal{E}}-\mathrm{U}_{f} \geq 0
$$

Partindo de (14):

$$
\begin{aligned}
\bar{U}_{B}-\bar{U}_{f}=-\phi^{\prime}(\xi n-1) \cdot\left[G_{2}(x)\right. & \left.-F_{2}\left(x_{0}\right)\right]+ \\
& +\sum_{s=1}^{n-2} \phi^{\prime}\left(n_{0}\right) \cdot\left[G_{2}\left(x_{0}\right)-F_{2}\left(x_{0}\right)\right] \cdot \Delta \xi=
\end{aligned}
$$

pelo teorema do valor medio..

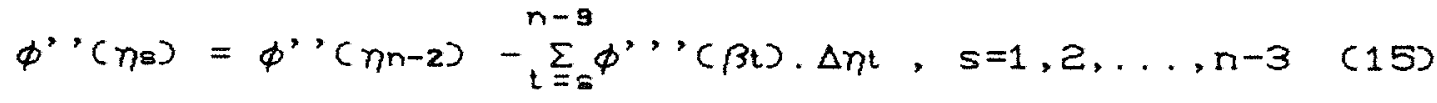

onde

St $\&$ um ponto qualquer entre $n^{t} \in \eta^{t+1} e$

$\Delta n t=n t+1-n t$

Substituindo (15) em (14), temos:

$$
\begin{aligned}
\bar{U}_{8}-\bar{U} f=-\phi^{\prime} & \left(\xi_{n-1}\right) \cdot\left[G_{2}\left(x_{s}\right)-F_{2}\left(x_{s}\right)\right]+ \\
& +\sum_{s=1}^{n-2}\left[\phi^{\prime}\left(n_{n-2}\right)-\sum_{t=8}^{n-9} \phi^{\prime} \cdot\left(\beta_{t}\right) \cdot \Delta n_{t}\right] \cdot\left[G_{2}\left(x_{s}\right)-F_{2}\left(x_{s}\right)\right] \cdot \Delta \xi=
\end{aligned}
$$




$$
\begin{aligned}
& =-\phi^{\prime}(\xi n-1) \cdot\left[G_{2}(x \leq)-F z(x \leq)\right]+ \\
& n-2 \\
& +\phi^{\prime}(n n-2) \cdot \sum_{=1}\left[G_{2}\left(x_{s}\right)-F_{2}\left(x_{s}\right)\right] \cdot \Delta \xi s+ \\
& -\sum_{t=a} \phi " '{ }^{\prime}(\beta t) \cdot \Delta \beta_{t} \sum_{s=1}\left[G_{2}\left(x_{s}\right)-F_{2}\left(x_{s}\right)\right] \cdot \Delta \xi s=
\end{aligned}
$$

por hipotese: $\phi \phi^{\prime}>0, \phi^{\prime \prime}<0$ e $\phi^{\prime \prime}$ '>0,

como

$$
\sum_{s=1}^{n-2} G_{2}\left(x_{s}\right) . \Delta \xi=G_{g}\left(x_{t}\right) \text { e } \sum_{s=1}^{n-2} F_{2}\left(x_{s}\right) \cdot \Delta \xi_{s}=F_{s}\left(x_{t}\right),
$$

admitindo que $G_{9}(x t)-F_{9}(x t) \leq 0$, então

$$
\overline{\mathrm{U}}_{8}-\overline{\mathrm{U}}_{f} \geq 0
$$

para ao menos uma desigualdade irrestrita.

As condiçes da Dominancia Estocática de Tercelro Grau (DET) são ditas mais fracas que as da DES, que por sua vez são mals fracas que as da DEP. Os criterios desta são ditos mais poderosos por apresentarem poucas restriçóes e pressuposif̧ós, mas seu poder de discriminação e menor. Um pequerio número de al ternativas $\epsilon$ descartado como ineficiente pelos criterios da DEP. A DES classifica um maior número e a DET e capaz de descartar mais alternativas que a DES. Há grupo de alternativas que não pode ser or denado nem mesmo empregando os criterios da DET. Neste caso as alternativas que permanecem ser 30 consideradas igual mente eficientes.

A selecaro de alternativas empregando o metodo da Dominancia Estocástica basela-se na comparação das distribuifores cumulativas de probabilidade. A alternativa escolhida (dominante) sera aquela cuja distribulçăo encontra-se intelramente abalxo da alternativa dita domi rada. 


\subsubsection{4 - A D ominância Estocástica e a Análise Media-Variância}

Nos processos de escolha de tecrolagias, em geral empregam-se o metodo da Analise $E-V$ Cou suas variaçóes) ou os processos de Dominancia Estocástica. Conforme fol comentado nos capitulos anteriores a principal diferença entre os dois é quanto às pressuposiçóes sobre as formas da função de utilidade e da função de distribuição da variàvel em estudo. O fato de a Dominancia Estocástica nåo tomar estas restriçóes ine confere superioridade sobre a análise E-V CGARCIA \& CRUZ, 1979 ; PORTER \& GAUMNITZ, 1972). Alguns trabalhos empregaram os dois metodos tentando comparar seus resultados. Em geral o que se tem observado é que o grupo selecionado por Media-Variancia aproxima-se muito daquele selecionado com o emprego da Dominancia Estocástica. CPACHECO, 1985; SALOMAO, 1990; ANDERSON, 1974; PORTO et aiii, 1982).

PORTER \& GAUMNITZ (1972), compararam exaustivamente os grupos definidos pelos dois metodos a partir de número grande de alternativas. Gerada a fronteira eficiente $E-V$ e de posse do grupo de al ternativas dominantes pela DEP, DES e DET, concluiram que - uso da DEP como critério de decisaro mostrou-se inefetivo pois poucas alternativas for am eliminadas. A DET, por sua vez, reduziu bastante o numero de alternativas, el iminando o confilito quanto à eficiencia de metodos. 
Comparando as alternativas escolnidas com o emprego da DES e o metodo $E-V$, verificaram que algumas al ternativas eflcientes em $E-V$ foram eliminadas pela DES, e foram exatamente as que apresentaram baixo retorno. Nos casos em que havia elevados retorno e variancia, ou seja aquelas que seriam preferidas por investidores menos aversos a risco, poder-se-ia empregar indiferentemente os dols metodos, pois quanto mais elevadas as medias e variancias, mais os grupos eficientes de acordo com E-Ve DES se tornam semel hantes. A explicação estaria no fato de que como a aversão absoluta ao risco decresce com o aumento da riqueza, o individuo se move mals para cima na fronteira eficiente tornando as alternativas semelhantes pelos dois métodos.

Quanto aos investidores altamente aversos a risco, seriam penalizados com o emprego do metodo E-V, pois levaria a alternativas de baixo retorno. As alternativas com esta caracteristica adotadas como eficientes pelo metodo $E-V$ for am eliminadas empregardo-se DES. Dessa forma, utilizando-se alternativas classificadas pelo metodo $\mathrm{E}-\mathrm{V}$, nos casos de elementos al tamente aversos a risco, ha maior probabilidade que elas apresentem baixos retornos do que no emprego da DES.

Resumindo, Porter \& Gaumnitz deduziram que onde a aversão a risco eforte, as regras de DES e DET săo mais consistentes com a maximização da utilidade esperada que as regras da media-variancia. Essas conclusơes reafirmam a 
importancia da Dominancia Estocástica, especialmente no caso da DES e DET ao objetivar-se selecionar alternativas incertas dirigidas a "investidores" aversos a risco como admite-se serem os agricultores.

Uma das deficiencias atribuidas a Dominancia Estocástica seria que em geral năo se pode escolher acs melhorces dentre as alternativas em julgamento. Os processos de D.E. fornecem um grupo de alternativas dominante sobre as demais (dominadas). Apenas descarta-se alternativas ineficientes. ANDERSON $(1974)$ justifica que há um preço a pagar quando se generaliza sem restriçóes um criterio de escolha. No caso da DE consegue-se identificar um grupo de alternativas de "eficiencia-risco", em contraste com alternativas de otimo-risco, que dependeria das preferencias individuais. For outro lado, ainda segundo Anderson $(1974)^{1}$, citado por MOUTINHO et alii.(1978), a determinaçăo de um comjunto de alternativas eficientes reflete a enfase colocada nas extremidades das distribuiçôes comparadas. Para que uma distribulçăo $f$ domine estocasticamente outra distribuiçăo $\&$, é necessário que $f$ apresente seu menor valor possivel maior que o menor valor de $\&$ e que a média de $f$ não seja menor que a media de 8. Este fato se mostra importante na medida em que é à

1 ANDERSON, J.R. Risk efficiency in the interpretation of agricultural production research. Review of Marketing and Agricultural Economics. September - 1974, $131-184$. 
extremidade esquerda das curvas de distribulcăo que se encontra associada a noção de risco. 


\title{
3. MATERIAL E MÉTODOS
}

\section{1 Material}

\begin{abstract}
No estudo da estabilidade de materiais geneticos disponiveis para cultivo, uma serie de trabalhos vem sendo deservol vidos visando comparar os genotipos de acordo com seu comportamento em diferentes condiçóes ambientals e temporais e dessa forma facilitar a indicação dos mesmos aos agricultores. Para comparar a performance dos metodos de escolha por estabilidade com a dos
\end{abstract} metodos que incorporam risco, for am tomados alguns desses trabalhos, tendo sido selecionados cinco, pelas seguintes razóses: 1 s cada trabalno envolve o estudo de uma cultura diferente; 3 todos comparam uma serie de genótipos diferentes de cada espécie, visando eleger os mais estáveis, ou seja, aquele que forneça altos rendimentos com certa segurarça ao agricultor; 3 cada estudo fol realizado com dados de experimentos desenvolvidos em locais variados e repetidos em anos diferentes, oferecendo portanto uma serie de produtividades relativamente grande. Os trabalhos selecionados foram os seguintes: 1) BONATO (1979); o estudo compara 10 (dez) cultivares de 
soja em 11 (onze) locals diferentes durante 3 (tres) anos; e) SANTOS (1980), compara 12 (doze) variedades de feijão em 11 (onze) ambientes diferentes; 3) FERNANDES (1988), compara 15 (quinze) hibridos de milho em 10 (dez)locals durante 3 (tres) anos; 4 ) RAIDAN (1988), compara 3 (tres) genotipos de algodão em 6 (seis) lócais e 9 (nove) genotipos da mesma cultura em 6 (seis) locais em anos diferentes; 5) SCHVARTZMAN (1989). compara 10 (dez) diferentes variedades de trigo, cultivadas em 7 (sete) locais durante 2 (dois) anos.

\section{2 Metodos}

Os dados constantes das Tabelas A.1 a A.11 Cem Apendicel foram tomados caso a caso e submetidos aos criterios da escolha incorporando o risco envolvido no pracesso de decisão. Conforme definido no item 2.2.4.4, dentre os criterios de seleção estudados foi empregado o da Dominância Estocástica (D. E.) por levar a escolhas mais consistentes com a maximização da utilid888 esperada. 0 metodo também oferece resultados dirigidos a "investidores" aversos a risco e considera que a aversăo diminui à medida que aumenta sua riqueza. Outra vantagem do metodo a não necessidade do conhecimento detal hado da funçăo de utilidade e da forma da funçăo de densidade de probabilidade. 
Para ser detectada a superioridade de um genotipo sobre os demais, utilizando o metodo da D. E. , fol feito o ajustamento (manual) das Funçóes de Distribuição Cumulativas (F.D.C.) para cada uma das variedades que foram comparadas, de acordo com o Metodo dos "Dados Esparsos" (ANDERSON, 1973), artificio que gera a curva de distribulçáo de probabilidades. Os poritos for am obtidos pela regra de Schiaiffer: "AO se ordenar de forma crescente as $N$ observaçós disponiveis, a p-esima observaçăo e uma boa estimativa do fractil p/N+1) de probabilidade acumulada." [ANDERSON (1973) citando Schlaifer ${ }^{1}$.

Os valores extremos, correspondentes a 0 e $100 \%$ de probabilidade procuraram reproduzir os valores extremos que as variedades poderăo atingir. Foram calculados empregando as seguintes formulas:

$$
\begin{aligned}
& V \operatorname{Max}_{i}=V m_{i}\left[1+\frac{\mu m-A}{A}\right] \\
& V \operatorname{Min}_{i}=V p_{i}\left[1+\frac{\mu p-A}{A}\right]
\end{aligned}
$$

onde:

$$
\begin{aligned}
& \operatorname{VMax}_{i} \text { valor maximo calculado para a } \\
& \text { produtividade da variedade } i . \\
& V m_{i} \text { : valor de produtividade máximo } \\
& \text { apresentado pela variedade } i .
\end{aligned}
$$

${ }^{1}$ SCHLAIFER, R., Probability and Statistics for Business Decisions, New York, McGraw-Hill Book Company, 1959. 
$\mu m$ : Media de produtividade apresentada por todas as variedades no melhor ano de produça.

Ai : Media de produtividade de todas as variedades em todos os anos;

VMin : valor minimo calculado para a produtividade da variédade 1.

$V_{p_{i}}$ : Valor de produtividade minimo apresentado pela variedade $i$.

Hpi : Media de produtividade apresentada por todas as variedades no pior ano de produçă

De posse das F.D.C. ajustadas, for am comparadas duas a duas, descartando-se as ineficientes sob o ponto de vista da Dominancia Estocástica, de acordo com as condiçóes expostas na seção e. 2. 4.

A partir da classificaça oferecida pela Dominancia Estocástica do Primeiro Grau (DEP), as variedades dominantes for am separadas e consideradas como as que podem ser recomendadas a agricultores considerados aversos, indiferentes ou propensos a risco, ja que elas săo as que oferecem maiores probabilidades de conseguir os mais altos rendimentos e, portanto, preferidas por qualquer elemento.

Separadas as dominantes em primeiro grau, elas for am submetidas à comparaçăo visando encontrar as que são dominantes segundo os criterios da Dominancia Estocástica 
do Segundo Grau (DES). As varledades consideradas dominarites săo as que podem ser recomendadas a agricultores considerados aversos a risco. A DES apresenta um poder de discriminação maior, pois estabelece a seguinte restrição ao comportamento dos individuos: a sua curva de utilidade cóncava, ou seja apresenta retornos marginais decrescentes. Eles preferem uma determinada alternativa com ganhos certos a uma outra que, mesmo apresentando maiores ganhos, são incertos. Para um individuo com estas caracteristicas, as perdas na ut1lidade, devido a perda de uma certa quantid são maiores que os ganhos de utilidade prov.. ganho de bens da mesma magnitude.

Separadas as alternativas pelos critérios da DEP e da DES, podem ainda permanecer alternativas impossiveis de serem discriminadas. Nestes casos, foi empregado o criterio da Dominancia Estocástica do Terceiro Grau (DET). Segundo este criterio, as alternativas separadas como dominantes seriam indicadas a elementos com aversão a risco decrescente, ou seja, sua curva de utilidade a partir de um determinado ponto, ou nivel de riqueza, transforma-se de concava para convexa, passando o individuo a ser cada vez menos averso a risco.

$$
\text { De posse da classificação dos grupos }
$$

variedades pelos criterios d.... TES e DET, foi procedida a comparaça com a class. trabalhos escolhidos, verificando se possiveis "em 
entre as variedades classificadas como estaveis e produtivas e aquelas indicadas aos individuos de acordo com seu grau de aversão ao risco.

0 metodo da Dominancia Estocastica, apesar H. sua complexidade teorica, e de aplicaçăo bastante simpl com o emprego de microcomputadores. Cada etapa de sua aplicaça se encontra detal hada no Apendice deste trabal ho Cpaginas 104 a 115), inclusive com a reproduçăo do programa desenvol vido por ANDERSON (1977) para seleçăo por eficiencia estocástica. 


\section{RESULTADOS E DISCUSSÃO}

Neste capitulo encontram-se os resultados obtidos pela comparação entre os dois metodos de escolha de genótipos assim como sua avaliação. Nas seções 4.1 a 4.5 serão mostrados os resultados obtidos pela utilização dá Dominância Estocástica, comparando-os com as conclusores a que chegaram os trabalhos que empregaram os metodos de Estabilidade. As secores foram identificadas pel cultura que foi motivo do estudo. Em segi

4.6. será feito um balanço geral avaliando os resuicauos do estudo.

\subsection{Cultura do Algodão}

RAIDAN (1988), avaliou o comportamento de 10 (dez) genótipos de algodão, cultivados em 6 (seis) locais diferentes da regia oriental do Paraguai durante dois anos. No ano 1985,86 apenas 3 e no ano $1986,87,9$ genotipos foram cultivados. O método de ERERHART \& RUSSELL (1966) fol utilizado, detectando diferencas significativas entre os genótipos. 
As produtividades, constantes das Tabelas A.1 e A. $己$ do Apendice, extraidas de RAIDAN (1988), foram utilizadas para o ajustamento das funçóes de distribuiçăo cumulativas dos genótipos permitindo o emprego dos criterios de Dominância Estocástica. Na Tabela 1 encontram-se resumidas as seleços dos genotipos de algodão de acordo com o criterio utilizado.

Dos genótipos estudados, for am considerados eficientes em primeiro grau de Dominancia Estocástica os genotipos SP-51 OxP-279-32 (G-4), SP-510xP-279-29/43 (G-5), $S P-510 \times P-279-40 / 42(G-6)$, Guazuncho $(G-7)$ e Tamcot $S P-21-S$ (G-8). Estes genotipos, dentro das condiçōes em que foi conduzido o ensaio, poderäo ser indicados a acr: aversos, indiferentes ou propensos a risco.

Los 5 genotipos escolnidos por DEF, for an selecionados como eficientes em segurido grau de Dominancia Estocastica (DES) os genotipos G-4, G-5 e G-7, os quais, dentro daquelas condiçoes, seriam iridicados a agricultores considerados aversos a risco. Ao nivel de terceiro grau de Domináncia Estocástica, năo foi possivel qualquer discriminacăo, continuando como eficientes os mesmos tres genótipos. Eles poderão então ser recomendados a agricultores cujas caracteristicas são de redução da aversáo ao risco com o aumento da riqueza.

Entre os genótipos descartados por DEP CG-1, S-2, S-3, G-9 e G-10) foram tambem el - por estabilidade $6-1, G-3 e G-10$, em virtude de 
produtividade ou desvios significativos. Os genotipos G-2 (SP-51 OXP-270-100) e G-9 (SP-510XP-279-38/41) for am considerados estávels.

Os genótipos escolhidos pelos criterios de DEP $(G-4, G-5, G-6, G-7$ e G-8) for am os mesmos selecionados por estabilidade, com exceção do $G-8$ que não se adaptou ao modelo, apresentando desvios significativos.

Tabela 1 - Seleção por Estabilidade e Dominancia Estocástica de genótipos de algodão cultivados em 6 locais da região Oriental do faraguai nos anos de $1985 / 86$ e 1986,87 .

\begin{tabular}{|c|c|c|c|c|}
\hline \multirow{2}{*}{$\begin{array}{c}\text { Genotipos } \\
\text { em } \\
\text { Estudo }\end{array}$} & \multicolumn{3}{|c|}{ Genótipos Selecionados ${ }^{1}$} & \multirow[b]{2}{*}{$D E$ : } \\
\hline & Estabilidade & DEP & DES & \\
\hline$G-1$ & - & - & - & - \\
\hline$G-2$ & $x$ & - & - & - \\
\hline$G-3$ & - & - & - & - \\
\hline$G-4$ & $x$ & $x$ & $x$ & $x$ \\
\hline$G-5$ & $x$ & $x$ & $x$ & $x$ \\
\hline$G-6$ & $x$ & $x$ & - & - \\
\hline $6-7$ & $x$ & $x$ & $x$ & $x$ \\
\hline$G-8$ & - & $x$ & - & - \\
\hline$G-9$ & $x$ & - & - & - \\
\hline $\mathrm{G}-10$ & - & - & - & - \\
\hline Total & 6 & 5 & 3 & 3 \\
\hline
\end{tabular}

Do total de genotipos em estudo, foram selecionados por estabilidade $60 \%$ deles. Por DEF foram selecionados 50\% dos genótipos, tendo sido deste grupo, separados 3 (tres) como eficientes em segundo grau de DE, ou seja, indicados a agricultores aversos a risco. Entre os genotipos considerados estáveis, cerca de $67 \%$ foram 
considerados eficientes pelos criterios de Dominancia Estocastica de Primeiro Grau (DEP). Entre os genotipos considerados eficientes pela DE, $80 \%$ encontravam-se entre os estaveis. Em resumo, para este grupo de genótipos de algodá, os resultados mostram que ao selecionar-se por $D E$, estariam sendo descartados $33 \%$ dos genótipos considerados estáveis. A escolha feita por estabilidade excluiria $20 \%$ dos estocasticamente eficientes.

4. 2 Cultura do Feijăo

SANTOS 619802, utilizou produtividades de 12 (doze) cultivares de feijão em 11 (onze) ambientes do Sul de Minas Gerais, durante 4 anos. Estudou seus comportamentos no que diz respeito a estabilidade fenotipica empregando o metodo de EBERHART \& RUSSELL (1966). De acordo com Santos os cultivares reagiram de forma diferente as variaģes ambientais embora seus coeficierites de regressáo, com excecăo de um úrico cultivar, não tenham diferido significativamente de 1 . A avaliação da estabilidade foi feita com base ras medias de produtividade e nos desvios da regressáo.

A partir dos dados de produtividades constantes da Tabela A. 3 do Aperidice, extralda de SANTOS (1980), foram estimadas funçöes de distribuicăo cumulativas de probabilidade, permitindo o emprego dos eriterios de Dominancia Estocástica. Na Tabela e, encontra-se resumido o resultado da seleção pelo emprego dos criterios de estabilidade e Dominância Estocástica. 
Dentre os cultivares comparados, 6 (sels) foram considerados eficientes em primeiro grau de Dominancia Estocástica (DEP): Rico $23(C-1)$, Costa Rica 1031 (C-2), Carioca $1030(C-4)$, ESAL 1 (C-5), Pintado (C-6) e Vi 1011 $(c-9)$. Estes cultivares podem, dentro das condiçżes em que fol conduzido o ensaio, ser recomendados a agricultores de qualquer natureza com relaçăo ao comportamento de risco. Dentre os cultivares selecionados pelos criterios da DEP. foram considerados como eficientes pelos criterios da Dominancia Estocastica de Segundo Grau CDES os cultivares $C-2, C-6$ e $C-9$. Entre estes, năo foi possivel aumentar o poder de discriminação, permanecendo os tres como eficientes pelos criterios da Dominancia Estocástica de Terceiro Grau (DET). Os cultivares costa Rica 1031 , Pintado e Vi 1011, podem então ser indicados a agricultores aversos a risco como tambem aqueles cuja aversão a risco reduz-se com o aumento da riqueza.

Os cultivares rejeitados pelos criterios da DEF, tambem for am eliminados pelos criterios da estabilidade por causa da baixa produtividade erou por apresentarem desvios significativos.

Os cultivares $c-1, \quad c-4 \in c-5$ que for am selecionados por DEP e rejeitados por DES tambem foram descartados pelos criterios de estabilidade por apresentarem elevados desvios apesar da alta produtividade. 
Costa Rica 1031 (c-2). Pintado (C-6) e Vi 1011 $(C-9)$, seiecionados como eficientes por DES e DET foram destacados por estabilidade. Os cultivares $c-2, c-6 \in c-9$ apresentaram todas as caracteristicas desejaveis calta produtividade, baixos desvios e adaptaçăo geralı, embora C-e tenha mostrado alguma tendencia para ambientes mais promissores e C-6 para ambientes mais pobres.

Tabela 2 - Seleça por Estabilidade e Dominancia Estocástica de cultivares de feijão cultivados em 11 ambientes (combinação de locais e aros) do Sul de Minas Gerais.

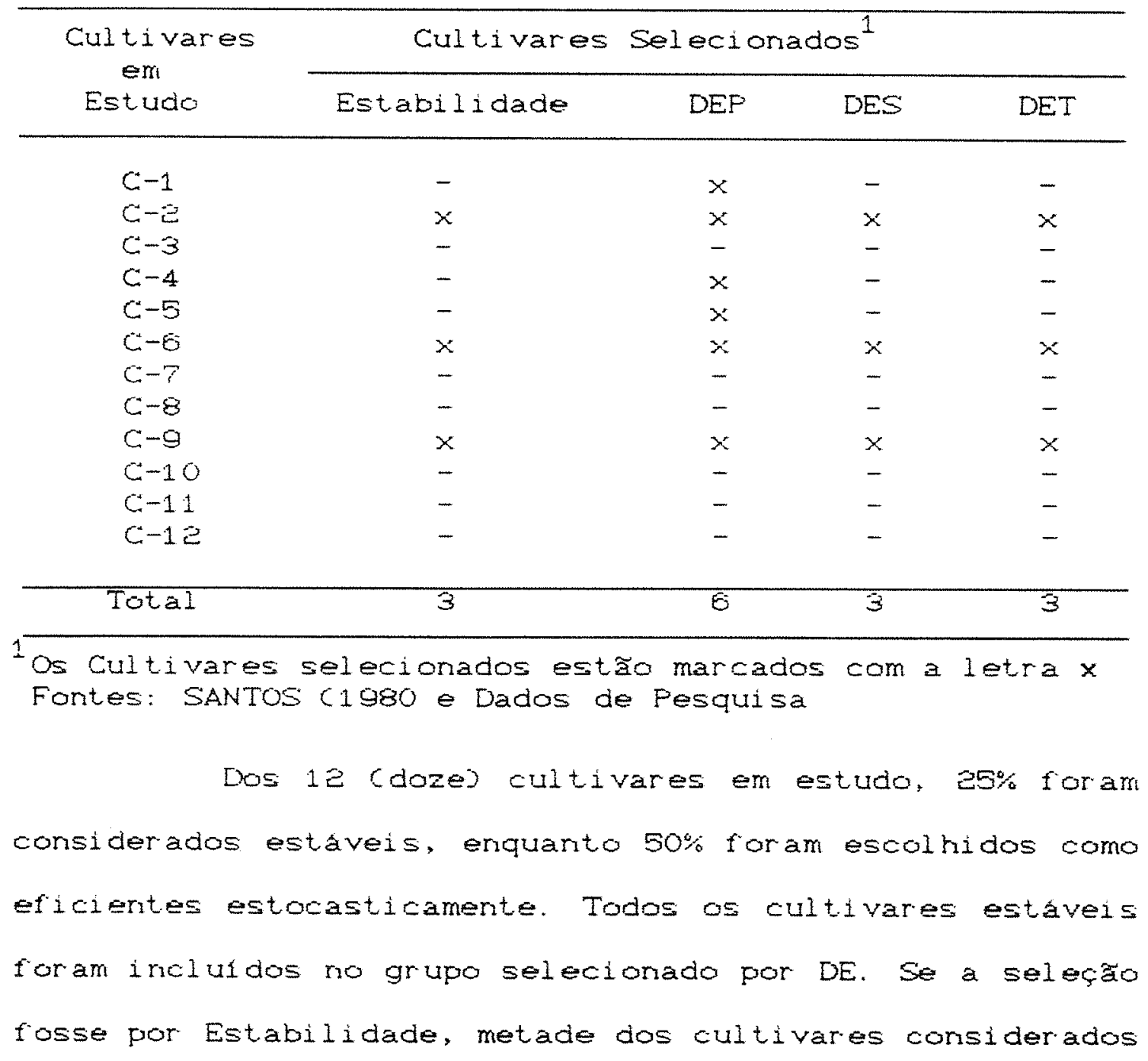


estocasticamente eficientes ficariam de fora. Os resultados indicam que os cultivares estáveis são os mesmos que poderiam ser indicados a agricultores considerados aversos a risco.

\section{3 Cultura do Milho}

FERNANDES (1988), estudou o comportamento, com respeito a estabilidade, de 15 hibridos de milho cultivados em 10 locais da regiáo Centro Sul do Brasil, durante 3 (tress anos consecutivos. Empregou os metodos de EBERHART \& RUSSELL (1966) e SILVA \& BARRETO (1985), tendo constatado que houve diferenças significativas entre os hibridos.

As produtividades coristarites das Tabelas A. 4 a A. 6 do Aperrdice, for am utilizadas para 0 ajustamento das funçốes de distribuição cumulativas, permitindo o emprego dos criterios de Dominancia Estocástica. Os resultados da aplicação dos critérios de Estabilidade e Dominancia Estocastica encontram-se resumidos na Tabela 3.

Dos 15 hibridos em estudo, for am selecionados como eficientes em Dominancia Estocástica de Frimeiro Grau (DEP) Contimax 3ee $(H-1)$, Cargill $111(\mathrm{C}-7)$, Cargill 115 $(C-8)$ e Dina $10(C-13)$. Estes híbridos, dentro das condiçôes em que for am cultivados, podem ser recomendados para agricultores com caracteristicas de aversão, indiferenca ou propensăo a risco. O poder de discriminaçăo fol bastante elevado para os hibridos de milho, tendo sido da ordem de $73 \%$ 
Dos quatro hibridos selecionados por DEP, apenas o hibrido CONIIMAX 3ee $(H-1)$ foi considerado eficiente ao nivel de segundo grau de Dominancia Estocástica. 0 poder de discriminação atingiu $93 \%$. CONTIMAX 322 seria entäo recomendado a agricultores com caracteristica de aversão a risco.

Todos os hibridos rejeitados pelos criterios de Dominancia Estocástica tambem o foram pelos criterios de estabilidade por causa de baixa produtividade ou desvios significativos. Entre os hibridos selecionados por DEP e rejeitados por DES $(H-7, H-8, H-13)$, for am considerados estáveis $H-7$ e H-13. As concluszes de Fernandes demonstram que o primeiro apresentou todas as caracteristicas desejáveis de acordo com os criterios do método de Eberhart \& Russell e permaneceu com coeficientes de regressá iguais a 1 pelo metodo de Silva \& Barreto. 0 segundo foi selecionado por apresentar as caracteristicas desejavels de acordo com os ariterios do método de Silva \& Barreto.

O hibrido CONTIMAX 3e2 $(\mathrm{H}-1)$ constituiu-se num foco de divergência entre as classificaçóes por Dominancia Estocastica e por Estabilidade. Enquanto o hibrido foi escolhido como indicado a agricultores aversos a risco, foi rejeitado pelos metodos de estabilidade pois apesar de sua boa produtividade e adaptação geral cooficiente de regressão não diferiu de 1 significativamentej apresentou elevados desvios da Iinearidade. 
Tabela 3 - Seleça por Estabilidade e Dominancia Estocástica de hibridos de milho cultivados em 10 locais da região Centro-Sul do Brasil nos anos $1983 / 84,1984 / 85$ e $1985 / 86$.

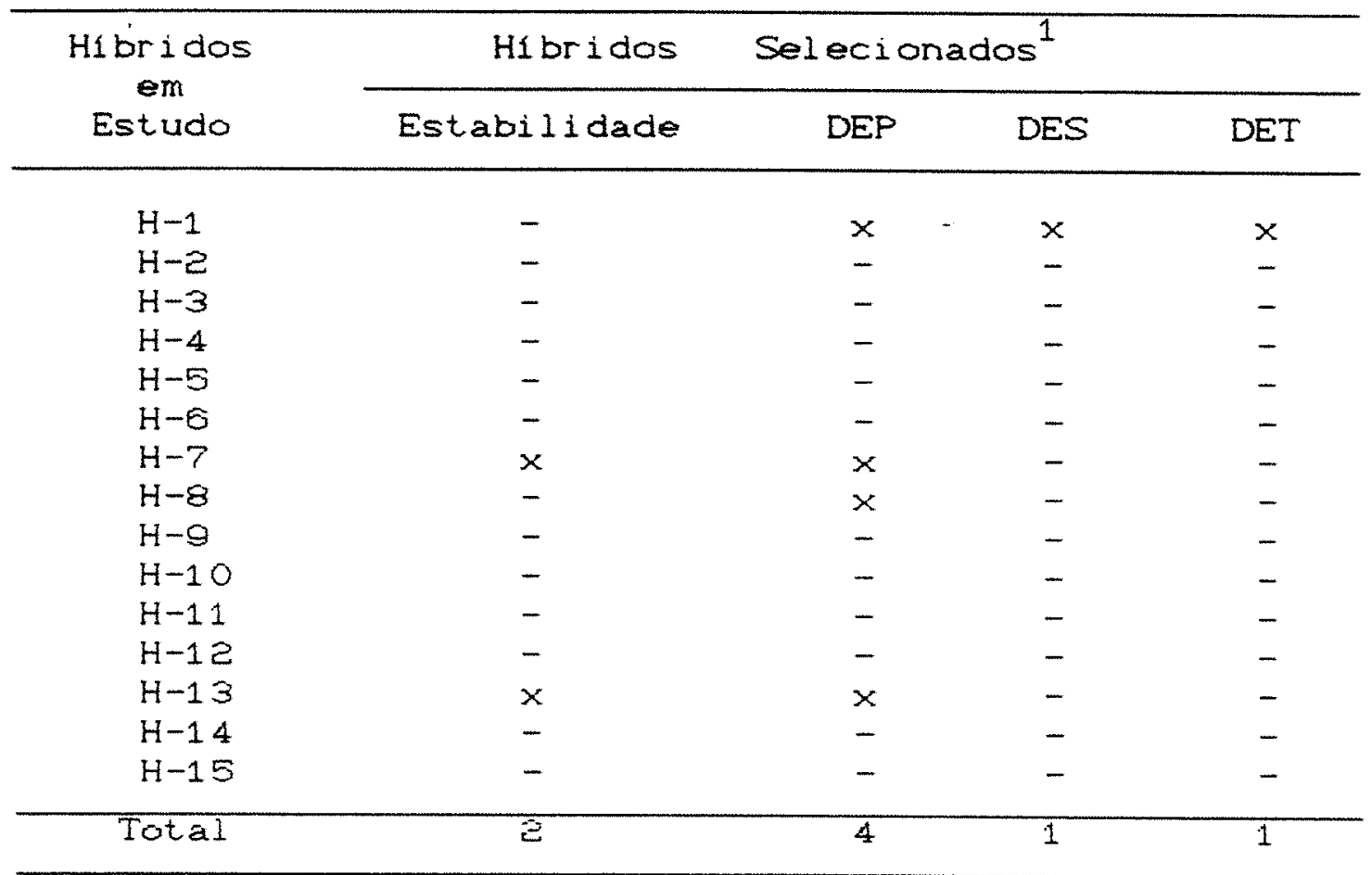

1 Os híbridos selecionados estão marcados com a letra $x$ Fontes: FERNANDES (1988) e Dados de Fesquisa

Foram selecionados por estabilidade 2 cdois hibridos, correspondendo a $13 \%$ do total em estudo. Felos criterios de primeiro grau de Dominancia Estocastica foram escolnidos cerca de $27 \%$ dos hibridos, tendo sido selecionado apenas 1 (um) deles como eficiente em segundo grau de Dominaricia Estocástica ( cerca de $6,7 \%$ do totals. Entre os escolnidos como eficientes pela Dominancia Estocastica de Primeiro Grau todos os considerados estáveis foram incluidos. Entretanto o hibrido $\mathrm{H}-1$ considerado como indicado a agricultores aversos a risco, 
foi excluido do grupo dos estáveis tendo em vista que mostrou desvios significativos, ou seja, nao mostrou adaptaçăo ao modelo adotado para seleçăo por estabilidade. Em resumo, tambem neste caso, a seleção por Dominancia Estocástica incluiria os hibridos estáveis. Inversamente, a escolha considerando apenas os criterios de estabilidade eliminaria 50\% dos hibridos eficientes estocasticamente.

\section{4 Cultura da Soja}

BONATO (1979), estudou o comportamento de 10 (dez) cultivares de soja cultivados durante tres anos consecutivos em 11 Conzej locais do Rio Grande do Sul. Em seu trabalio de estabilidade, empregou o metodo de EBERHART \& FUSSELL $(1966)$ e constatou que os cultivares mostraram-se semel hantes em comportamento. Os coeficientes de regressão năo diferiram significativamente de 1 (um), permitindo a avaliaçáo do comportamento a partir das medias de produtividade e dos desvios apresentados pelas regresóes.

A partir das produtividades fornecidas pelos cultivares e constantes das Tabelas A.T a A. 9 do Apericice, extraldas de BONATO (1979), foram ajustadas funços de distribuifão cumulativas de probabilidade de ocorrencia das produtividades, permitindo o emprego dos oriterios de Dominancia Estoctstica CDE. A Tabela 4 mostra os cultivares selecionados tanto pelos oriterios de DE como de estabilidade. 
Dos 10 (dez) cultivares de soja estudados, foram considerados eficientes a nivel de $1^{\circ}, 2^{\circ}$ e $3^{\circ}$ graus de Dominancia Estocástica IAS-1 $(C-4)$, IAS-4 (C-6), IAS-5 $(C-7)$, Perola $(C-8)$ e Planalto $(C-9)$. Estes cultivares, dentro das condiços em que foi conduzido o ensaio, poderão ser indicados a agricultores aversos, indiferentes ou propensos a risco, pelo fato de terem sido eficientes nos tres graus de DE. As funçóses cumulativas estimadas mostraram-se muito semelhantes, impedindo um maior poder de discriminação mesmo a nivel de terceiro grau de dominância.

Dos 5 (cincos cultivares rejeitados pelo emprego da Dominancia Estocástica, tres também o for am pelos criterios de estabilidade. Os cultivares Bragg (C-2) e Prata $(C-10)$ não for ami rejeitados por estabilidade tendo sido considerados desejáveis com a ressalva de que ci-e demonstra uma tendencia a melhor desempenho em ambientes considerados promissores enquanto $\mathrm{C}-10$ apresenta produtividade abaixo da media do grupo.

Houve uma certa divergencia entre os resultados conseguidos por DE e por Estabilidade. Os cultivares C-4, $C-7, C-8$ e $C-9$ considerados eficientes estocasticamente, foram rejeitados pelos criterios de estabilidade por apresentarem desvios da regressão ajustada altamente significativos o que demonstra que eles năo se adaptam ao modelo Iinear adotado. Apenas $C-6$ foi considerado como eficiente pelos dois criterios. 
Conforme ressaltado por Bonato, as semelhancas existentes entre as respostas ineares apresentadas pelos cultivares provavelmente demonstram que as pesquisas tem conseguido selecionar materiais com caracteristicas de responder bem à melhoria no ambiente ccoeficientes de regressão năo diferem de 1), mas não tem conseguido indicar as que apresentam resultados consistentes atraves dos ambientes cbaixos desvios da regressão ajustadas. A semelhança entre os cultivares, quanto ao comportamento, encontra-se refletida tambem em suas distribuiçóses de probabilidade, impedindo, como dito anteriormente, um maior poder de discriminação pela Dominăncia Estocástica.

Tabela 4 - Seleção por Estabilidade e Dominancia Estocástica de cultivares de soja cultivados em 11 locais do Rio Grande do Sul nos anos $1972 / 73,1973 / 74$ e 1974,75 .

\begin{tabular}{|c|c|c|c|c|}
\hline \multirow{2}{*}{$\begin{array}{c}\text { Cultivares } \\
\text { em } \\
\text { Estudo }\end{array}$} & \multicolumn{4}{|c|}{ Cultivares Selecionados ${ }^{1}$} \\
\hline & Estabilidade & DEF & DES & DET \\
\hline$c-1$ & - & - & - & - \\
\hline$c-2$ & $x$ & - & - & - \\
\hline$c-3$ & - & - & - & - \\
\hline$c-4$ & - & $x$ & $x$ & $x$ \\
\hline$c-5$ & - & - & - & - \\
\hline$c-6$ & $x$ & $x$ & $x$ & $x$ \\
\hline$c-7$ & - & $x$ & $x$ & $x$ \\
\hline$c-8$ & - & $x$ & $x$ & $x$ \\
\hline$c-9$ & - & $x$ & $x^{x}$ & $x$ \\
\hline$c-10$ & $x$ & - & - & - \\
\hline Total & 3 & 5 & 5 & 5 \\
\hline
\end{tabular}

1 Os cultivares selecionados estão marcados com a letra $x$ Fontes: BONATO (1979) e Dados de Pesquisa 
o emprego dos criterios de estabilidade permitiu a indicaçăo de 3 (tres) cultivares de soja como os mais estáveis entre os componentes do grupo estudado. Os criterios de Dominancia Estocástica indicaram 5 (cinco) como sendo aqueles que poderiam ser recomendados a agricultores, indiferentes, aversos ou propensos ao risco. Para este caso, houve uma única coincidencla na escolha pelos dois criterios, o cultivar IAS-4 (C-6).

Os cultivares selecionados por Dominăncia Estocastica, formam um grupo diverso daquele que constitui - grupo de cultivares mais estáveis. Apenas 1 (um) dos selecionados por estabilidade foi considerado eficiente estocasticamente, enquanto $20 \%$ dos selecionados por DE poderiam ser considerados estáveis. Ou seja, se a escolna fosse simplesmente por DE, cerca de $67 \%$ dos estaveis ficariam de fora. A escolha sendo apenas por estabilidade deixa de considerar $80 \%$ daqueles cultivares indicados a agricultores de acordo com sua preferencia com relação ao risco.

\section{5 Cultura do Trigo}

SCHVARTZMAN (1989) comparou o desempenho de 10 (dez) cultivares de trigo nos anos de 1986 e 1987 em 7 (sete) locais da regiao Oriental do Paraguai. Empregou em seu estudo o metodo sugerido por CRUZ et aliz 41988 para detectar a estabilidade dos materiais geneticos. O autor concluiu que os cultivares näo mostraram diferenças 
significativas quanto a estabilidade pois de um modo geral exibiram desvios da regressão significativos.

As produtividades fornecidas pelos cultivares. CTabelas A.10 e A.11 do Apendice), permitiram o ajustamento da funçăo de distribuição cumulativa para cada um deles, objetivarido o emprego dos critérios de Domináncia Estocástica. Os cultivares selecionados por estes critérios e pelo da estabilidade são mostrados na Tabela 5 .

Seis cultivares foram considerados eficientes ao nivel de primeiro, segundo $e$ terceiro graus de Dominancia Estocástica: Cordiliera 4 (C-2), IAN-7 (C-4), Itapua $30(c-6),(-8289(c-7), \quad c-8055(C-8)$ e $E-8109$ $(c-9)$. Estes cultivares podem, dentro das condiçóes em que foi desenvolvido o ensaio, ser recomendados a agricultores aversos, indiferentes ou propensos a risco. A semelhança entre as distribuiçoses cumulativas não permitiu um maior poder de discriminaça em segundo ou mesmo em terceiro graus de Dominarncia Estocástica.

$$
\text { os } 4 \text { cquatrol cultivares rejeitados pelos }
$$
eriterios da DE tambem o foram por estabilidade por causa de seus desvios sigrificativos. Entretanto dentre os seis escolhidos como eficientes pelos criterios de DE for am rejeitados por estabilidade os cultivares $c-e, c-6, c-7 e$ c-s tambem por causa da significancia dos desvios. 0 cultivar cujas respostas reuriram as caracteristicas mais desejâveis em estabilidade fol o c-8055 (c-8) que tambem consta do grupo eficiente por DE. 
O emprego da Dominancia Estocástica permitiu a escolha de 6 (seis) cultivares considerados eficientes, correspondendo a $60 \%$ do total em estudo. A seleção pelo emprego dos criterios de estabilidade destacou apenas 2 (dois) cultivares considerados estáveis. No grupo considerado eficiente por DE encontra-se incluida a totalidade dos cultivares estaveis, ou seja, se a escolha fosse apenas por DE, incluiria tambem aqueles cultivares considerados estaveis, enquanto que a escolha apenas pelos criterios de estabilidade descarta $67 \%$ dos cultivares que podem ser indicados a agricultores com caracteristicas de aversăo ao risco.

Tabela 5 - Seleção por Estabilidade e Dominancia Estocastica de cultivares de trigo cultivados em 7 localidades da Região Oriental do Paraguai nos anos 1986 e 1987 .

\begin{tabular}{|c|c|c|c|c|}
\hline \multirow{2}{*}{$\begin{array}{c}\text { Cultivares } \\
\text { em } \\
\text { Estudo }\end{array}$} & \multicolumn{4}{|c|}{ Cultivares Selecionados ${ }^{1}$} \\
\hline & Estabilidade & $D E P$ & DES & DET \\
\hline$c-1$ & - & - & - & - \\
\hline$c-2$ & - & $x$ & $x$ & $x$ \\
\hline$c-3$ & - & - & - & - \\
\hline$c-4$ & $x$ & $x$ & $x$ & $x$ \\
\hline$c-5$ & - & - & - & - \\
\hline$c-6$ & - & $x$ & $x$ & $x$ \\
\hline$c-7$ & - & $x$ & $x$ & $x$ \\
\hline$c-8$ & $x$ & $x$ & $x$ & $x$ \\
\hline$c-9$ & - & $x$ & $x$ & $x$ \\
\hline$c-10$ & - & - & - & - \\
\hline Total & 2 & 6 & 6 & 6 \\
\hline
\end{tabular}




\section{6 Avali ação Geral}

Comparando os grupos selecionados pelo emprego dos criterios da Domináncia Estocástica e dos métodos de Estabilidade, foi possivel observar que, no caso da cultura do algodáo, a seleção por Domináncia Estocástica deixou de incluir $33 \%$ dos genótipos considerados estáveis. Para a cultura da soja, $67 \%$ dos cultivares estaveis năo constavam entre os estocasticamente eficientes. Em contrapartida, nas culturas do Feijăo. Trigo e Milho, os genotipos escolnidos como eficientes estocasticamente incluiram a totalidade dos genotipos estaveis. Em todos os grupos avaliados năo houve caso em que a totalidade dos genotipos eficientes estocasticamente estivessem contidos no conjunto dos estaveis.

Fazendo uma avaliaça pelo total de genotipos seleciorados, observa-se que dos 57 Coinquenta e setes genotipos estudados, foram selecionados 30 (trintas pelos dols criterios de escolha. Do total selecionado, 16 Caproximadamente 53\% pertencem ao grupo dos estaveis e 26 Ccerca de 87\% ao grupo dos eficientes estocáticamente, sendo que 12 ( $46 \%$ for am classificados, simultaneamente, pelos dois criterios. Assim. entre os genotipos selecionados, apenas $13 \%$ năo săo corsiderados eficientes estocasticamente, enquanto cerca de $46 \%$ do total näo for am considerados estáveis. 
Avaliando apenas os genotipos classificados por Estabilidade, $75 \%$ deles mostraram-se eficientes estocasticamente, enquanto os restantes $625 \%$ foram descartados pela Dominancia Estocástica. Dentro do grupo classificado como estocasticamente eficiente, $46 \%$ foram classificados como estáveis e $54 \%$ não. Desse modo, percebe-se uma tendéncia maior de os genótipos estáveis constarem do grupo dos Dominantes estocásticos do que o inverso. Se a seleçáo fosse feita exclusivamente por DE, se descartaria apenas $13 \%$ do total selecionado, enquanto a seleçăo, que leva em conta a Estabilidade, abandonaria $54 \%$ do total de genotipos escolnidos, pelos dois criterios.

Todos os genótipos eliminados por criterios de estabilidade e que constam do grupo dos eficientes estocasticamente apresentaram desvios da regressáo significativos, inclusive os eficientes em segundo e terceiro graus de Dominaricia Estocástica, indicando falta de adaptação ao modelo linear empregado nos métodos de estabilidade. Este fato demonstra que a variancia das distribuiçós de probabilidade, năo apresenta relaçăo com os desvios da regressáo. A funçăo de distribuiçăo cumulativa reflete, entre outros momentos da distribuicão, a variancia da produtividade de cada um dos gerotipos e a Dominancia Estocastica ao selecionar genótipos em nivel de segundo e terceiro graus considera a magnitude da variancia na escolha. Em tais casos, os genotipos selecionados podem ser indicados a agricultores com 
caracteristicas de aversão a risco e, portanto, é de se esperar que eles apresentem caracteristicas especiais, entre as quais que as variancias apresentadas pelas distribuiçós näo sejam el evadas.

O grupo selecionado por DE mostrou-se maior que o grupo gerado pelos criterios de estabilidade e engloba um percentual bastante elevado dos genótipos classificados como estáveis.

No estudo dos genótipos de milho, o hibrido $\mathrm{H}^{-1}$ que ravia sido descartado por criterios de Estabilidade foi selecionado em segundo grau de Dominancia Estocástica, recomendando-o a agricultores com características de aversáo ao risco.

os cultivares de fsijac pico $23(c-1)$, Carioca $1030(C-4)$ ESAL $1(c-5)$ que, no trabal ho de SANTOS (1980), terido sido excluidos pelos criterios de Estabilidade devido a seus elevados desvios da regressão, receberam comentarios do autor quanto a sua popularidade entre os agricultores do Sul de Miras Gerais e sua aceitação comercial. Estes cultivares foram tambem escolhidos por DE, mostrando a abrangencia do metodo em incluir em sua selsça grande numero de genotipos estáveis e tambem, como não podia deixar de ser, aqueles que são preferidos pelos agricultores. Para a cultura do feijăó importante selecionar-se cultivares de acordo com a prefersncia do agricultor, pois na escolna do material para plantio eles consideram elementos como cor, textura e sabor do grăo. 
Nos métodos para medir estabilidade, em geral, empregam-se modelos lineares, descartando-se genotipos cuja regressáo ajustada demonstra elevados desvios, ou seja aqueles que não se adaptam ao modelo. E discutivel a imposifão de um modelo linear de resposta. Não necessariamente um genotipo necessita oferecer respostas Iineares. Outros modelos (talvez curvilineos) com os quais as respostas de um genotipo mostrassem melhor adaptação poderiam ser tentados, permitindo a escolna de genotipos altamente previsiveis $C S_{d}^{2} \simeq O$ em suas respostas dentro do novo modelo. Assim, genótipos, como no caso do CONTIMAX 32e (H-1) na cultura do milho, e Rico $23(\mathrm{C}-1)$, Carioca $1030(C-4)$ ESAL $1(C-5)$ no caso do feijão, que for selecionados para indicaçăo a agricultores por Dominancia Estocástica e eliminados por Estabilidade devido à falta de previsibilidade (desvios significativos), talvez viessem a apresentar adaptaçăo a outro modelo adotado para ajustar a regressăo, no qual seus desvios se mostrassem não significativos.

Uma resposta curvilinea foi referida por STORCK (1989) ao propor um novo modelo para aplicação na análise de estabilidade de genotipos. O autor admite que as respostas das produtividades podem variar de acordo com uma função com forma semelhante a da curva de Gompertz. Sua proposta é um modelo linear que substitua a curva de Gompertz já que a estimação e interpretação de seus parămetros não seria simples. 


\section{CONCLUSÖES}

o objetivo principal deste trabalho consistiu na comparaça de grupos de genotipos considerados eficiertes pelo emprego dos metodos deserivolvidos para detectar estabilidade, com grupos de genotipos escolnidos pelo emprego dos criterios da Teoria da Decisão. Entre os metodos estudados visando seleçáo de alterrativas em condiços de iricerteza fol aplicado o da Dominaricia Estocastica. A escolra se deu por ter sido o metodo considerado superior aos demais, em virtude de uma serie de razoes tesricas derivadas da recessidade de se 1 mpor menos retrifoes a forma especifica das funcbes de utilidade dos agricultores.

Comparados os grupos de genotipos obtidos pelos dois criterios, foi possivel chegar as seguintes corcl usos:

As escolnas realizadas por Dominancia Estocastica e por métodos de Estabilidade apresentaram maior número de semelnangas do que de divergéncias nos diversos estudos realizados. As divergencias se verificaram no estudo envolvendo genotipos de soja e algodáo. Fara estes, o grupo considerado estocasticamente 
eficlente delxou de inclutr $33 \%$ dos genotipos escolnidos por estabilidade. No estudo para a cultura da soja, o percentual não incluido alcançou $67 \%$ dos cultivares considerados estaveis. Entretanto, para os trabalhos realizados para as culturas do trigo, milho e feljă, $100 \%$ dos genótipos estavels, fizeram parte de grupo considerado estocasticamente eficiente.

Dos 57 genotipos estudados, 30 for am selecionados pelos dois oriterios e dentre os escolhidos apenas $13 \%$ rão constavam do grupo dos selecionados por Domináncia Estocástica. 0 número de genotipos estocasticamente eficlentes fol maior e englobou $75 \%$ dos genótipos estáveis, demonstrando haver uma tendência de os estáveis pertencerem ao grupo selecionado por DE.

f fato de alguns materials apresentarem elevados desvios da regressão näo mostrou associação com as varianclas das funçoes de distribuiçăo de probabilidades, pois genotipos excluídos pelos eriterios de Estabilidade devido aos elevados desvios apresentados, foram selecionados por Dominancla Estocastica de segundo e terceiro graus, podendo ser indicados a agricultores com caracteristicas de aversão ao risco.

A Dominancia Estocastica mostrou-se capaz de Incluir em sua seleção genótipos estávels e tambem, como era de se esperar, aqueles que seriam preferidos pelos agricultores. Entre os excluidos por Estabilidade e selecionados por Domináncia Estocástica for am encontrados 
alguns cultivares de feljao considerados como sendo de boa aceltaço comercial e populares entre os agricultores da regizo onde for am testados.

0 estudo apresentou $11 \mathrm{mitaç}$ tes por comparar um número pequeno de grupos de genotipos. Estes primeiros resultados, no entarito, apesar das restriçóes, permitem sugerir que, antes da utilização dos metodos para avaliar estabilidade, seja felta uma preseleça de genotipos empregarido metodos que levem em consideraçăo as preferencias do agricultor quanto as suas caracteristicas de aversão ao risco.

Conforme fol observado, com o emprego da Dominancia Estocastica, a possibilidade de serem descartados genotipos "estávels" mostra-se pequera. Em cortrapartida, o seu emprego certamente aumentaria em muito a segurança a ser levada ao agricultor quando da seleção dos genótipos mais estaveis.

os coeficientes de regressäo sán furcá das produtividades e os desvios da regressăo, conforme destacou KNIGHT (1970), dependem da semelhança ou não eritre os genotipos estudados. Assim, o emprego dos metodos de estabilidade dentro de um grupo de genotipos eficientes estocasticamente pode levar a resultados diferentes dos obtidos aperas com o emprego da estabilidade. Esta pratica talvez verha a permitir a selecáo de materiais que. apenas com o uso dos metodos de Estabilidade, seriam descartados, alnda que teria sido constatada sua preferencia para 
cultivo $C$ caso da cultura do feljäos ou quando recomendados a agricultores aversos a risco pelos criterios de Dominancia Estocástica.

A seleçáo de genotipos, seja por Estabilidade seja utilizando os criterios de Dominancia Estocástica, tem como objetivo maior levar segurança ao agricultor, grandemente exposto as adversidades. A aplicação dos dois criterios, sequencialmente, por certo aumentaria o grau de segurança no processo de adoçăo de variedades melhoradas. Selecionar genotipos por estabilidade dentro do grupo estocasticamente eficiente estar 1 a, antes de avaliar o comportamento dos genotipos nas variadas condiçós ambientais que se apresentam, dando prioridade as preferencias do agricultor diante de situaçores envolvendo incerteza. 
REFERENCI AS BIBLIOGRAFICAS

ANDERSON, J.R. Sparce data, climate variability and yield uncertainty in response analysis. American Journal of Agricultural Economics, Carbondale, 55(1): 77-82, 1973.

ANDERSON, J.R. Sparce data, estimational reliability, and risk-efficient decisions. American Journal of Agricultural Economics, Carbondale, 56( 3$): 564-72,1974$.

ANDERSON, J.R.; DILLON I.L.; HARDAKER, E. Agricultural decision analysis. 1.ed. Iowa. Iowa State University Press, 1977.344 p.

ARROW, J.K. Essays in the theory of risk-bearing. 1.ed. North-Holland, North-Holland Publishing Company, 1974. 278 p.

AZEVEDO FO., A.J.B.V. \& PERES, F.C. Competitividade da cultura da soja em uma empresa da regia de Campinas, SP. In: EMBRAPA, ed. Planejamento da propriedade agricola; Modelos de Decisão. Brasilia, EMBRAPA-DDT, 1984. p. $289-300$. 
BARNARD, C.S. \& NIX, J.S. Farm planning and control. 2 ed. Cambridge, Camb. Univ. Press, 1979. $600 \mathrm{p}$.

BONATO, E.R. Estabilidade fenotipica da produção de grãos de dez cultivares de soja cGlycine max L. Merrils nas condiçóes do Rio Grande do Sul. Piracicaba, 1979. 75 p. CMestrado - Escola Superior de Agricultura "Luiz de Queiroz"/USPS.

BORCH, $K$. The rationale of the mean-standard deviation analysis: comment. American Economic Review, Ithaca, $64(3): 428-30,1974$.

BREEZE, E.L. The measurement and significance of genotype-enviromment interaction in grasses. Hexedity. London, 24(1): $27-44,1969$.

CHAHAL, G.S. \& VERMA, M.M. Limitations of conventional regression analysis: a proposed modification. Theoretical Applied Genetics, Berlin, 53: 89-91, 1978.

CHI ANG, A.C. Matemática para Economistas. 2.ed. São Paulo. MCGraw Hill, 1982. $684 \mathrm{p}$.

CORVALAN LATAPIA, L.M. O risco na escolna de cultivares de milho. Piracicaba, 1987. 135 p. CMestrado - Escola Superior de Agricultura "Luiz de Queiroz"/ USP). 
CRUZ, C.D.; TORRES, R. A. A.; VENCOVSKY, R. Modelo alternativo para a analise de estabilidade proposto por Silva e Barreto. In: CONGRESSO NACIONAL DE MILHO E SORGO, 17., Piracicaba, 1988. Resumos. Piracicaba, Fundaçăo Cargi11, 1988. p.121.

CRUZ, E.R. Aspectos teoricos sobre incorporaçăo de risco em modelos de decisão. In: EMBRAFA, ed. Planejamento da empresa agricola ; Modelos de Decisão. Brasilia. EMBRAFA-DUT, $1984 . p$.

DILLON, J.L. Avaliação de tecnologias agricolas sob risco. Revista Econômica do Nordeste. Fortaleza, 7(3):407-32, 1976.

EBERHART S.A. \& RUSSELL W.A. Stability parameters for comparing varieties. Crop science, Madison, $6(1): 36-40,1966$

FELDESTEIN, M.S. Mean-variance analysis in the theory of liquidity preference and portfolio selection. Review of Economic Studies, London, 36: 5-12, jan 1969.

FERNANDES, J.S.C. Estabilidade ambiental e de cultivares de milho (Zea mays L.) na regiäo centro sul do Brasil. Firacicaba, 1988. 94 p. CMestrado - Escola Superior de Agricultura "Luiz de Queiroz",USPS. 
FINLAY, K.W. \& WILKINSON G.N. The analysis of adaptation in a plant breeding programme. Australian Journal of Agricultural Research, Melbourre, 14:742-54, 1963.

FRANCIS, T.R. \& KANNENBERG, $w . L$. Yield stability studies in short-season maize. I. A descritive method for grouping genotypes. Canadian Journat of Plant Science, Ontar10, 58:1029-34, 1978 .

FRIEDMAN, M. \& SAVAGE, L.I. The utility analysis of cholces involving risk. Journal of poitical economy, Chicago, 56:279-304, Ago. 1948.

GARCIA, J.C. Seleção de cultivares e sistemas de produçăo de milho com respeito a risco. In: EMBRAPA, ed. Planejamento da empresa agrícola; Modelos de Decisäo. Brasilia, EMBRAFA-DDT, 1984. p. 261-27e.

GARCIA, J.C. \& CRUZ, J.C. Seleção pela dominâneia estocastica de praticas agricolas eficientes com respelto ao risco - uma aplicaçáo para a cultura do milho. Revista de Economia Rural, Brasilia, 17C2): $131-42$, abr.jun. 1979.

HADAR, J. \& RUSSEL, W.R. Rules for ordering uncertain prospects. American Economics Review, Itahaca, $59: 25-34,1969$ 
HAZELL, P.B.R. A Iinear alternative to quadratic and semivariance programming for farm planning under uncertainty. American Journal of Agricultural Economics, Carbondale, 53(1): 53-62, 1971.

KNIGHT, F.H. Risco, incertead e lucro. Trad. de Cantuaria, H. Rio de Jarieiro, Expressão e Cultura, 1972. $385 \mathrm{p}$.

KNIGHT, R. The measurement and interpretation of genotype-environment interactions. Euphytica, Wagentngen, 19: 225-35, 1970.

MIEZAN, K. ; MILLIKEN, G.A. ; LIANG, G.H. Using regression coefficiert as a stability parameter. Theoretical and Applied Genetics, Berlin, 54: 7-9, 1979.

MOUTINHO, D.A.; SANDERS Ir., I.H.; WEBER, M.T. Tomada de decisáo sob condiçós de risco em relaçáo a nova tecnologia para a produção do feijão de corda. Revista de Economia Rural, Brasilia, 16(4):41-58, out-dez 1978.

PACHECO, I.A.C. Modelos de decisáo ná analise economica de experimentos agricolas. Piracicaba, 1985. $111 \mathrm{p}$. CMestrado- Escola Superior de Agricultura "Luiz de Queiroz" NSPS. 
PEIXOTO T.C. et. alii. Ténicas de análise de interação genotipo $x$ ambiente e estabilidade de clones de cana-de-açúcar. In: SIMPOSIO DE ESTATISTICA APLICADA A EXPERIMENTACAOO AGRONOMICA. Piracicaba, 1985. Anais. Campinas, Fundaçăo Cargil1, 1985. p. 243-258.

PERES F.C. Planejamento da empresa agricola em condiḉes de risco. In: EMBRAPA, ed. Planejamento da propriedade agricola : Modelos de Decisão. Brasilia, EMBRAPA-DDT, 1984. F. 273-288.

PERKINS, M.J. \& JINKS, J.L. Environmental and genotype-enviromental components of variabitity. III. Multiple Iines and crosses. Heredity. Londor, 23: $339-56,1968$.

PORTER, R. \& GAUMNITZ, J.E. Stochastic dominance vs. mean-variance portfolio analysis: an empirical evaluation. American Economic Review, Ithaca, $62(3): 438-46.1972$.

PORTO V.H.F. \& CRUZ, E.R. Metodologia para incorporação de risco em modelos de decisão usados na arálise comparativa entre alternativas - o caso da cultura do arroz irrigado. Revista de Economia Rural, Brasilia, 20(2): 193 - 211. abr. Jun. 1982. 
QUIRK, I.P. \& SAPOSNIK, R. Admissibility and measurable utility functions. Review of Economic Studies, London, $29(1): 140-46,1962$.

RAIDAN GONZALES, L.M.A. Estudo da interação de genót 1 pos $x$ ambientes para a cultura do algodá CGossypium 50.3 na regiao oriental do Paragual. Piractcaba, 1988 . 91 p. CMestrado - Escola Supertor de Agricultura "Luiz de Quelroz"/USPS.

SALOMAO, C. C. Sistema de plantio direto e convencional um enfoque de analise de decisăo. Plracicaba, 1990. 126 p. CMestrado - Escola Superior de Agricultura "Luiz de Queiroz" USPS.

SANTOS, J.B. Estabilidade fenotipica de cultivares de feijäo (Phaseolus vulgaris L.) nas condiços do sul de Minas Gerais. Piracicaba, 1980. 110 p. CMestrado Escola Superior de Agricultura "Luiz de Queiroz" NSPs.

SCHOEMAKER, P.J.H. The expected utility model: 1ts variants, purposes, evidence and limitations. Journal of Economic Literature, Tennessee 20(2): 529-563, 1972.

SCHVARTZMAN BERWINKUNKIN, J.J. Estabilidade de cultivares do trigo (Triticum destivum L.) e escolha de locais para seleção nas condlçors da regiăo oriental do Paragua1. Piracicaba, 1989.80 p. CMestrado - Escola Superior de Agricultura "Luiz de Queiroz" USPy. 
SHUKLA, G.K. An invariant test for the homogenelty of variances in a two-way classification. Biometrics, Hashington, 28:1063-72, Dec. 1972.

SILVA, J.G.C. \& BARRETO, J.N. Aplicação da regressão linear segmentada em estudos de interaçăo genótipo $x$ ambiente. In:SIMPOSIO DE EXPERIMENTAÇZO AGRICOLA, 1., Piracicaba, 1985. Resumos. Campinas, Fundaçăo Cargill, 1985. p. $49-50$.

STONE, B.K. Risk, return and equilibrium. Cambridge, Mass.: M.I.T. Press, 1970.

STORCK, L. Modelo de regressão bi-segmentado descontinuo com erros de medida aplicado na análise de estabilidade de cultivares. Piracicaba, 1989 . 217 p. CDoutorado Escola Superior de Agricultura "Luiz de Queiroz",USP3.

TOBIN, J. Comment on Borch and Feldstein. Review of Economic Studies, Londor, 36:13-14, Jar. 1969.

TSIANG, S.C. The rationale of the mean-standard deviation analysis, skewness preference, and the demand for money Americar Economic Review, Ithaca, 626 3):354-71. 1972 
VENCOVSKY, R. \& TORRES, R. Estabilidade geografica e temporal de alguns cultivares de milho. In: CONGRESSO NACIONAL DE MILHO E SORGO, 16., Belo Horizonte, 1986. Ancis. Sete Lagoas, EMBRAPA - CNPMS, 1988. p. 295-300.

YATES, F. \& COCHRAN, W.G. The analysis of groups of experiments. Journal of Agricultural Science, London, $28: 556-580.1938$. 
$A P \hat{E} N D I C E$ 
Tabela A.l Produtividade media en $\mathrm{kg} / 20$ de genotipos de algodao en seis localidades da Regiao Oriental do Paraguai: 1985/86

\begin{tabular}{|c|c|c|c|c|c|c|c|c|}
\hline GENOTIPOS & & Pirareta & Ybycui & $\begin{array}{l}\text { LOCAIS } \\
\text { Caaguazu }\end{array}$ & Cazzapa & $\begin{array}{l}\text { Cel. } \\
\text { Bogado }\end{array}$ & Concepcion & $\begin{array}{l}\text { MEDIA } \\
\text { GENOTIPO }\end{array}$ \\
\hline $\begin{array}{l}\text { Reba } P-279 \\
5 P-510 \times P-27 \theta-100 \\
5 P-510 \times P-279-22\end{array}$ & $\begin{array}{l}(G-5) \\
(G-2) \\
(G-3)\end{array}$ & $\begin{array}{l}2.1137 \\
2.2487 \\
2.2275\end{array}$ & $\begin{array}{l}4.4862 \\
3.2825 \\
3.9975\end{array}$ & $\begin{array}{l}5.1062 \\
5.9437 \\
4.4625\end{array}$ & $\begin{array}{l}3.4150 \\
2.9325 \\
2.7737\end{array}$ & $\begin{array}{l}1.8387 \\
1.8112 \\
1.7800\end{array}$ & $\begin{array}{l}5.9187 \\
5.8437 \\
5.9937\end{array}$ & $\begin{array}{l}3.8131 \\
3.5271 \\
3.5392\end{array}$ \\
\hline KEDIA LOCAL & & 2.1966 & 3.9221 & 4.8708 & 3.0404 & 1.8190 & 5.9187 & 3.6264 \\
\hline
\end{tabular}

Fonte: RAIDAN (1988)

Tabela A.2 Produtividade media su $4 \mathrm{~g} / 20$ me de genotipos de algodao em seis localidades da Regiao Oriental do Paraguai: 1986/87

\begin{tabular}{|c|c|c|c|c|c|c|c|c|}
\hline GENDTIPDS & & Pirareta & Ybyeai & $\begin{array}{l}\text { LOCAIS } \\
\text { Caaguazu }\end{array}$ & Cazzapa & $\begin{array}{l}\text { Cel. } \\
\text { Bogado }\end{array}$ & Concepcion & $\begin{array}{l}\text { METIA } \\
\text { GENOIIPD }\end{array}$ \\
\hline$R e b$ a $P-279$ & $(6-1)$ & 4.6890 & 4.3690 & 3.6125 & 7.6750 & $6.327^{5}$ & 6.3875 & 5.5071 \\
\hline $5^{p}-510 x^{p}-27 b-100$ & $(6-2)$ & 3.3475 & 5975 & 3.6250 & 7.1250 & 6.2250 & & 3.3096 \\
\hline $5 P-519 \times p-279-32$ & $(6-4)$ & 5.9625 & 4.4425 & 3.8375 & 7.6490 & 6.5050 & & .7313 \\
\hline $5 p-519 \times p-279-29 / 43$ & $(6-5)$ & 5.4350 & 4.2450 & 3.8159 & 7.6025 & 6.1475 & 7.0090 & 5.7075 \\
\hline$S P-510 \times P-279-40 / 42$ & $(6-6)$ & 5.4475 & 4.1800 & 3.4625 & 7.8375 & 6.3475 & 6.6125 & 5.6479 \\
\hline Guazuncho & $(6-7)$ & 5.6550 & 4.5350 & 4.3250 & 6.7275 & 6.295 & 6.6750 & 5.5821 \\
\hline Tancot $5 P-21-5$ & $(6-8)$ & 3.9900 & 4.3700 & 4.3375 & 7.5500 & 6.1700 & 5.7875 & 5.3675 \\
\hline $5^{p}-510 \times p-279-38 / 41$ & $(6-9)$ & 4.8000 & 3.8725 & 3.3000 & 7.7300 & 6.1550 & 5.6090 & 5.2429 \\
\hline $9 p-510 \times p-279-28 / 391$ & $(6-19)$ & 4.6475 & 3.6225 & 3.8625 & 7.2350 & 5.6475 & 4.8625 & 4.9796 \\
\hline MEOIA SOCAL & & 4.7183 & 4.2472 & 3.7975 & 7.4581 & 6.2022 & 6.2403 & 5.4439 \\
\hline
\end{tabular}

Fonte: RAIDAN (1988) 


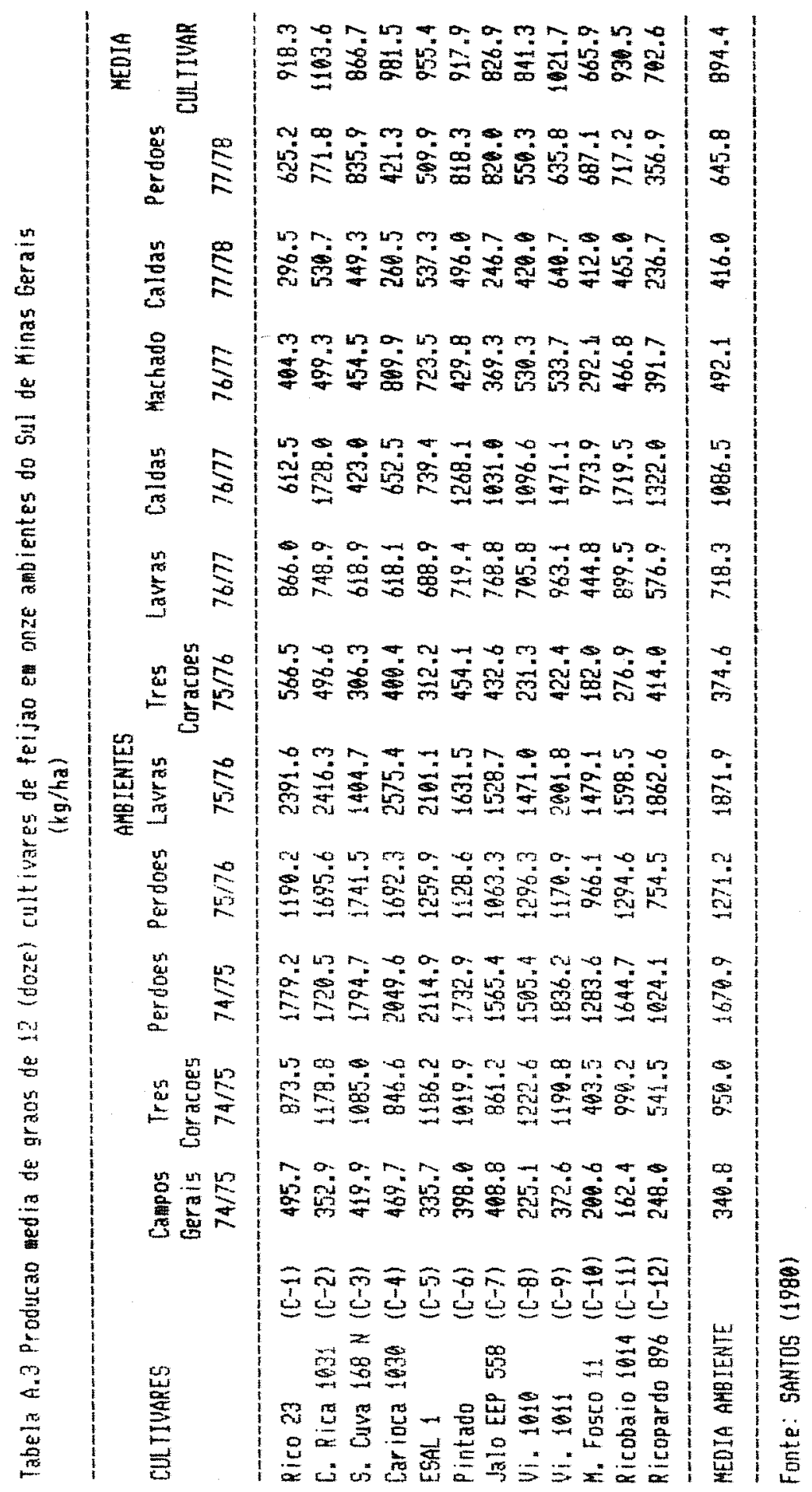


Tabela A.4. Producao nedia eng ke 15 (quinze) hibridos de witho varios locais da regiao Centro Sul do Brasil

$$
1983 / 84
$$

\begin{tabular}{|c|c|c|c|c|c|c|c|c|c|c|c|}
\hline $\begin{array}{l}\text { HIBRI- } \\
\text { DOS }\end{array}$ & $\mathrm{LI}$ & $L^{2}$ & {$[3$} & $L 4$ & $\begin{array}{l}\text { LOCAIS } \\
\text { L5 }\end{array}$ & L6 & 17 & $\angle B$ & 19 & L10 & $\begin{array}{l}\text { MEDIA } \\
\text { HIBRIDO }\end{array}$ \\
\hline$H-1$ & 5400.0 & 8838.0 & 8952.8 & 7384.0 & 5943.0 & & 7184.0 & & & & 12.2 \\
\hline$H-2$ & 3726.0 & 6053.0 & 6502.8 & 4906.0 & 5117.0 & & 6227.0 & & & 4717.0 & 5892.4 \\
\hline $\mathrm{H}-3$ & 3852.0 & 6324.0 & 7890.0 & 5425.0 & 6856.0 & 5026.0 & 5819.8 & 9324.0 & 933 & 4307.0 & 6335.3 \\
\hline $\mathrm{H}-4$ & 3346.0 & 6166.0 & 5959.0 & 5659.0 & 5360.0 & 6450.0 & 6698.0 & 8851.0 & 1014 & 4764.0 & 339.5 \\
\hline$H-5$ & 3463.0 & 8426. & 6453.0 & 5918.0 & 6472.0 & 5695.0 & 6179.0 & 8963.0 & 924 & 5318.0 & 6613.0 \\
\hline $4-6$ & 3665.0 & 6574.6 & 8254.0 & 5004.0 & 5391.0 & 543 & 5535.6 & 7964.9 & 0 & 4120.0 & 6651.3 \\
\hline$H-7$ & 4147. & 7397.0 & 8114.0 & 6144.0 & 5803.8 & 5925.0 & 6163.0 & 9382.0 & 10567.0 & 4968.0 & 6861.0 \\
\hline$H-8$ & 4599.0 & 8967.0 & 7916. & 6991.0 & 5102.0 & 6077.0 & 6506.0 & 9349.0 & 9498.0 & 4912. & 6982.7 \\
\hline$H-9$ & 4120.6 & 7788.0 & 7690.9 & 5960.0 & 4790. & 5697.0 & 6022.0 & 8115.8 & 8390.0 & 5982.8 & 6356.4 \\
\hline$H-10$ & 4138.0 & 6172.0 & 8616.0 & 5620.0 & 5825. & 5399.0 & 6240.0 & 898 & 927 & 4490.0 & 6476.2 \\
\hline$H-11$ & 4954.0 & 5411.0 & 6837.0 & 5266.9 & 5629.0 & 5326.6 & 5061.0 & 7631.0 & 9762.0 & 4592.0 & 5947.8 \\
\hline$H-12$ & 3456.0 & 6246.0 & 7080.0 & 4995.0 & 5345.0 & 5474.0 & 5582.0 & 6966.0 & 8568.0 & 4376.0 & 5860.8 \\
\hline $\mathrm{H}-13$ & 3970.0 & 7536.0 & 7061.0 & 6336.0 & 5241.0 & 6498.0 & 6866.0 & 9471.0 & 10637.0 & 4895.9 & 6842.1 \\
\hline$H-14$ & 3861.8 & 6881.0 & 6356.9 & 4609.0 & 5811.0 & 5600.0 & 5892.0 & 8291.9 & 9496.6 & 4535.0 & $6144_{2} 2$ \\
\hline$H-15$ & 3242.0 & 6111.8 & 7203.0 & 3988.0 & 5793.0 & 5383.0 & 4828. & 8307.0 & 9187.0 & 4345.0 & 5838.7 \\
\hline & & & & 5613.7 & 5565.2 & 5686.4 & 6942.1 & 8589.1 & 9366.5 & 4730.6 & 6390.2 \\
\hline
\end{tabular}

Fonte: FERNANDES (4988)

Tabela A.4.4 Iónt iticacao dos Hibridos de Milho

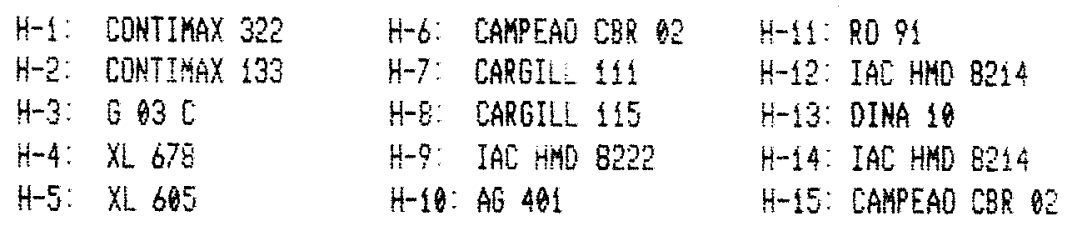

Fonte: FERNANDES (1988)

Tabela $A_{2} 4.2$ Identificacao dos Locais

\begin{tabular}{|c|c|c|c|}
\hline U: & Co:abra-MG & L6: & Calopinas-SP \\
\hline L: & Rio Paranaiba-k6 & 17: & Jardinopolis-se \\
\hline 5 & Sete Lagoas-MG & $18:$ & Jacarezinho-PR \\
\hline L4: & AIt inopolis-sp & 19: & Brasilia-0F \\
\hline LE: & Birigui-SP & L4: & $601 a n i a-60$ \\
\hline
\end{tabular}

Font 8 : FERNANDES (1988) 
Tabela A.5. Producao media en kg/ha de 15 (quinze) hibridos de willo el varios locais da regiao Centro Sul do Brasi]

$1984 / 8$

\begin{tabular}{|c|c|c|c|c|c|c|c|c|c|c|c|}
\hline $\begin{array}{l}\text { HIBRI- } \\
\text { DOS }\end{array}$ & $t:$ & $L 2$ & L3 & $L 4$ & $\begin{array}{c}\text { LOCAIS } \\
15\end{array}$ & L6 & $L 7$ & L8 & 19 & L10 & $\begin{array}{l}\text { KEDIA } \\
\text { HIBRIDO }\end{array}$ \\
\hline$H-1$ & 8219.0 & 5395.0 & 7285. & 6273.0 & $7757 \times 0$ & 7602.0 & 8274.0 & 4138.0 & 6105.0 & 5980.0 & 6702.8 \\
\hline$H-2$ & 7538.9 & 4885.0 & 6379.4 & 5329.0 & 6883.0 & 5948.0 & 7091.0 & 2963.0 & 5595.0 & & 5747.4 \\
\hline $\mathrm{H}-3$ & 5923.0 & 3526.0 & 6670.0 & 4961.6 & 6121.0 & 5274.0 & 6210.0 & & & & 4969.3 \\
\hline$H-4$ & 7973.0 & 5098.0 & 7198.0 & 4863.0 & 7637.0 & 5808.0 & 5790.0 & 3476.0 & 5776.0 & 4802.0 & 5842.1 \\
\hline$h-5$ & 7905.0 & 4942.0 & 6234.0 & 4726.0 & 7273.0 & 5585.0 & 7040.0 & 3334.0 & 5752.0 & 4596.0 & 5738.7 \\
\hline$H-6$ & 6274.0 & 4721.0 & 6676.0 & 5223.0 & 6413.0 & 6105.0 & 6938.0 & 2661.0 & 5309.0 & 5264.0 & 5528.4 \\
\hline$H-7$ & 6956.0 & 5348. & 7432.8 & 4660.0 & 7194.0 & 6199.0 & 7534.8 & 3244.0 & 5444.9 & 5790.0 & 5989.1 \\
\hline$H-8$ & 7103.0 & 5934.0 & 7645.0 & 4449.0 & 6938.0 & 6639.0 & 7451.0 & 3276.0 & 5129.0 & 6568. & 6023.2 \\
\hline$H-9$ & 4331.0 & 3415.0 & 4163.0 & 3973.0 & 4920.9 & 4072.0 & 5140.0 & 2807.0 & 3742.0 & & 4096.5 \\
\hline$H-10$ & 7321.0 & 4660.0 & 5796.0 & 4573.0 & 7011.0 & 5731.6 & 6845.0 & 2938.0 & 5464.0 & 5899.0 & 5623.8 \\
\hline$H-11$ & 7336.8 & 4910.0 & 6377.0 & 4565.0 & 6687.0 & 6378.0 & 7481.0 & 3149.0 & 523 & 516 & 5728,0 \\
\hline $4-12$ & 4931.0 & 3919.6 & 5044.0 & 4277.0 & 4589.0 & 4584.0 & 5653.0 & 2949.0 & 3856.0 & 3387.0 & 4228.9 \\
\hline$H-13$ & 8535.0 & 5362.0 & 7712.8 & 4956.0 & 6373. & 6578.0 & 7219. & 4122.0 & 5986.0 & 6640.6 & 6348.3 \\
\hline$H-14$ & 6187.0 & 4938.9 & 6399.8 & 3920.0 & 5373 & 5496.0 & 6107.0 & 3218.9 & 4482.0 & 4904.6 & 5102.4 \\
\hline $4-15$ & 6584.0 & 2497.0 & 5865.0 & 3935.0 & 5772.6 & 4496.8 & 6116.0 & 2612.0 & 4486.0 & 4134.0 & 4610.7 \\
\hline MEDIA & 6874.4 & 4443.3 & 6458.3 & 4712.2 & 6442.7 & 5760.3 & 6725.9 & 3189.7 & 5085.5 & 5894.7 & 5478.7 \\
\hline
\end{tabular}

Fonte: FERNANOES (1988)

Tabela A.5.i Identificacao dos Hioridos de Milho

\begin{tabular}{|c|c|c|c|c|}
\hline$H-1:$ & CONTIMAX 322 & $H-6:$ & CAKPEAO CBR O2 & H-11: R0 91 \\
\hline$H-2$ & CONTIMAX 133 & $4-7$ & CARGILL II & H-2: IAC HHO B2:4 \\
\hline$H-3:$ & $603 \mathrm{C}$ & $4-8:$ & CARGILL 115 & H-13: OINA 10 \\
\hline$H-4$ & $x \leq 78$ & $H-9:$ & IAC + WO 8222 & H-IA: IAC HMO 8214 \\
\hline & X 69 & $n-10$ & $A 6401$ & H-15: CAMPEAO CBR \\
\hline
\end{tabular}

Fonte: FERNANDES (1988)

Tabela A.5.2 Identificacao dos Locais

\begin{tabular}{|c|c|c|c|}
\hline L1: & Capinopolis-MG & $6:$ & Ribeirao Preto-SP \\
\hline L2: & Lavras-Mb & 17: & Goiania-60 \\
\hline L3: & Sete Lagoas-166 & $8:$ & Guar a-9\% \\
\hline & jabot icabal-sf & 19: & Santa Kelena-60 \\
\hline $5:$ & Matao-Sp & Lia: & Jatai-se \\
\hline
\end{tabular}

Fonte: FERNANDS (1988) 
Tabela A.6. Produsao wedia $\mathrm{kg} / \mathrm{ha}$ de 15 (quinze) hibridos de wilho en varios locais da regiao Centro Sul do Brasil

$1985 / 86$

\begin{tabular}{|c|c|c|c|c|c|c|c|c|c|c|c|}
\hline $\begin{array}{l}\text { HIBRI- } \\
\text { DOS }\end{array}$ & LI & $L 2$ & $\mathrm{L3}$ & 14 & $\begin{array}{c}\text { LOCAIS } \\
\text { L5 }\end{array}$ & 16 & L7 & L8 & L9 & L10 & $\begin{array}{l}\text { MEDIA } \\
\text { HIBRIDO }\end{array}$ \\
\hline$H-1$ & 8295.0 & 9431.0 & 8358.0 & 6600.0 & 8810.0 & 9115.0 & 8955.0 & 8268.0 & 5145.0 & 6335.0 & 7931.2 \\
\hline $\mathrm{H}-2$ & 8497.0 & 7815.0 & 6882.0 & 7142.0 & 8810.0 & 8911.0 & 8370.0 & 6793.0 & 5741.0 & 5813. & 7477.4 \\
\hline$H-3$ & 6885.0 & 6887.0 & 7720.0 & 7462.0 & 8478.0 & 10102.0 & 8172.0 & 6915.0 & 5389.6 & 7866.0 & 7587.6 \\
\hline$H-4$ & 8491.0 & 8148.0 & 6965.0 & 8062.0 & 8810.0 & 9798.0 & 7831.0 & 6954.0 & 5695.0 & 7660.0 & 7841.4 \\
\hline$H-5$ & 8298.0 & 7584. & 6766.0 & 8238.0 & 7833.0 & 9241.0 & 7105.0 & 6854.0 & 5813.0 & 6342.0 & 7497.4 \\
\hline $\mathrm{H}-6$ & 7080.0 & 7948.0 & 8334.0 & 5912.0 & 7428.0 & 9367.0 & 7227.0 & $6978=0$ & 5642.0 & 6450.0 & 7236.6 \\
\hline $\mathrm{H}-7$ & 7631.6 & 8288. & 7320.0 & 6960.0 & 8330.0 & 9207.0 & 7137.0 & 6912.0 & 5763. & 6436.0 & 7398.4 \\
\hline$H-8$ & 8165.0 & 8750.0 & 8853.0 & 5573.0 & 7258.0 & 10236.0 & 8057.0 & 8002.0 & 4990.0 & 7314.0 & 7719.5 \\
\hline$H-9$ & 6097.0 & 7728.0 & 7835.0 & 6999. & 8948.0 & 7885.8 & 7372.0 & 6419.0 & 4941.0 & 6610.0 & 6895.4 \\
\hline$H-10$ & 6423. & 6486.0 & 6410.0 & 6303.0 & 7856.0 & 8152.0 & 7814.0 & 7427.0 & 5487.0 & 7496.0 & 6945.4 \\
\hline$H-11$ & 6863.0 & 7206.0 & 7641.6 & 6080.0 & 7055.6 & 8838.0 & 7992.0 & 6959.0 & 4234.0 & 6752.8 & 6962.6 \\
\hline $\mathrm{H}-12$ & 7581. & 7619.0 & 6819.0 & 6135.0 & 7443.0 & 7899.0 & 7361.0 & 5666.0 & 5687.0 & 5860.0 & 6807. \\
\hline$H-13$ & 7709.0 & 8632.6 & 7993.9 & 6770.0 & 8606.0 & 9666.0 & 8971.0 & 5482.0 & 6498.0 & 5733.0 & 7696.8 \\
\hline$H-14$ & 6750.0 & 7202.0 & 7644.0 & 6258.0 & 6941.0 & 8269.0 & 7900.0 & 4298.0 & $42 r_{3} x_{n}$ & 8095.0 & 6660.2 \\
\hline $\mathrm{H}-15$ & 6644.0 & 5872.0 & 7584.0 & 4623.0 & 5774.0 & 6579.8 & 5647.0 & 4169.0 & 3877.0 & 8269. & 5903.8 \\
\hline MEDIA & 7427.3 & 7706.4 & 7541.6 & 6547.8 & 7832.0 & 8879.0 & 7667.4 & 6539.7 & 5249.1 & 6862.5 & 7225.3 \\
\hline
\end{tabular}

Fonte: FERNANDES (1988)

Tabela A.b. I Identiticacao dos Hibridos de Milho

\begin{tabular}{|c|c|c|c|c|}
\hline$H-1$ & CONTIHAX 322 & $\mathrm{H}-\mathrm{E}$ & CAMPEAO SOR QR & $H-11: 1091$ \\
\hline$H-2$ & CONTIMAX 133 & $H-7$ & CARGLLL II & H-12: IAC HWD 8214 \\
\hline$H-3$ & 6030 & $H-8:$ & CARGILL IIS & H-13: OINA 19 \\
\hline$H-4$ & $x \in 678$ & $4-9$ & IAC HWO 8222 & H-14: IAC HMD 8214 \\
\hline$-4-5$ & 605 & $H-10$ & $A E 404$ & H-15: CAMPEAO CBR \\
\hline
\end{tabular}

Fonte: FERNANDES (1988)

Tabela A.6.2 Identificacao dos Locais.

\begin{tabular}{|c|c|c|}
\hline Cafinopolis-WG & L6: & Hococa-sp \\
\hline Ris Paranaiba-mb & 17: & Ribeirao Preto-sP \\
\hline 13: Sete Lagoas-166 & 18: & Goiania-60 \\
\hline 1. Londrina-PR & 1.9 & Itumbiara-60 \\
\hline 15: Cravinhos-sp & L10: & Sao Joao da Barra-Sp \\
\hline
\end{tabular}

Fonte: FERNANDES (1988) 


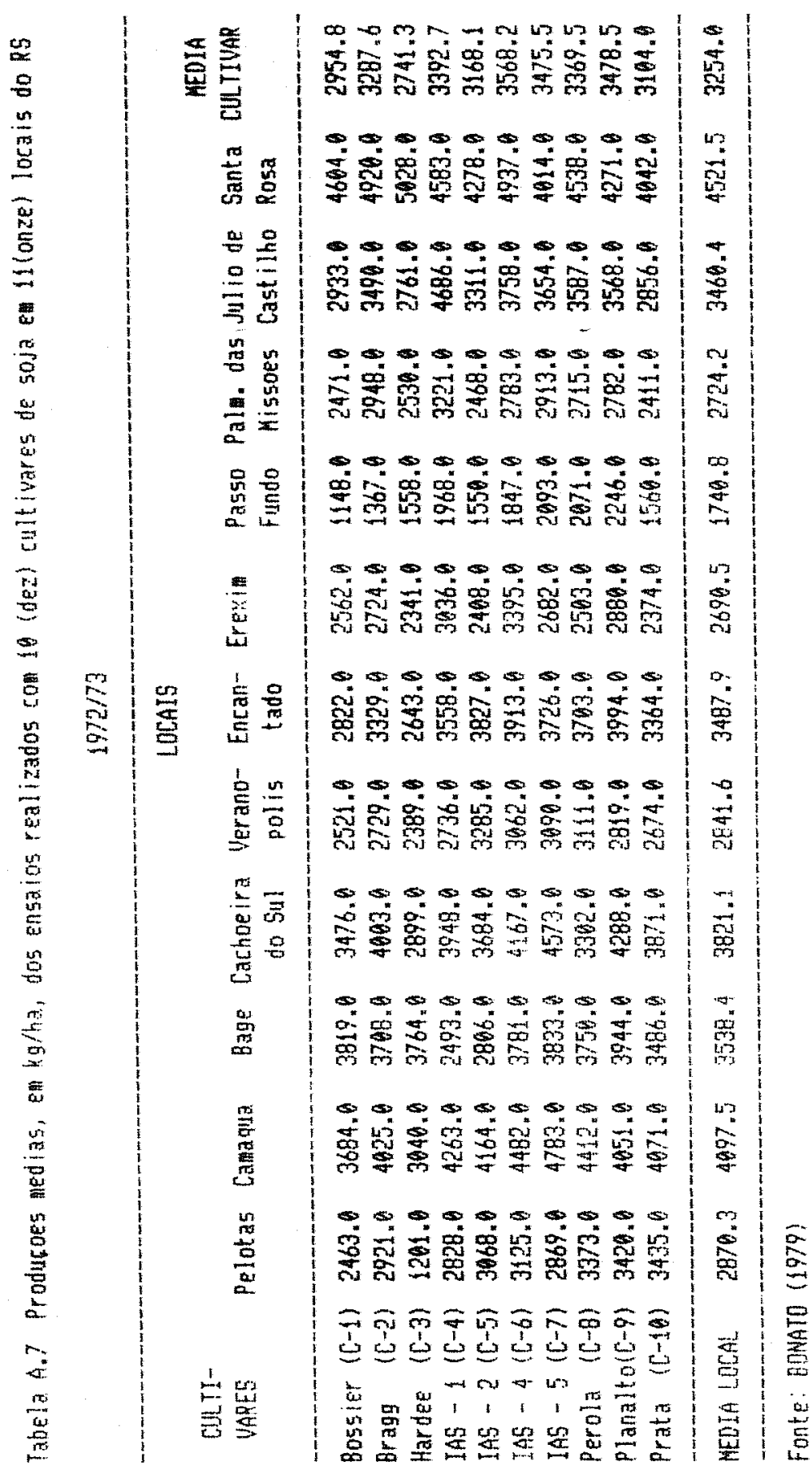




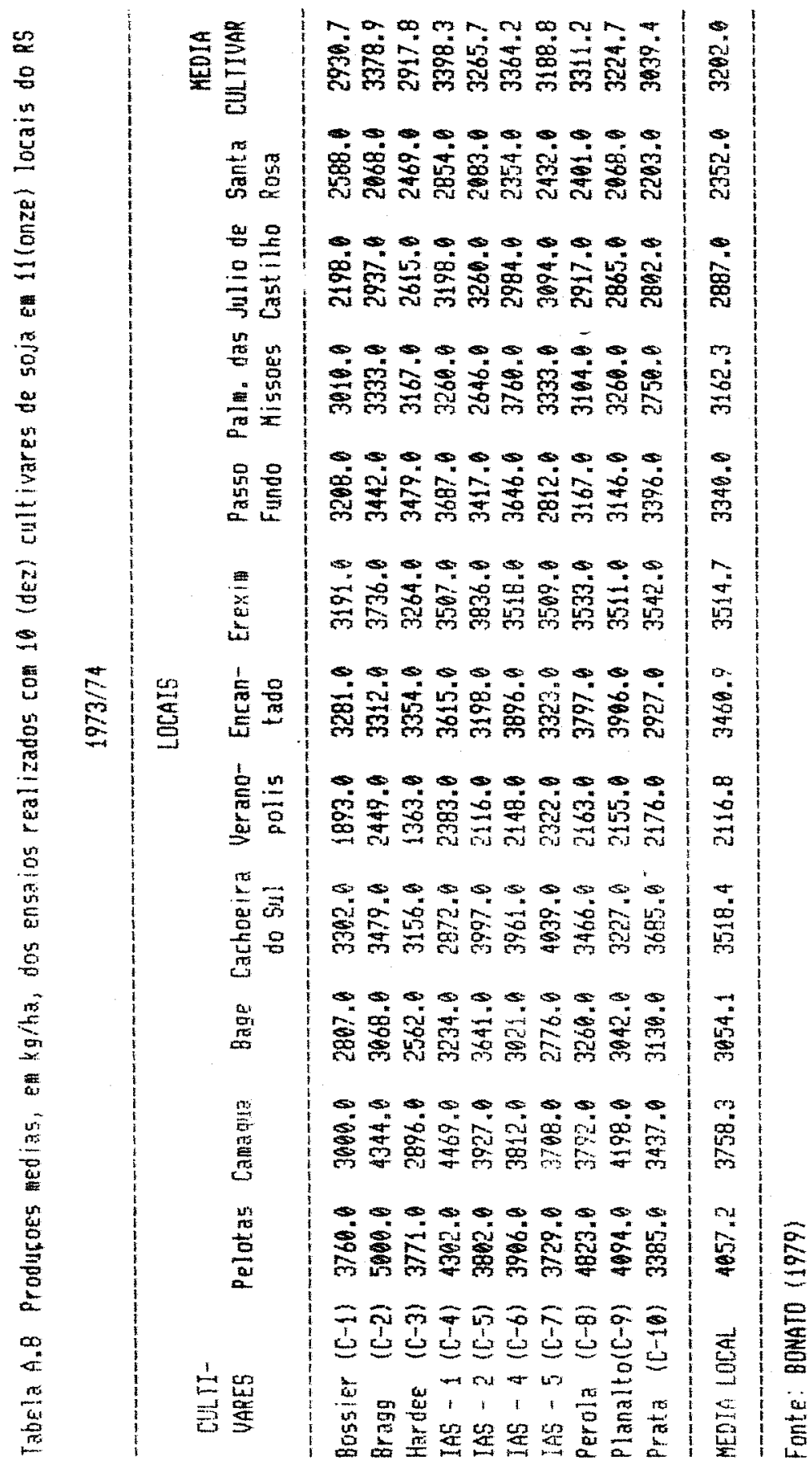




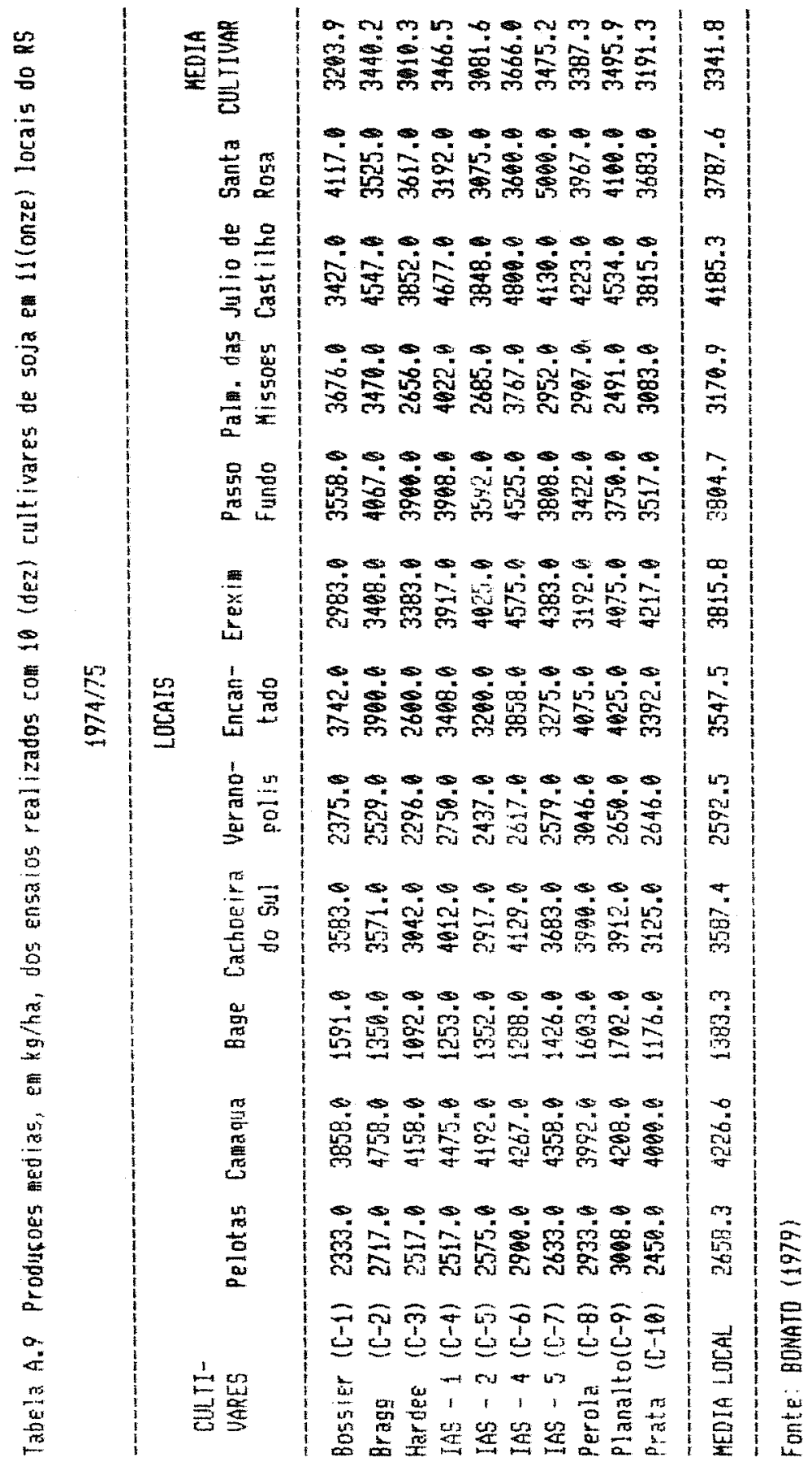


Tabela A.10 Rendiento edio de graos (kg/ha) de 10 (dez) cultivares de trigo e. 7 (sete) localidades da Regiao Oriental do Paragua i 1986

\begin{tabular}{|c|c|c|c|c|c|c|c|c|c|}
\hline CULTIUARES & & Caacupe & Volendan & $\begin{array}{l}\text { LocaIS } \\
\text { Colonia } \\
\text { Yguazu }\end{array}$ & $\begin{array}{l}\text { T. R. } \\
\text { Pereira }\end{array}$ & $\begin{array}{l}\text { Capitan } \\
\text { Miranda }\end{array}$ & $\begin{array}{c}\text { S. } j . \\
\text { Baut ista }\end{array}$ & Agriex & $\begin{array}{c}\text { MEDIA } \\
\text { CULTIUAR }\end{array}$ \\
\hline Cordillera & $3(c-1)$ & 1640.8 & 2585.0 & 2313. & 1703.0 & 2672.0 & 2366.0 & 1844.0 & 2160.4 \\
\hline Cordillera & $4(C-2)$ & 1211.0 & $2002=0$ & 2574.0 & 1898.0 & 2419.0 & 2159.0 & 1438. & 1944.4 \\
\hline IAll 5 & $(C-3)$ & 1525.0 & 2118.0 & 1917.0 & 1333.0 & 2406.8 & 1950.0 & 1391.0 & 1805.7 \\
\hline IAN 7 & $(C-4)$ & 1738.0 & 1944.0 & 2707.6 & 1752.8 & 2269.0 & 2897.0 & 1375.0 & 1983.1 \\
\hline Itapua 25 & $(c-5)$ & 1224.0 & 2202.0 & 1636.6 & 1272.6 & 2147.0 & 1747.0 & 1563.0 & 1684.4 \\
\hline It apua 30 & $(c-6)$ & 1503.0 & 2302.0 & 2778.0 & 2184.6 & 1769.0 & 1763.0 & 1688.0 & 1998.1 \\
\hline$C-8289$ & $(C-7)$ & 1652.0 & 2065.0 & 2761.0 & 2523.0 & 2206.0 & 2147.9 & 2000.0 & 2193.4 \\
\hline$c-8055$ & $(C-8)$ & 1476.8 & 2874.0 & 2410.0 & 2186.6 & 2188. & 2084.0 & 1594.0 & 2001.7 \\
\hline$E-8109$ & $(c-9)$ & 1399.0 & 2193.0 & 3088.0 & 2426.0 & 1969.0 & 2375.0 & 2000.0 & 2194.3 \\
\hline$c-81116$ & $(c-10)$ & 1894.0 & 2570.0 & 1779. & 1282.0 & 1509.0 & 2213.0 & 875. & 1734.7 \\
\hline MEDIA LOCAL & & 1517.2 & $225=$ & 2396.3 & 1846.9 & 2155.4 & 2090.1 & 1576.8 & 1969.7 \\
\hline
\end{tabular}

Fonte: SCHUARTZMAN (1989)

Tabela A.lt Rendimento medio de graos (kg/ha) de lo (dez) cultivares de trigo elit 7 (sete) localidades da Regiao uriental do Paragual 1987

\begin{tabular}{|c|c|c|c|c|c|c|c|c|c|}
\hline CULIIVARES & & Caacupe & Volenday & $\begin{array}{l}\text { LOCAIS } \\
\text { Colonia } \\
\text { Yguazu }\end{array}$ & $\begin{array}{r}\text { T. R. } \\
\text { Pereir }\end{array}$ & $\begin{array}{l}\text { Capitan } \\
\text { Miranda }\end{array}$ & $\begin{array}{c}5 . \mathrm{J} \\
\text { Baut ista }\end{array}$ & Agriex & $\begin{array}{c}\text { MEDIA } \\
\text { CULTIVAR }\end{array}$ \\
\hline Cordillera 3 & $3(c-1)$ & 2146. & 2021.0 & 1854.0 & 1719.9 & 3434.0 & 881.0 & 1650.0 & 1957.9 \\
\hline Cordillera 4 & $4(C-2)$ & 1313.0 & 2153.6 & 2185. & 2135, & 3247.6 & 1441.0 & 1759.6 & 2033.3 \\
\hline IAN 5 & $(c-3)$ & 2010.0 & 2131.0 & 2267.0 & 2243.0 & 3391.0 & $1009=0$ & 1809.0 & 2122.9 \\
\hline IAN 7 & $(c-4)$ & 1729.0 & 2463.0 & 2379.0 & 2260.6 & 3088.0 & 1169.0 & 1875.6 & 2137.6 \\
\hline It ариа 25 & $(c-5)$ & 1349.0 & 2181.0 & 1528. & 1948.1 & 2634.0 & 1009.0 & 1522.0 & 1738.7 \\
\hline Itapua 30 & $(C-6)$ & 1771.0 & 2245.0 & 1813,0 & 1823.0 & 3997. & 1300.0 & 1441.0 & 1927.1 \\
\hline$C-8289$ & $(c-7)$ & 2375.0 & 2524. & 2175. & 1986.0 & 2738. & 988.0 & 1703.0 & 2069.9 \\
\hline$c-8055$ & $(C-8)$ & 1843.8 & 2020. & 2629.0 & 2583.4 & 3284.0 & 1100.0 & 1778.9 & 2176.7 \\
\hline$E-8109$ & $(c-9)$ & 2021. & 1991.0 & 2922.0 & 2469.0 & 3872. & 981.0 & 2113.8 & 2338.4 \\
\hline$c-81110$ & $(6-10)$ & 25.0 .6 & 2291.0 & 2265.0 & 2490.6 & 3822.6 & 981.0 & 1796.0 & 2295. \\
\hline MEDIA LOCAL & & 1906.7 & 2202.0 & 2201.7 & 2165.6 & 3260.7 & 1085.9 & 1735.6 & 2079.7 \\
\hline
\end{tabular}

Fonte: SCHUARTZMAN (1989) 


UTILIZAGAO DA DOMINANCIA ESTOCASTICA COM O EMPREGO DE
MICROCOMPUTADORES
De acordo como exposto ra secao 2.4 os
criterios da Dominancia Estocastica visam escolner um
grupo de alternativas eficientes que poderão ser
recomendadas a individuos de acordo com seu comportamento
em relaça a situaçóses erivolverido incerteza. Fela aplicação dos eriterios de Domináncia Estocástica de Primeiro Grau CDEP să descartadas uma serie de alternativas consideradas ineficientes. O grupo restante ceficientes recebe uma restricăo $\left(\mathrm{U}^{\prime}<0\right.$. Destacam-se, com isso mais alternativas, separando-se um novo grupo agora considerado eficiente em Dominancia Fstocastica de Segundo Grau (DES). As alternativas que constituem o grupo eficiente em DES podem ser recomendadas a elementos considerados aversos ao risco. O grupo eficierte em DES ainda pode receber rova restrifăo $\mathrm{Cu}^{\prime \prime}$ '> o), separando-se as eficientes em Dominancia Estocástica de Terceiro Grau CDET, as quais podem ser recomendadas a individuos cuja aversăo reduz-se com o aumento da riqueza. Para selecionar alterrativas eficientes pela DEF. DES e DET, 5äo utilizadas as Furiçós de Distribuiçăo Cumulativas CFDCs dá variável en estudo. Da comparaçăo entre as FDC: e que surgem as alternativas consideradas eficientes.

A comparaça marual das FDo e um processo bastante trabalho, porén com o emprego do programa para 
microcomputadores sugerido por ANDERSON (1977), rapidamente chega-se ao resultado esperado.

Fara aplicação da Domináncia Estocástica rá seleço de variedades melhoradas os sequintes passos dever ser obedecidos:

1. Para cada genotipo, tomar o maior número possivel de produtividades obtidas nas mais variadas situaçóes (adversas e favoraveisj. As n produtividades são entăo dispostas em or dem crescente para aplicação da regra de Schlaifer. De acordo com esta regra, a k-esima produtividade constitui uma razoavel aproximação do $k / n+1$ fractil da Funça de Distribuifáo Cumulativa CFDC de probabilidade. Assim, se dispusermos de 3 produtividaes com valores 4,5 e 7 por exemplo; elas constituiräo, nestá ordem. uma razoavel aproximaçă das fraçŏes $0,25,0,50$ e 0,75 da FDC. As produtividades relativas a 0.0 e 1.0 de probabilidade acumulada deveráo ser estimadas como a menor. e a malor produtividade que se espera daquela variedade. Neste trabalno e em outros envolvendo Dominaricia Estocástica, as produtividades extremas foram calcuiadas pelas formulas apresentadas na seção 3.2.

2. As produtividades e respectivas fragoes de probabilidade acumulada $5 a ̈ o$ entáo plotadas num grálico Gpreferencialmente usando papel milmetrado, para facilitar a leituras, objetivando traçar a FDC. Desenha-se entäo, passando pelo maior numero de pontos possivel, uma curva em $s$, de acordo com o exemplo na fligurá A.1. 
Prob. Acum.

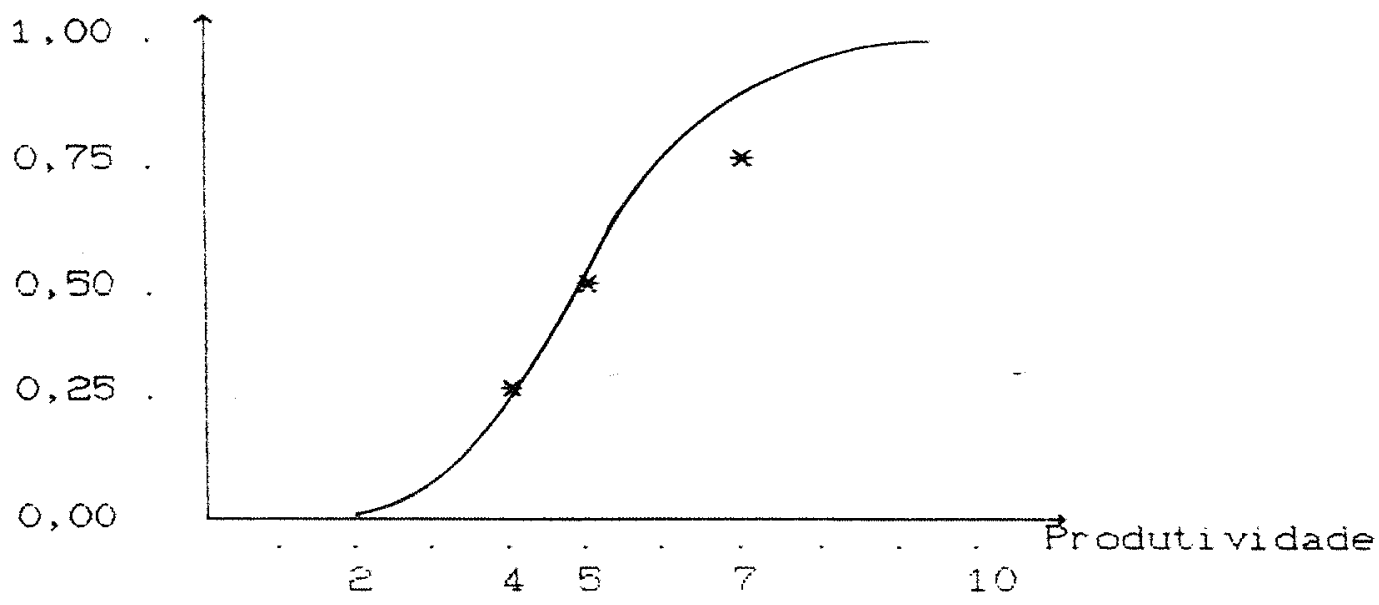

Figura A.1 - Ajustamento manual da Funçăo de Distribuiçäo Cumulativa $(F D C)^{2}$

3. De posse das FDC, uma para cada genótipo, e possivel verificar, para a curva ajustada, qual a produtividade correspordente as fraçoes de probabilidade acumuladas que se deseja $(0,10 ; 0,20 ; 0,30 ;$ eto....

o programa deserivolvido por ANDERSON (1977). tem como irialidade a escolna de aiternativas eficientes pela Dominância Estocástica. Da forma como se encontra, no final destá seção, permite a comparação de 40 al ternativas C40 FDCs, com el fracoes de probabilidade cada uma.

1

As produtividades $e e 10$ da figura A.I. correspordentes aos extremos de probabilidade, foram arbitrariamente tomadas para exemplificar o tracado da FDC. 
Nas FDC ajustadas citem 2 , são tomadas então 21 produtividades, correspondentes as fraçós de probabilidade 0,$00 ; 0,05 ; 0,10 ; 0,15 ; \ldots, 0,95 \in 1,00$. As produtividades $5 \widetilde{a} o$ então distribuidas em uma tabela, de acordo com o exemplo a seguir: Na tabela A. 12 estăo distribuidas as el produtividades de 10 cultivares que estão sendo comparadas. Cada 3 (tres) Iinhas, correspondem as produtividades de um cultivar.

4. A matriz devera ser digitada em um processador de texto, obdecendo a seguinte estrutura: Na primeira linha constara o numero de FDC comparadas e o número de fraçóes que foram tomadas para comparaçác crno exemplo da Tabela A.12, respectivamente $10 \in 213$. Os dols numeros deverão terminar sempre nas colunas 10 e 0 do processador de texto, respectivamente. Nas inmas seguintes serão digitadas as produtividades correspondentes as fraçoes de probabulidade cde 0,00 a 1,00 sempre em ordem crescente Cada uma das produtividades devera ter seu valor sempre terminario nas colunas $7,14,21$, eto. ate a coluna de numero 70 , continuando na Iinha seguinte, sempre obedecendo a mesmo criterio. Comciuida a digitaçăo das produtividades, nas I irhas seguintes e sempre terminando ná columa de numero 10, serão distribuidos os números correspondentes aos genotipos comparados. Estes numeros funcionam como nome para cada FDC. A matriz digitada sera entăo "salva" em disquete para posterior leitura pelo programa. 
Tabela A.12 Matriz das produtividades para leitura pelo programa de Eficiéncia Estocástica

1021

1125.51592 .52042 .52312 .52440 .02545 .02654 .02755 .02864 .02965 .6 3970.03175 .03280 .03385 .03490 .03580 .03677 .53782 .53895 .91165 .0 4711.0

1323.61810 .02170 .02485 .02716 .02875 .1310 .03145 .03272 .53377 .5 3437.53475 .03497 .53595 .3730 .03992 .54997 .54322 .54577 .54840 .9 5116.2

1070.61517 .51922 .52230 .2380 .02470 .02545 .02597 .52657 .52740 .0 2852.52965 .03085 .03295 .93325 .03460 .03610 .03769 .83955 .94232 .5 5144.8

1228.51952 .52417 .52590 .02740 .02867 .52987 .53107 .53220 .03340 .0 3460.03580 .03700 .03820 .03955 .04090 .04225 .04360 .04495 .04645 .8 4794.9

1325.51754 .02680 .02342 .52515 .02657 .52809 .02927 .53055 .03175 .0 3287.53385 .03482 .53589 .93677 .53775 .93872 .53985 .04997 .54225 .8 4377.4

1262.81787 .52237 .52620 .02875 .03962 .53235 .03498 .03550 .03685 .0 3769.03797 .53827 .53872 .53932 .54939 .04180 .94375 .04570 .04787 .5 5851.7

1398.11997 .52365 .02567 .52695 .02897 .52920 .03032 .53145 .03257 .5 3370.03482 .53595 .03709 .93895 .93925 .4990 .84277 .54502 .54795 .0 5116.2

1574.61960 .02275 .02590 .02837 .52950 .03047 .53130 .03212 .53295 .0 3377.53460 .03557 .53662 .53760 .9857 .53962 .54975 .04390 .04585 .0 4935.0

1668.71967 .52222 .52447 .52635 .02807 .52965 .03122 .53280 .03430 .6 3589.03736 .03850 .93955 .04922 .54969 .04195 .04172 .54247 .54367 .5 4639.3

1153.01727 .52972 .52320 .02492 .52642 .52777 .52905 .03832 .53160 .0 $3280.93370 .83497 .53452 .53512 .5 \quad 3692.53722 .53850 .93992 .54135 .9$ 4315.0

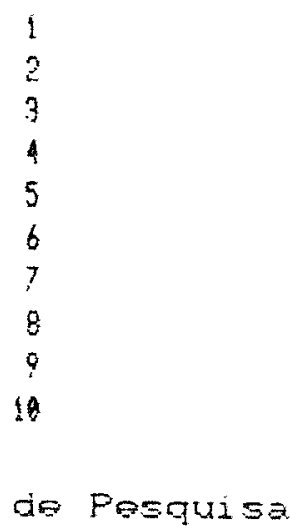

Fonte: Dados de Pesquisa 
5. O programa criado por Anderson. em linguagem FORTRAN, após digitado e compilado poderá ser utilizado para leitura e processamento da matriz de dados. Acessado o programá, será solicitado o arquivo de eritrada de dados, cujo nome deverá ser digitado no local correspondente, indicando o "drive"(se necessario) onde se encoritra armazenado. Em seguida seráa solicitado um nome para o arquivo de saida. Com este nome sera então colocado no disquete um arquivo contendo o resultado, ou seja indicando os grupos eficientes em primeiro. segundo e terceiro graus de Dominancia Estocastica. A leitura do resultado poder ser feita atraves do comando "TYFE" do mi crocomputador.

o programa pará determinar Eficiencia Estocastica encontra-se a seguir.

PFOAFAM EFISTOC

DIMENSION FC40,212. INC4O, IDC40, XC40\%

CHARACTER*E4 ARQENT

CHARACTER *64 ARQSAI

WPI TEC * 5000

500 FORMATC1X,"***** ANALISE DE EFICIENCIA

\&'***** Frograma: ANDERSON, J

Eritrada de dados: RODRIGUEZ, LCE *****:

\&" ***** Use sob oriertacao: PERES, FC * ****** ,

\&" ***** Depto Econ e Soc kur al ESALQUSF ******:2 WRI TEC * 502 ?

SOE FORMATK $1 \mathrm{X}$, "NOME DO SEU ARQUI VO DE DADOS:"

READC *,5042 AROENT

WPI TEC *.500)

504 FORMATCA)

$5 O E$ FORMATK $1 X$, "NOME DO ARQUI VO DE RESULTADOS:" "

READC *,504) ARQSAI

WRI TEC * 508 )

508 FORMATC $1 \mathrm{X}, \zeta<, \gamma^{*} * * * * * * * * *$ AGUARDE ***********,,$\gamma$ OPENCE, FILE=AROSAI, STATUS=*NEW'J

OPENC 3, FILE=AROENTS

PEADC 3,51O) NA, NC, IE, IT

DO $600 \quad I=1$, NA 


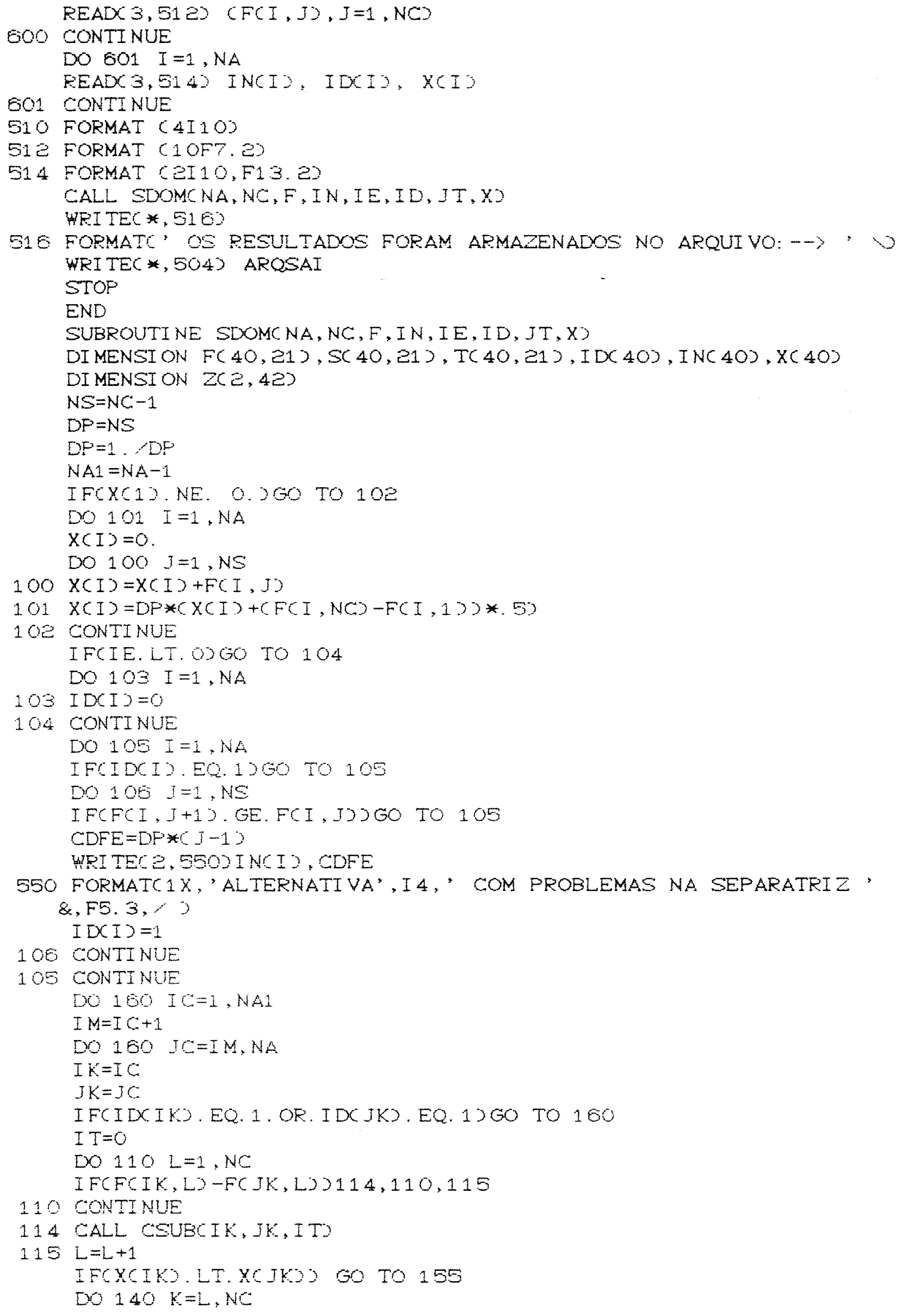




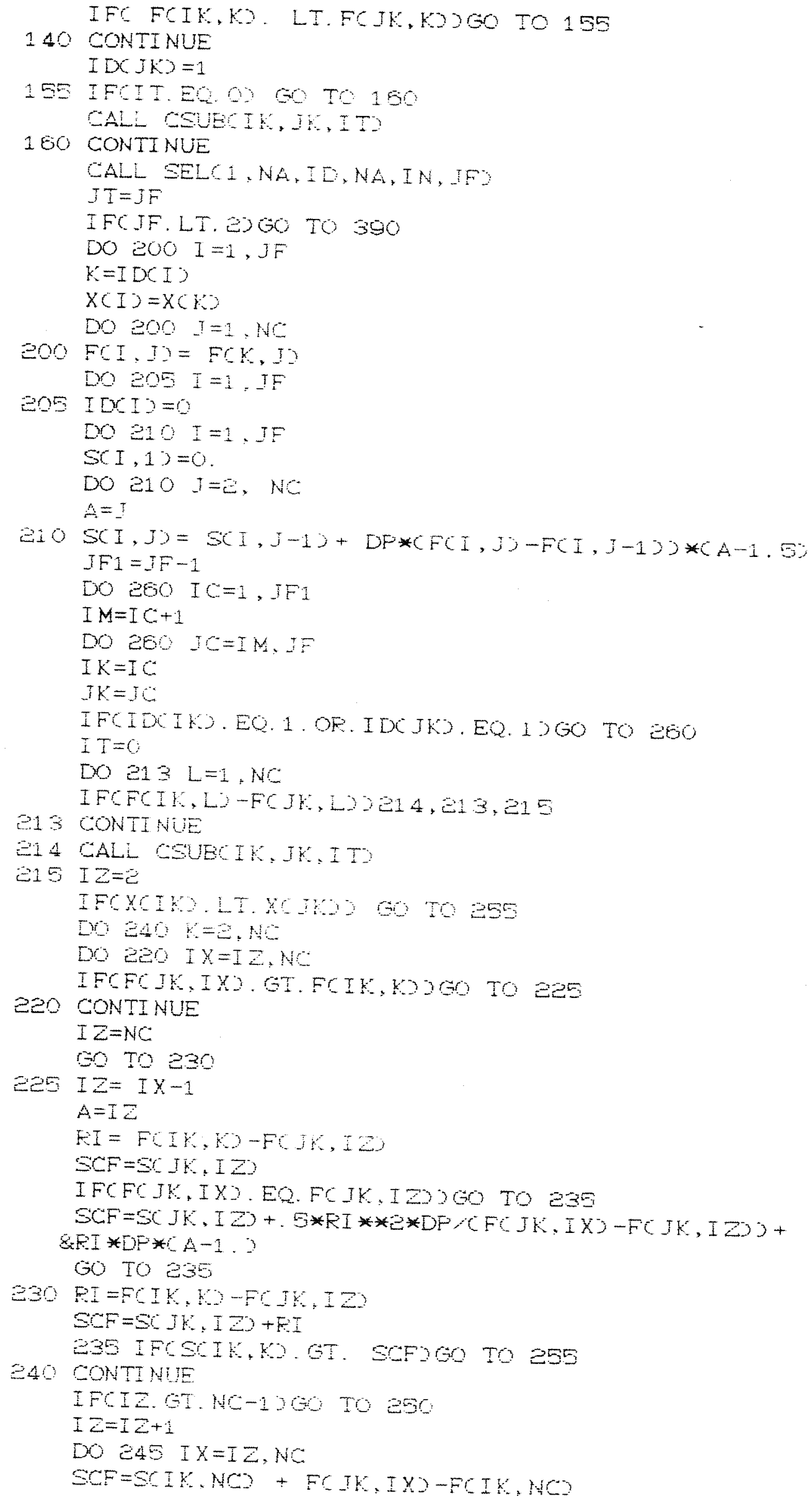




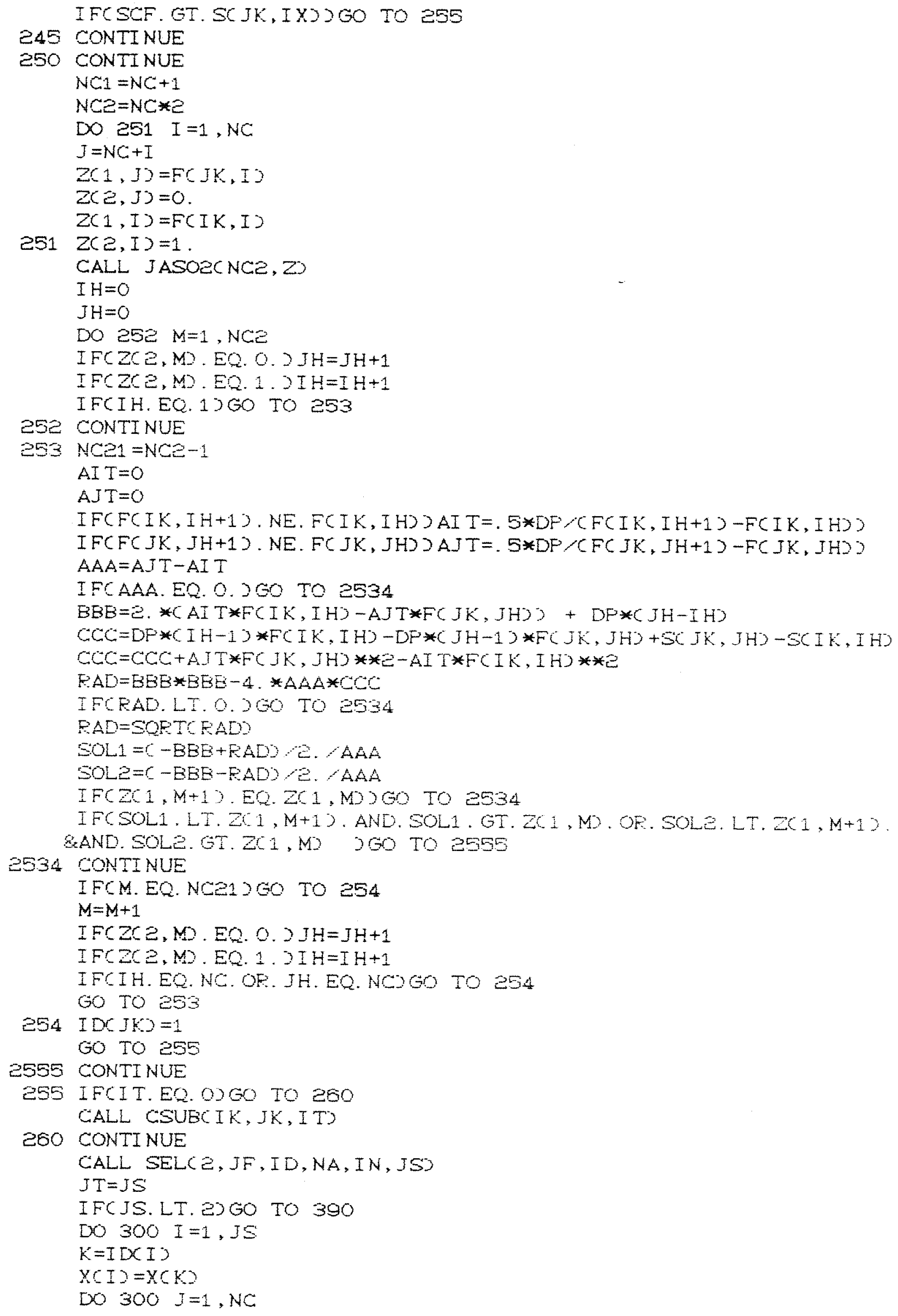


$F(I, J)=F(K, J)$

$300 S(I, J)=S(K, J)$

DO $305 I=1, I S$

305 IDCI $)=0$

DO $310 I=1, J S$

$T(I, 1)=0$.

DO $310 \mathrm{~J}=\mathrm{Z}, \mathrm{NC}$

$A=J$

$D I=F(I, J)-F(I, J-1)$

$310 T(I, J)=T(I, J-1)+.5 * D P * D I * D I *(A-2 .+1.3)+.D I * S(I, J-1)$

$J S 1=J S-1$

DO $360 \quad I C=1, J S 1$

I $M=I C+1$

DO $360 \mathrm{JC}=I \mathrm{M}, \mathrm{JS}$

$I K=I C$

$J K=J C$

IFCIDCIK. EQ.1. OF. IDK JKO.EQ.12GO TO 360

I $T=0$

DO $313 \mathrm{~L}=1, \mathrm{NC}$

IFCFCIK, L)-FCIK, LO)314,313,315

313 CONTINUE

314 CALL CSUECIK, IK, ITS

315 IZ $=2$

IFCXCIX) LT.XCIK) GO TO 355

318 IFCFCIK,NCS.LT.FCJK, NOS)GO TO 317

$R I=F C I K, N C)-F C J K, N C)$

$S C F=S C I K, N C Y+P I$

IFCSCIK, NO . GT. SCFOGO TO 350

GO TO 318

$317 \mathrm{SCF}=S C I \mathrm{~K}, N O+F C J \mathrm{~K}, N C \mathrm{NOCIK}, N C \mathrm{O}$

IFCSCF. OT. SC JK, NOY YO TO 355

319 CONTINUE

DO $340 \mathrm{~K}=2$. NC

DO 320 IX=IZ, NC

IFCFCIK, IX . OT.FIL, KOOGO TO 320

300 CONTINUE

$I Z=N C$

60 TO 330

325 IZ $=I X-1$

$A=I Z$

$P I=F C I K, K)-F(I K, I Z)$

$T C F=T C I K, I Z$

B+. 5*FI **2*DP*CA-1. Y +PI*SCIK, IZ

IFCFCJK, IX . EO. FOIK. IZYOO TO 395

$T C F=T C F+1.6 . * R I * 3 * D F, C F C J K, I X)-F(J K, I Z) 3$

GO TO 335

$330 R I=F(I K, K)-F(J K, I Z)$

$T C F=I C J K, I Z+.5 * R I * 2=+S C J K, I Z 3 * R I$

335 IFCTCIK, K. GT. TCFYGO TO 355

340 CONTINUE

IFCIZ. GT. $N C-1) G 0$ TO 350

$I Z=I Z+1$

DO 345 IX $=I Z, N C$

$R I=F(J K, I X)-F(I K, N C)$

$I C F=T C I K, N C S+.5 * R I * * 2+S C I K, N C) * R I$

IFCTCF. GI. TCJK, IX) 60 TO 355

345 CONTINUE 


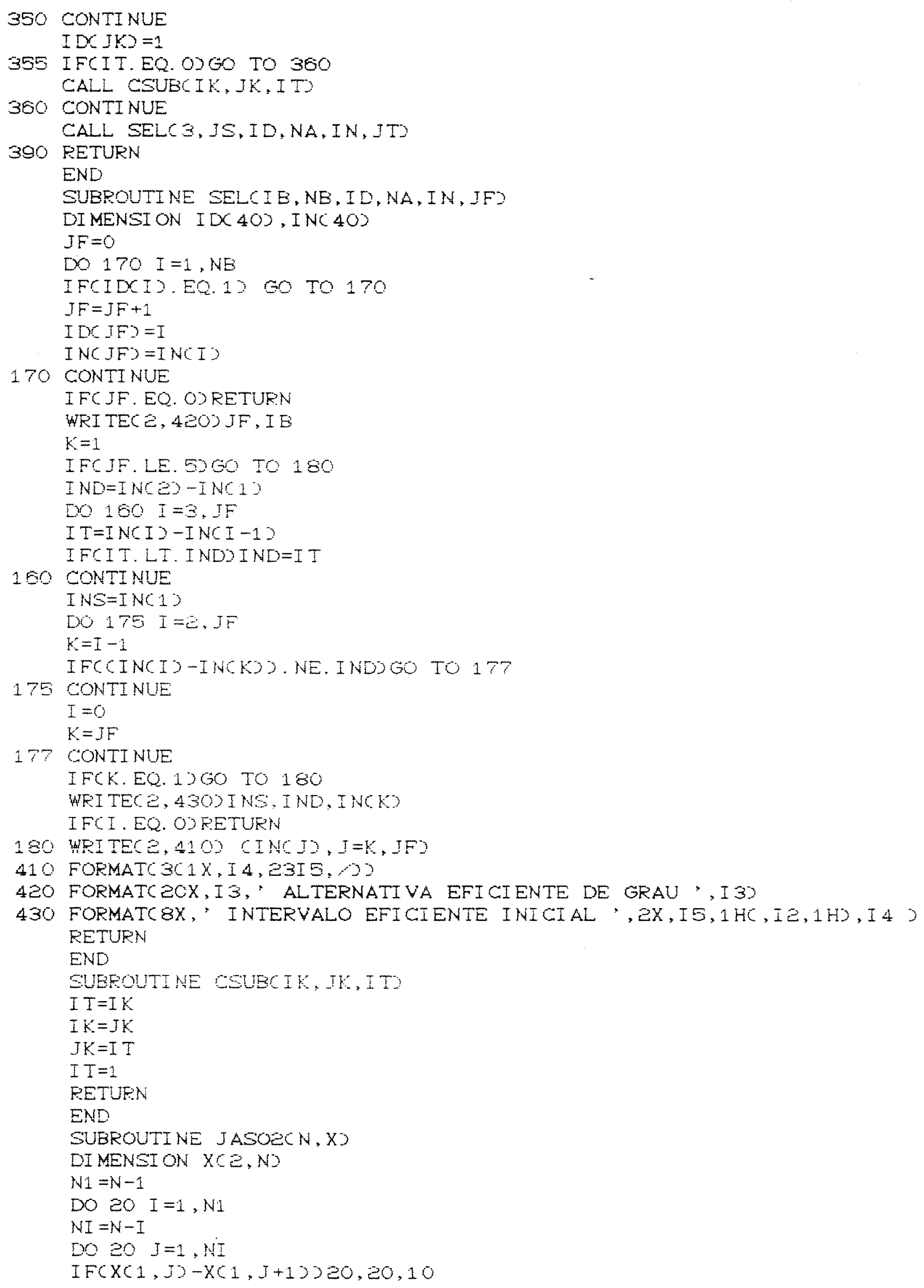




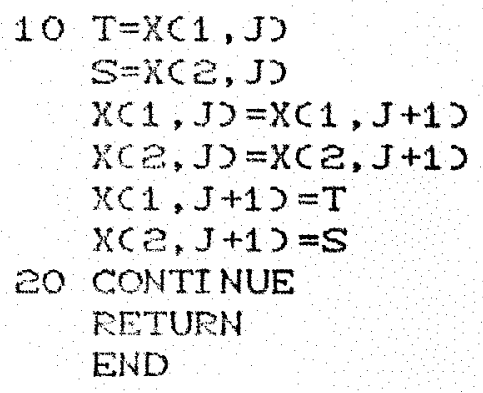

